\title{
Life Cycle Assessment of Pavements: A Critical Review of Existing Literature and Research
}

by Nicholas Santero, Eric Masanet, and Arpad Horvath

Prepared with the support of the Portland Cement Association through the Department of Energy under contract No. DE-AC02-05CH11231. 


\section{KEYWORDS}

Life-cycle assessment of pavements, environmental impact assessment, life-cycle modeling, asphalt pavements, concrete pavements

\section{ABSTRACT}

This report provides a critical review of existing literature and modeling tools related to lifecycle assessment (LCA) applied to pavements. The review finds that pavement LCA is an expanding but still limited research topic in the literature, and that the existing body of work exhibits methodological deficiencies and incompatibilities that serve as barriers to the widespread utilization of LCA by pavement engineers and policy makers. This review identifies five key issues in the current body of work: inconsistent functional units, improper system boundaries, imbalanced data for asphalt and cement, use of limited inventory and impact assessment categories, and poor overall utility. This review also identifies common data and modeling gaps in pavement LCAs that should be addressed in future work. These gaps include: the use phase (rolling resistance, albedo, carbonation, lighting, leachate, and tire wear and emissions), asphalt fumes, feedstock energy of bitumen, traffic delay, the maintenance phase, and the end-of-life phase. This review concludes with a comprehensive list of recommendations for future research, which shed light on where improvements in knowledge can be made that will benefit the accuracy and comprehensiveness of pavement LCAs moving forward.

\section{REFERENCE}

Santero, N., Masanet, E., and Horvath, A., Life-Cycle Assessment of Pavements: A Critical Review of Existing Literature and Research, SN3119a, Portland Cement Association, Skokie, Illinois, USA, 2010, 81 pages.

Revised April 2010: Page 43, Line 5, changed “consumption” to “efficiency.” 


\section{AUTHOR LIST}

Nicholas Santero, Ph.D.

Postdoctoral Scholar

Engineering and Project Management Program

Civil and Environmental Engineering

University of California, Berkeley

Eric Masanet, Ph.D.

Principal Investigator

Energy Analysis Department

Environmental Energy Technologies Division

Lawrence Berkeley National Laboratory

1 Cyclotron Road, Building 90R4000

Berkeley, California, USA 94720

Phone: 510.486.6794

Email: ermasanet@lbl.gov

Website: http://eetd.lbl.gov/staff/masanet/

Arpad Horvath, Ph.D.

Associate Professor

Engineering and Project Management Program

Civil and Environmental Engineering

University of California, Berkeley 


\section{TABLE OF CONTENTS}

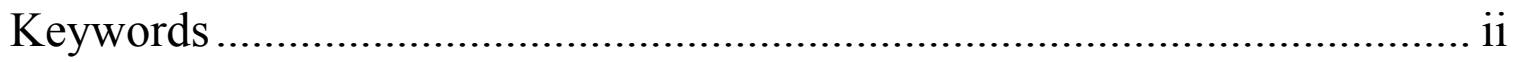

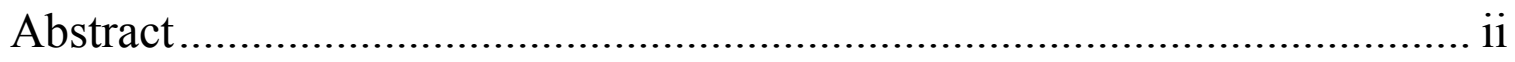

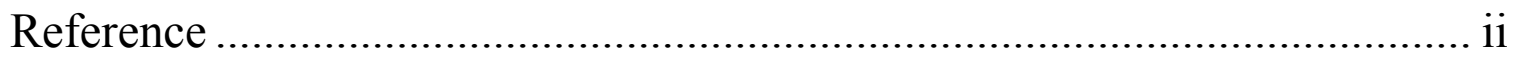

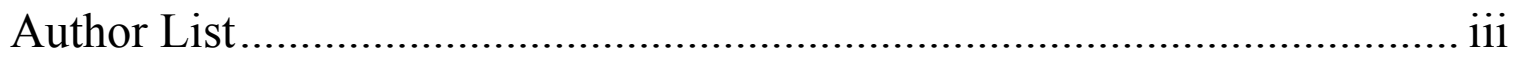

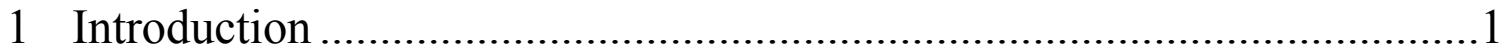

1.1 Objectives

$1.2 \quad$ Scope

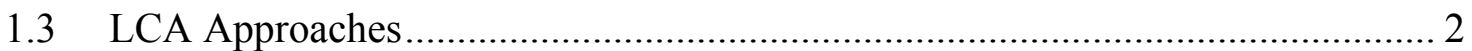

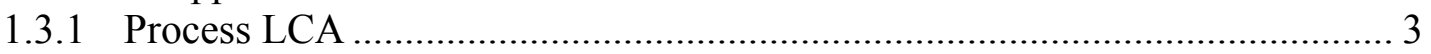

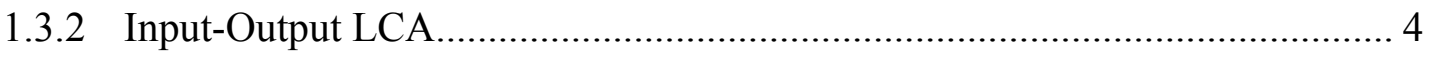

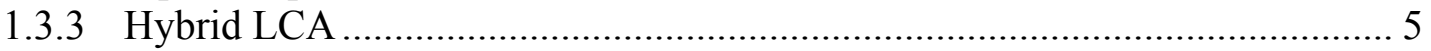

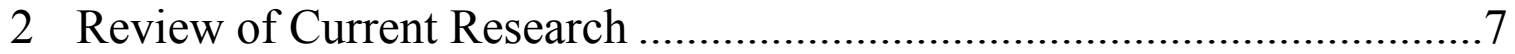

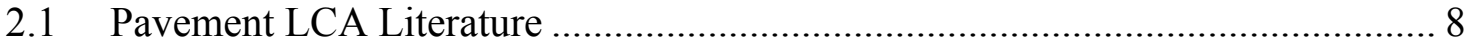

2.1.1 Relevant pavement LCA studies............................................................ 8

2.1.1.1 Häkkinen and Mäkelä (1996) _................................................................... 9

2.1.1.2 Horvath and Hendrickson (1998) ....................................................... 10

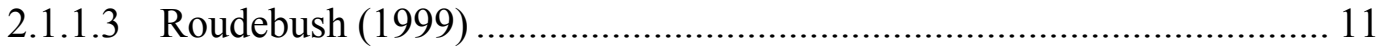

2.1.1.4 Berthiaume and Bouchard (1999) ......................................................... 12

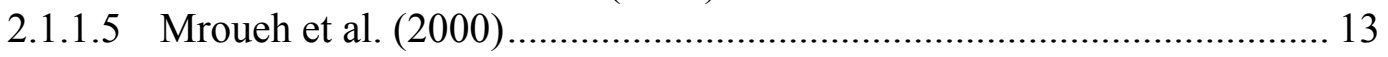

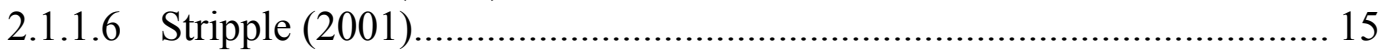

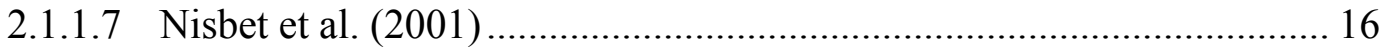

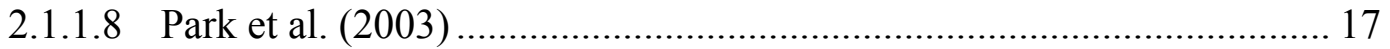

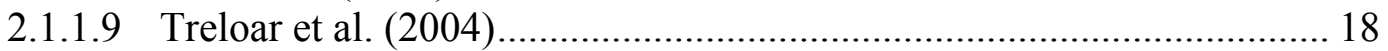

2.1.1.10 Zapata and Gambatese (2005)............................................................ 19

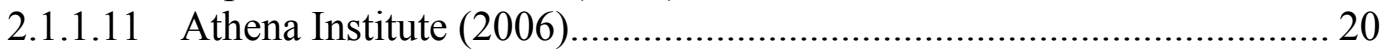

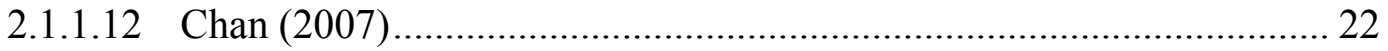

2.1.2 Secondary Materials in Pavements .......................................................... 23

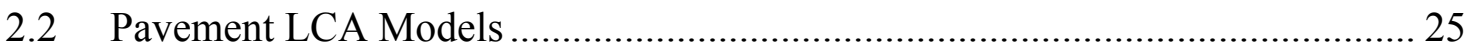

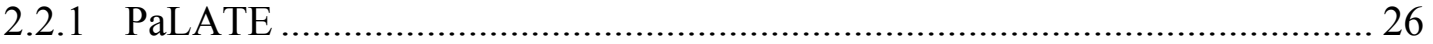

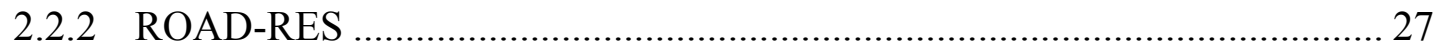

2.2.3 UK asphalt pavement LCA model................................................................ 28

2.2.4 Discussion of existing LCA models ……………….................................. 30

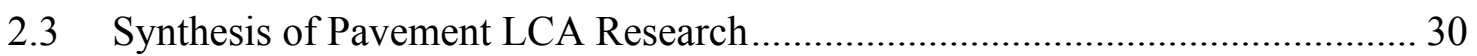

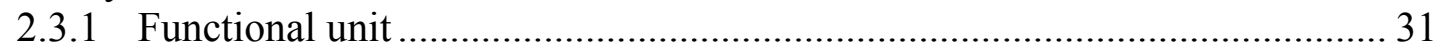

2.3.2 System boundaries .................................................................................. 32

2.3.3 Imbalanced information on bitumen and portland cement ............................. 33

2.3.4 Life-cycle inventory and impact assessment ……………............................... 34

2.3.5 Utility of current pavement LCA literature …………………….................. 35 


\section{TABLE OF CONTENTS (continued)}

3 Filling the Research Gaps .................................................................41

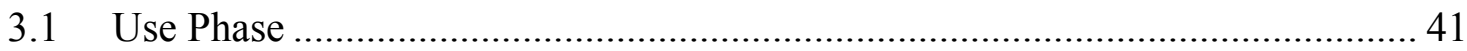

3.1.1 Rolling resistance ................................................................................ 41

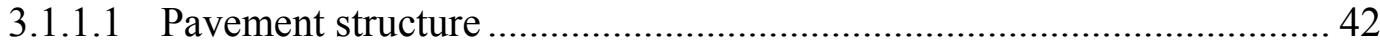

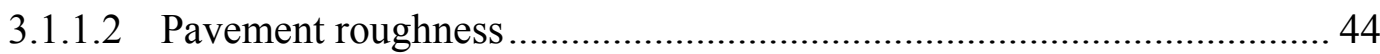

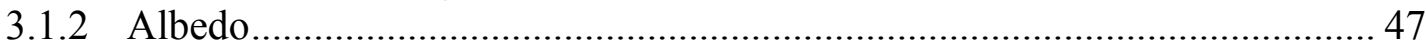

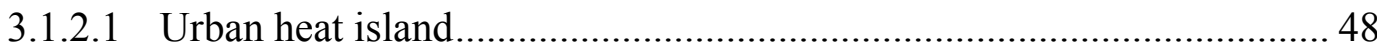

3.1.2.2 Radiative forcing .............................................................................. 49

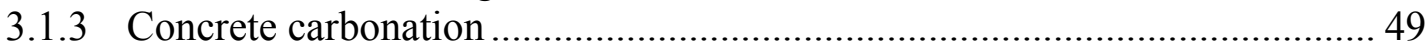

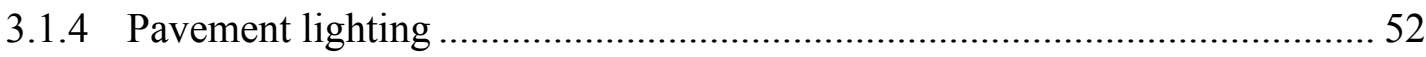

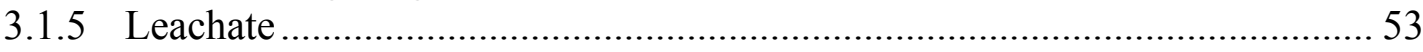

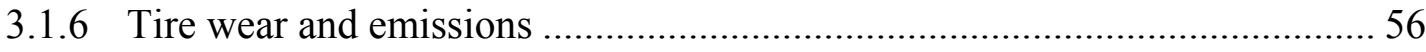

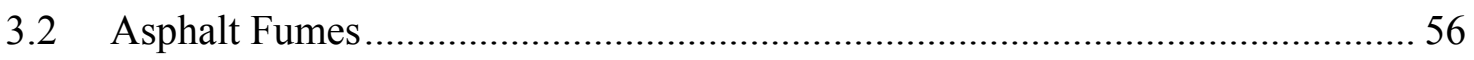

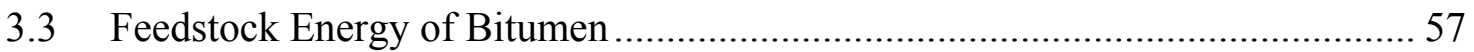

3.3.1 Bitumen as a direct energy source .......................................................... 58

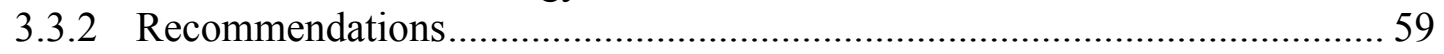

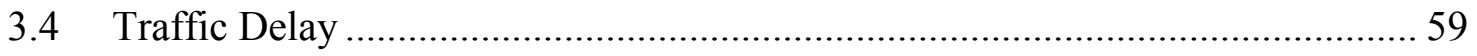

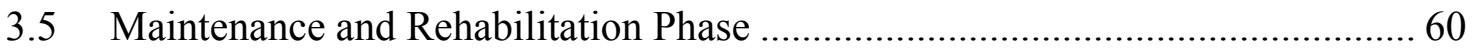

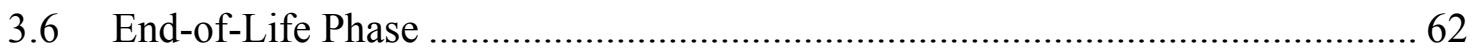

4 Recommended Future Research........................................................64

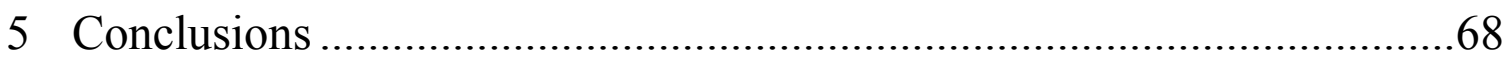

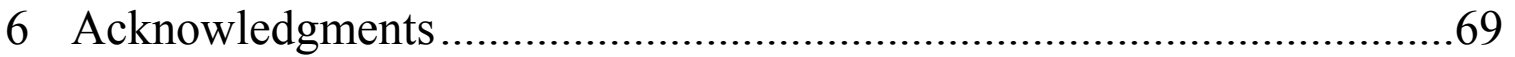

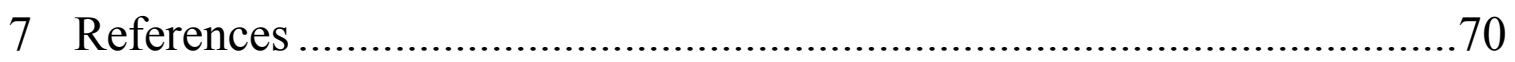




\section{LIST OF FIGURES}

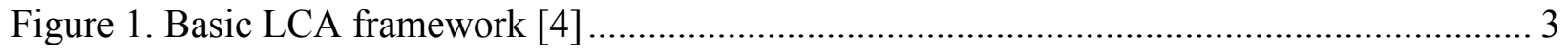

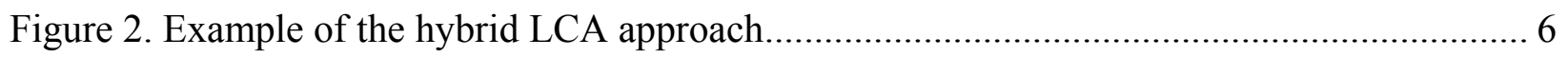

Figure 3. Phases of the pavement life cycle

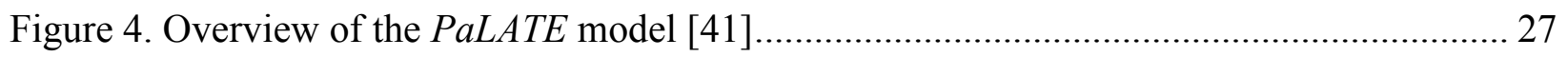

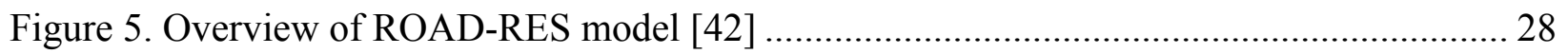

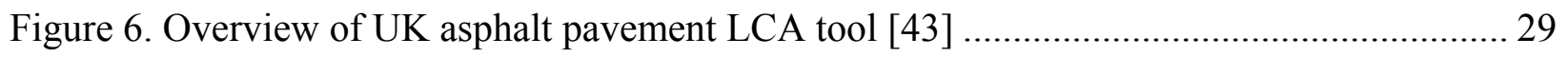

Figure 7. Location of reviewed pavement LCA studies and tools............................................. 38

Figure 8. Illustration of asphalt (left) and concrete pavement rolling resistance [57] .................. 42

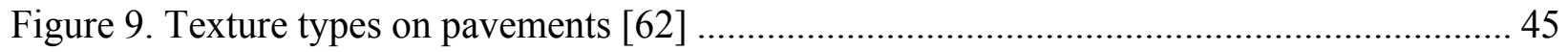

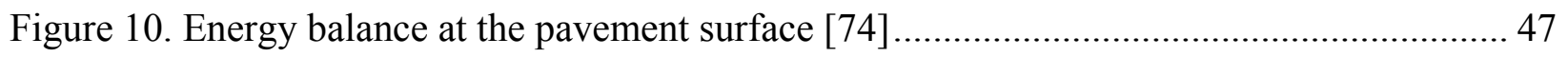

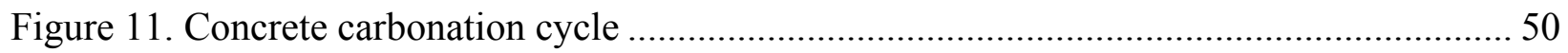

\section{LIST OF TABLES}

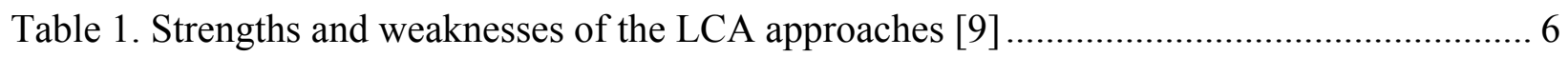

Table 2. Summary of Häkkinen and Mäkelä (1996).......................................................... 10

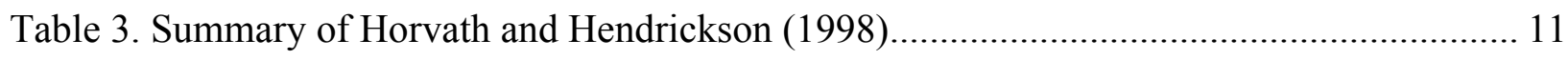

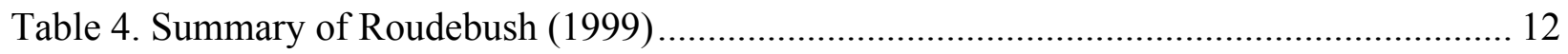

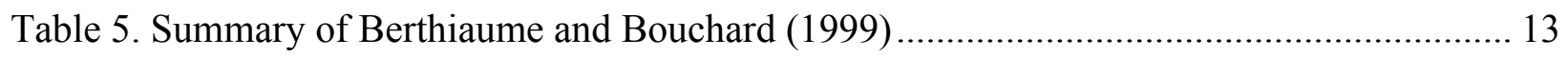

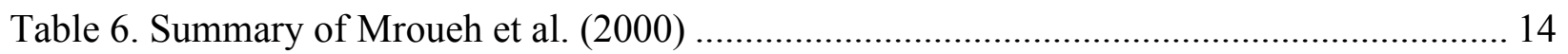

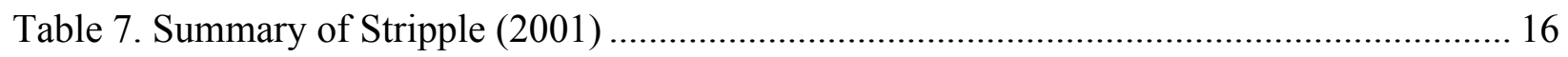

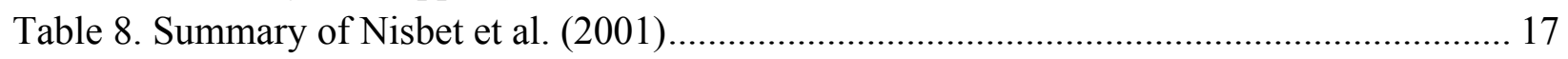

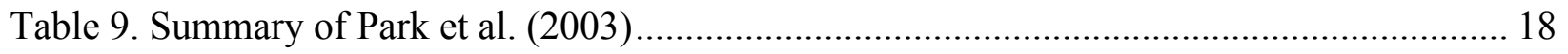

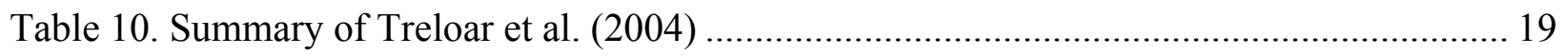

Table 11. Summary of Zapata and Gambatese (2005) ……..................................................... 20

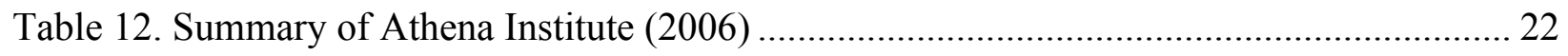

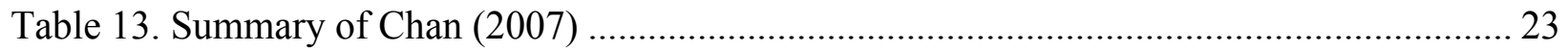

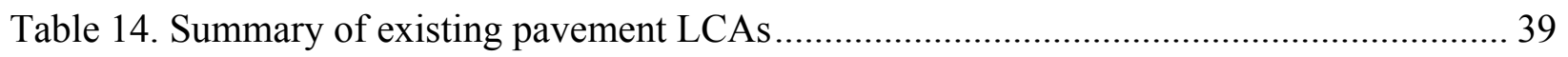

Table 15. Pavement class descriptions and illumination demands .............................................. 52

Table 16. PAH leachate test results and guidance concentrations (ng/L) .................................... 54

Table 17. Metal leachate test results and drinking water allowable limits $(\mu \mathrm{g} / \mathrm{L}) \ldots \ldots \ldots \ldots \ldots \ldots \ldots \ldots . . . . .55$

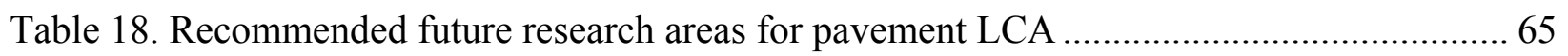




\section{LIST OF ACRONYMS}

\begin{tabular}{|c|c|}
\hline AADT & Annual average daily traffic \\
\hline AASHTO & American Association of State Highway and Transportation Officials \\
\hline $\mathrm{AC}$ & Asphalt concrete \\
\hline ASTM & American Society Testing and Materials \\
\hline CRCP & Continuously reinforced concrete pavement \\
\hline DOT & Department of Transportation \\
\hline EIO-LCA & Economic Input-Output Life-Cycle Assessment \\
\hline EPA & Environmental Protection Agency \\
\hline ESAL & Equivalent single axle load \\
\hline FHWA & Federal Highway Administration \\
\hline GWP & Global warming potential \\
\hline HMA & Hot-mix asphalt \\
\hline HTP & Human toxicity potential \\
\hline IO-LCA & Input-output LCA \\
\hline IPCC & Intergovernmental Panel on Climate Change \\
\hline IRI & International roughness index \\
\hline ISO & International Organization for Standardization \\
\hline JPCP & Jointed plain concrete pavement \\
\hline LCA & Life-cycle assessment \\
\hline LCCA & Life-cycle cost analysis \\
\hline LCI & Life-cycle inventory \\
\hline LCIA & Life-cycle impact assessment \\
\hline LED & Light emitting diode \\
\hline MEPDG & Mechanistic empirical design guide \\
\hline NCAT & National Center for Asphalt Technology \\
\hline NIOSH & National Institute for Occupational Safety and Health \\
\hline $\mathrm{NRC}$ & Natural Resources Canada \\
\hline PAH & Polycyclic aromatic hydrocarbons \\
\hline PaLATE & Pavement Life-cycle Assessment Tool for Economic and environmental effects \\
\hline PCA & Portland Cement Association \\
\hline QI & Quarter-car index \\
\hline RAP & Reclaimed asphalt pavement \\
\hline SETAC & Society of Environmental Toxicology and Chemistry \\
\hline SMA & Stone-mastic asphalt \\
\hline
\end{tabular}




\title{
Life-Cycle Assessment of Pavements: A Critical Review of Existing Literature and Research
}

\author{
by Nicholas Santero, Ph.D. \\ Eric Masanet, Ph.D. \\ Arpad Horvath, Ph.D.
}

\section{INTRODUCTION}

Expanding and maintaining our pavement network is an immensely resource-intensive process. Annually, nearly $\$ 150$ billion and 350 million tons of raw materials are invested into the construction, rehabilitation, and maintenance of this system [1-2], which covers over 8 million lane-miles while supporting 3 trillion vehicle-miles each year [3]. This does not include the added pavement needed for parking lots, alleyways, and other paved surfaces. The requirements and strain on the pavement network will continue to increase as the infrastructure ages and capacity attempts to satiate an ever-growing demand. The challenge is to meet this demand using environmentally sustainable engineering practices. However, our understanding of the environmental burdens associated with pavements is still limited, making it difficult to ascertain how to best meet this challenge.

For pavements, each phase of the life cycle - raw materials production, construction, maintenance, use, and end-of-life - poses a unique burden on the environment. Quantifying the environmental impact of pavements is best accomplished using a life-cycle assessment (LCA) approach. LCA assesses a product from cradle to grave, exploring everything from upstream supply-chain processes to recycling and disposal options when the product reaches its ultimate end-of-life. Ideally, an LCA includes all relevant environmental burdens related to resource use and emissions to air, water, and land. Pavements have been evaluated using the LCA methodology for over a decade, but the research field is still maturing. This critical review examines existing pavement LCA research and applications, and provides recommendations for future research to improve our understanding of pavements and the environment.

\subsection{Objectives}

The objectives of this critical review are:

1. To review and assess existing literature and modeling tools related to pavement LCA;

2. To explore the knowledge gaps currently overlooked by general pavement LCA practices; and

3. To provide a roadmap for future research based on the findings from objectives (1) and (2). 


\subsection{Scope}

The scope of this critical review is bounded by the nearly indiscernible line between a pavement and a roadway. This line is defined by whether or not the pavement itself influences a particular impact on the environment. If the environmental impact is independent of the materials, design, or other characteristics of a pavement, then that issue falls outside of the pavement life cycle. For instance, the grubbing and clearing of roadside vegetation is relevant to the roadway life cycle, but its impacts are not affected by pavement type and are therefore beyond the scope of this critical review. Conversely, impacts related to the placement of pavement materials is directly associated with the pavement itself, and are therefore within the scope of this critical review.

\subsection{LCA Approaches}

LCA is a methodology that is used to estimate and understand the environmental impacts of a product. Each phase of the life cycle - from materials extraction to end-of-life disposition - is ideally included in the assessment. The International Organization for Standardization (ISO) provides guidelines for performing an LCA in its 14040 series publications (14040:2006, 14044:2006, 14047:2003, 14048:2002) [4]. ISO suggests that LCA can be used to assist in the following ways:

- identifying opportunities to improve the environmental performance of products at various points in their life cycle;

- informing decision-makers in industry, government or non-government organizations (e.g. for the purpose of strategic planning, priority setting, product or process design or redesign);

- selecting relevant indicators of environmental performance, including measurement techniques; and

- marketing (e.g. implementing an eco-labeling scheme, making an environmental claim, or producing an environmental product declaration).

An LCA includes four basic components, as illustrated in Figure 1. Goal and scope definition describes the life-cycle system boundaries, functional unit used for the analysis, and the target audience. Inventory analysis quantifies the consumption of resources, waste flows, and emissions per functional unit attributable to all processes within the life-cycle system boundaries. Impact assessment provides additional environmental characterizations for more meaningful assessment of the life-cycle inventory results. Specifically, resource inputs and emissions are organized into environmental impact categories (e.g., global warming potential, acidification, and primary energy use) in order to better understand their environmental significance. The final component - interpretation - uses the results from the inventory analysis and/or the impact assessment to draw conclusions, make recommendations, identify analysis refinements, or otherwise aid in the decision-making process.

The ISO 14040 series of standards provides a generalized framework for many attributes and issues that are relevant for LCAs. However, apart from broad methodological guidance, the standards mostly avoid discussing the mechanics of conducting an LCA. Thus, they are only intended to provide general guidance for performing well-documented and transparent LCAs of different products and services. In practice, the ISO standards are necessarily supplemented by 
information relevant to the specific products under consideration, which in this case are pavements.

There are three different approaches to conducting an LCA: (1) process LCA; (2) inputoutput LCA (IO-LCA); and (3) hybrid LCA, which is a combination of the first two approaches. Each approach has its own strengths and weaknesses. These approaches are described in more detail in the following sections.

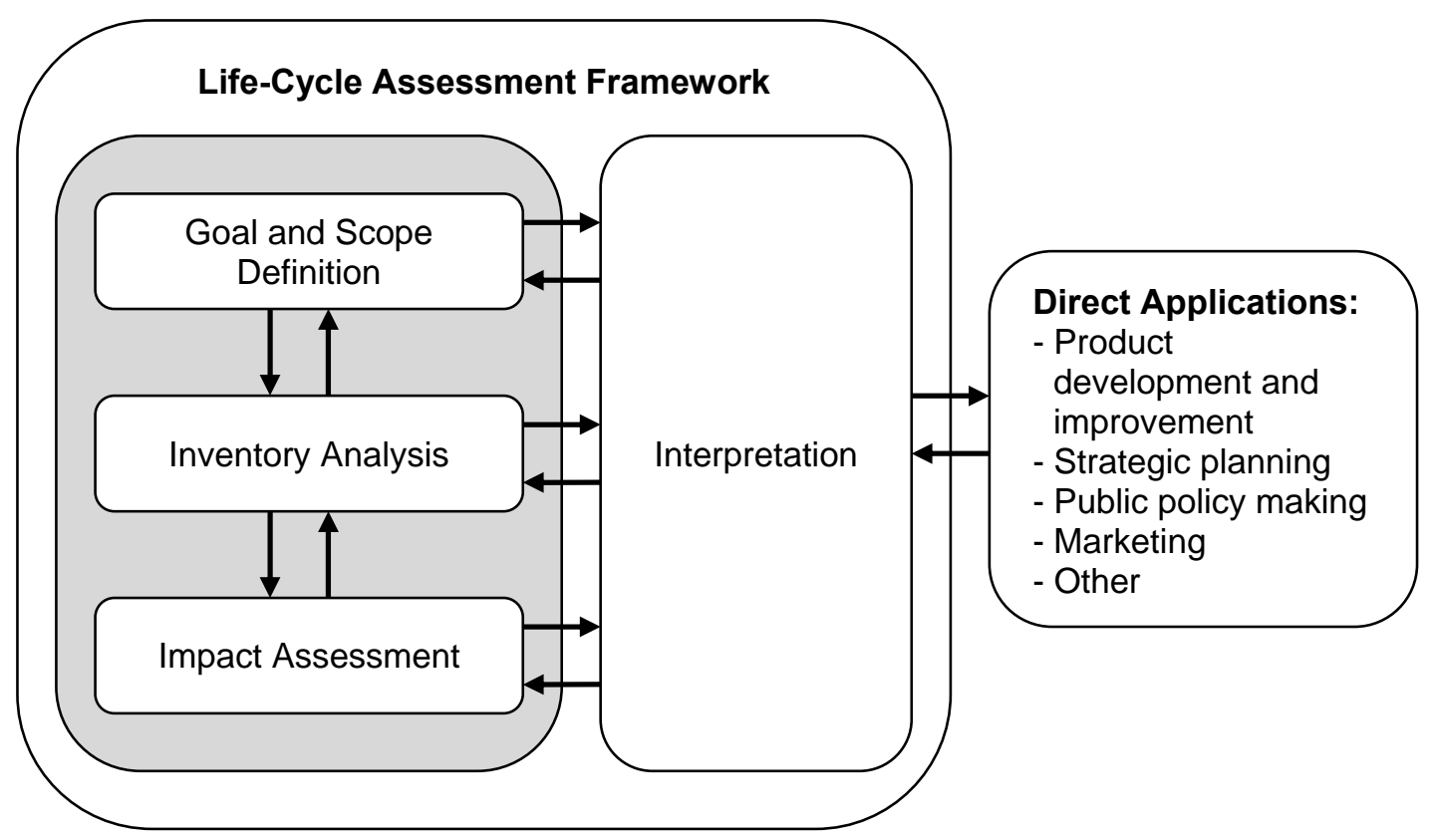

Figure 1. Basic LCA framework [4]

\subsubsection{Process LCA}

Process LCA is an approach that aims to quantify the inputs and emissions of each discrete process within a life-cycle system boundary. Total life-cycle inputs, emissions, and impacts are then estimated by summing up the data across all discrete processes. Functionally, this serves as a bottom-up method to characterizing the environmental impacts of a product. Process LCA traces its roots to approaches supported and refined by the Society of Environmental Toxicology and Chemistry (SETAC) and the United States Environmental Protection Agency (EPA). For this reason, it is sometimes referred to as the SETAC-EPA approach.

Both the greatest strength and greatest weakness of the process LCA approach lies in its attention to detail. Since each process that comprises the product's life cycle is discretely examined, the results are very specific to the product under study. As such, process LCA offers a detailed-oriented and straight-forward approach to product environmental characterization.

The extensive data requirements necessary to conduct a process LCA raise some key problems and pitfalls. The data collection necessary for process LCAs can often lead to timeintensive and costly studies. Additionally, a critical issue from an uncertainty perspective is the need to exclude much of the upstream supply chain. In reality, a product's supply chain continues indefinitely and eventually becomes either directly or indirectly dependent upon every other sector in the economy. Because it is not possible to individually examine an infinite 
number of upstream processes, process LCA requires setting an arbitrary system boundary for the analysis, which results in omission of processes. This is known as a truncation error and can be on the order of 50\% in some cases [5], although the error magnitude is highly dependent upon the product system under consideration. For the case of pavements and other materials and/or resource-intensive products, the collection of process data for all input material supply chains can help minimize truncation error. It should be noted, however, that in some product cases, truncation error may not be significantly reducible by increasing the system boundaries [6].

\subsubsection{Input-Output LCA}

IO-LCA is a top-down approach that includes all sectors of an economy in the analysis. It is based on the economic input-output (IO) approach developed by Wassily Leontief in 1936 [7]. By identifying the flows of goods and services between distinct sectors of an economy, IO models can trace all direct and indirect economic inputs required to produce a unit of output from a given economic sector (i.e., a unit of "final demand"). Beginning in 1947, the United States Department of Commerce began periodically publishing IO tables for the United States economy. The most recent publication is based on 2002 data and breaks the economy into 430 sectors [8]. IO-LCA methods couple such IO models with sector-level environmental data to generate estimates of the economy-wide environmental burdens associated with producing a given product (or service) [9].

One of the major advantages of IO-LCA is its ability to analyze entire supply chains with no truncation error. However, new and significant types of errors arise when using the IO-LCA approach. Lenzen (2001) identifies three important areas of uncertainties in the IO-LCA process [6]:

1. aggregation errors: due to grouping of different establishments into a single sector;

2. allocation errors: due to grouping of different products into a single sector; and

3. data source errors: due to unreliable data reporting, collection, and sampling.

The manifestation of these errors is effectively illustrated through the example of bitumen manufacturing. Bitumen manufacturing is included in the petroleum refining economic sector in the U.S. IO model, which encompasses other petroleum-based products such as gasoline, diesel, and waxes, to name a few. IO-LCA environmental data for this sector are based on information reported to government agencies by U.S. petroleum refineries. These environmental data are used to derive environmental intensities for the petroleum refining sector (e.g., emissions per dollar of output) that represent average values for all U.S. refineries.

In reality, the bitumen used in a given pavement probably comes from a single refinery with its own unique technology characteristics and environmental intensities. However, since the IO-LCA approach uses national average values for environmental intensities, it will invariably underestimate or overestimate the environmental impact of a product produced at any individual refinery. The difference between the national average intensity for a given environmental impact and the intensity at a specific refinery is known as aggregation error. One negative consequence of aggregation error is that it serves as a barrier for optimization of any specific facility or supply chain, since the IO-LCA approach can only characterize a "national average" facility or supply chain. 
A related issue is that although petroleum refineries produce many different products, in the IO-LCA approach national average environmental intensities are assumed valid for all products manufactured by the sector. For example, the environmental intensity of producing gasoline (emissions per dollar of output) is assumed to be the same as the intensity for producing bitumen even though the underlying processes, energy use, and emissions for these products can differ substantially. The practical result is that IO-LCA models assume that product cost is perfectly positively correlated with environmental impact for products within a given economic sector. Because this is not a perfect assumption, allocation error is introduced into the assessment.

Lastly, any incomplete or misreported data from U.S. petroleum refineries leads to data source errors. The magnitude of these errors may change depending on which environmental impact is being considered. For example, the energy consumption of petroleum refineries may be accurately documented, given that fuel purchases and energy use are commonly and easily tracked. However, volatile organic compound (VOC) emissions are typically determined through engineering estimation methods, which are more uncertain.

The previous paragraphs used bitumen as an example product, but these errors exist for nearly any product assessment conducted using IO-LCA methods. The errors inherent in the IOLCA approach are serious enough to undermine its integrity as a standalone LCA methodology. However IO-LCA is quite useful as a complementary approach to traditional process LCA because of its elimination of the truncation error.

\subsubsection{Hybrid LCA}

Both process LCA and IO-LCA approaches have their own strengths and weaknesses. However, as Hendrickson et al. (2006) point out, process LCA and IO-LCA approaches "are not rivals, but rather have comparative advantages. A hybrid analysis enhances the value of each approach to give better, more confident answers" [9]. Hybrid LCA is a method that combines process LCA and IO-LCA approaches in a manner that exploits their strengths and curtails their weaknesses. These strengths and weakness are summarized in Table 1.

The exact method of implementing a hybrid LCA depends on individual project constraints and data availability. A general approach is to use IO-LCA to fill in the gaps left by process LCA [10]. As a rule of thumb, hybrid LCA is best employed by using process LCA to analyze the most direct and influential processes, while using IO-LCA for the indirect, upstream processes. This exploits the primary strengths of process LCA (specificity) and IO-LCA (comprehensiveness) while minimizing the impact of truncation and aggregation errors that occur when using the two approaches independently.

Figure 2 illustrates an example application of the hybrid LCA approach for a generic product system. The approach uses IO-LCA to characterize processes A and B (and all direct and indirect processes upstream of those) and uses process LCA to characterize processes C and D (and everything downstream of those). This approach has the benefit of tackling specific manufacturing steps (e.g. process $\mathrm{C}$ and D) with a discrete process LCA approach while still creating a comprehensive scope by utilizing IO-LCA on the less pertinent upstream processes. Determining where to draw the line between the use of IO-LCA and process LCA within a system is a critical decision that must be assessed independently based on the product under study and the parameters of the project. 
Table 1. Strengths and weaknesses of the LCA approaches [9]

\begin{tabular}{|c|c|c|}
\hline & Process LCA & IO-LCA \\
\hline Strengths & $\begin{array}{l}\text { - Detailed process- } \\
\text { specific analyses } \\
\text { - Specific product } \\
\text { comparisons } \\
\text { - Process improvements, } \\
\text { weak point analyses } \\
\text { - Future product } \\
\text { development } \\
\text { assessments }\end{array}$ & $\begin{array}{l}\text { - Economy-wide, comprehensive assessments (all } \\
\text { direct and indirect environmental effects } \\
\text { included) } \\
\text { - System LCA: industries, products, services, } \\
\text { national economy } \\
\text { - Sensitivity analyses, scenario planning } \\
\text { - Publically available data, reproducible results } \\
\text { - Future product development assessments } \\
\text { - Information on every commodity in the economy }\end{array}$ \\
\hline Weaknesses & $\begin{array}{l}\text { - System boundary } \\
\text { setting subjective } \\
\text { - Tend to be time } \\
\text { intensive and costly } \\
\text { - New process design } \\
\text { difficult } \\
\text { - Use of proprietary data } \\
\text { - Cannot be replicated if } \\
\text { confidential data are } \\
\text { used } \\
\text { - Uncertainty in data }\end{array}$ & $\begin{array}{l}\text { - Many product assessments contain aggregated } \\
\text { data } \\
\text { - Process assessment difficult } \\
\text { - Difficulty in linking dollar values to physical units } \\
\text { - Economic and environmental data may reflect } \\
\text { past practices } \\
\text { - Imports treated as U.S. products } \\
\text { - Difficult to apply to an open economy (with } \\
\text { substantial non-comparable imports) } \\
\text { - Non-U.S. data availability a problem } \\
\text { - Uncertainty in data }\end{array}$ \\
\hline
\end{tabular}

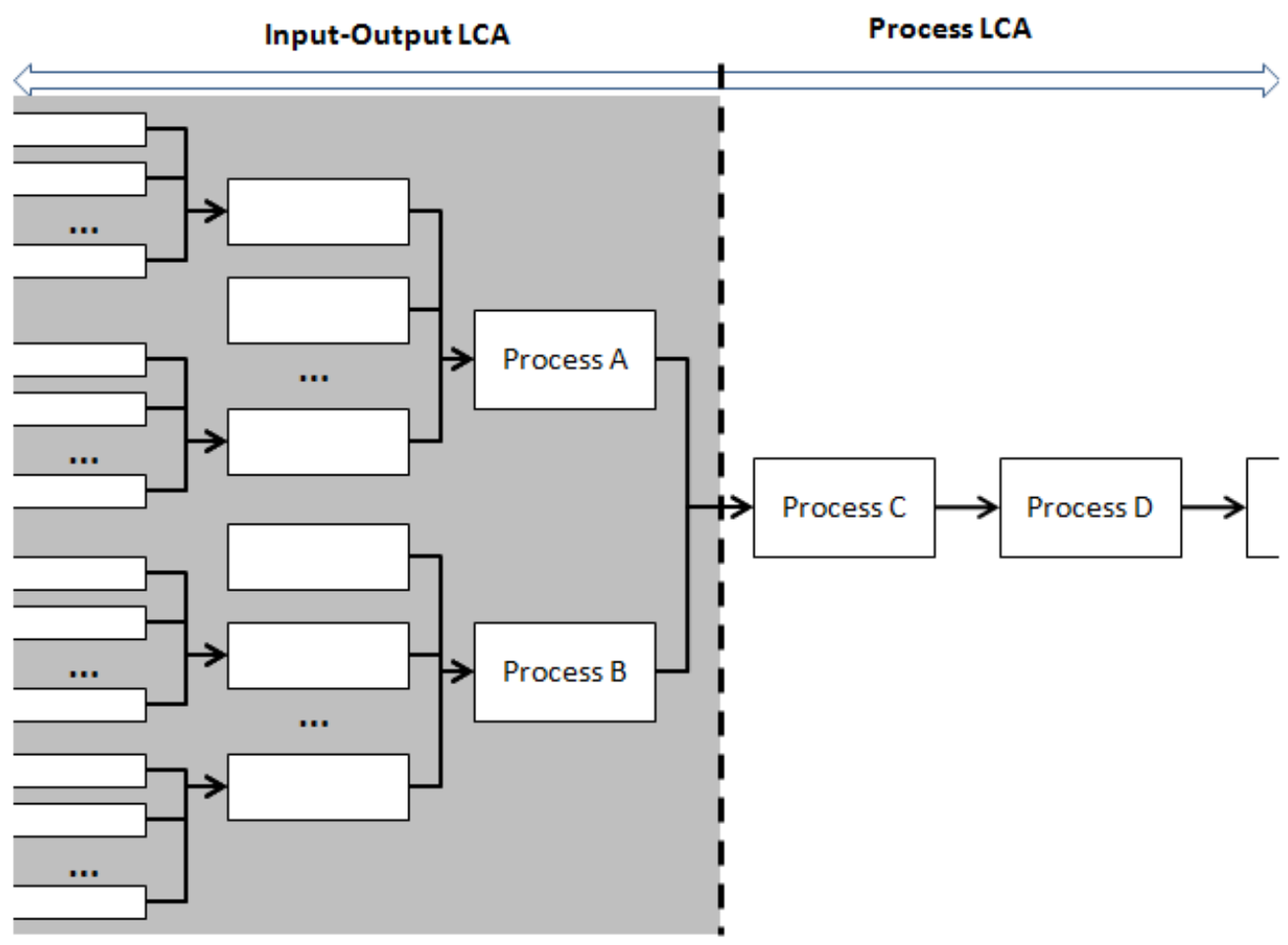

Figure 2. Example of the hybrid LCA approach 


\section{REVIEW OF CURRENT RESEARCH}

This section reviews the use of LCA as it has been applied to pavements. The review includes both literature sources (reports, papers, and other documents) and publicly-available models (software tools) relevant to pavement LCA. The intent of the review is to determine the current state of practice and identify any research and implementation gaps that exist.

The phases of the pavement life cycle categorize the different activities that occur during the life of the pavement. This review identifies five distinct life-cycle phases: materials production, construction, use, maintenance, and end-of-life. A summary of each phase is shown in Figure 3.

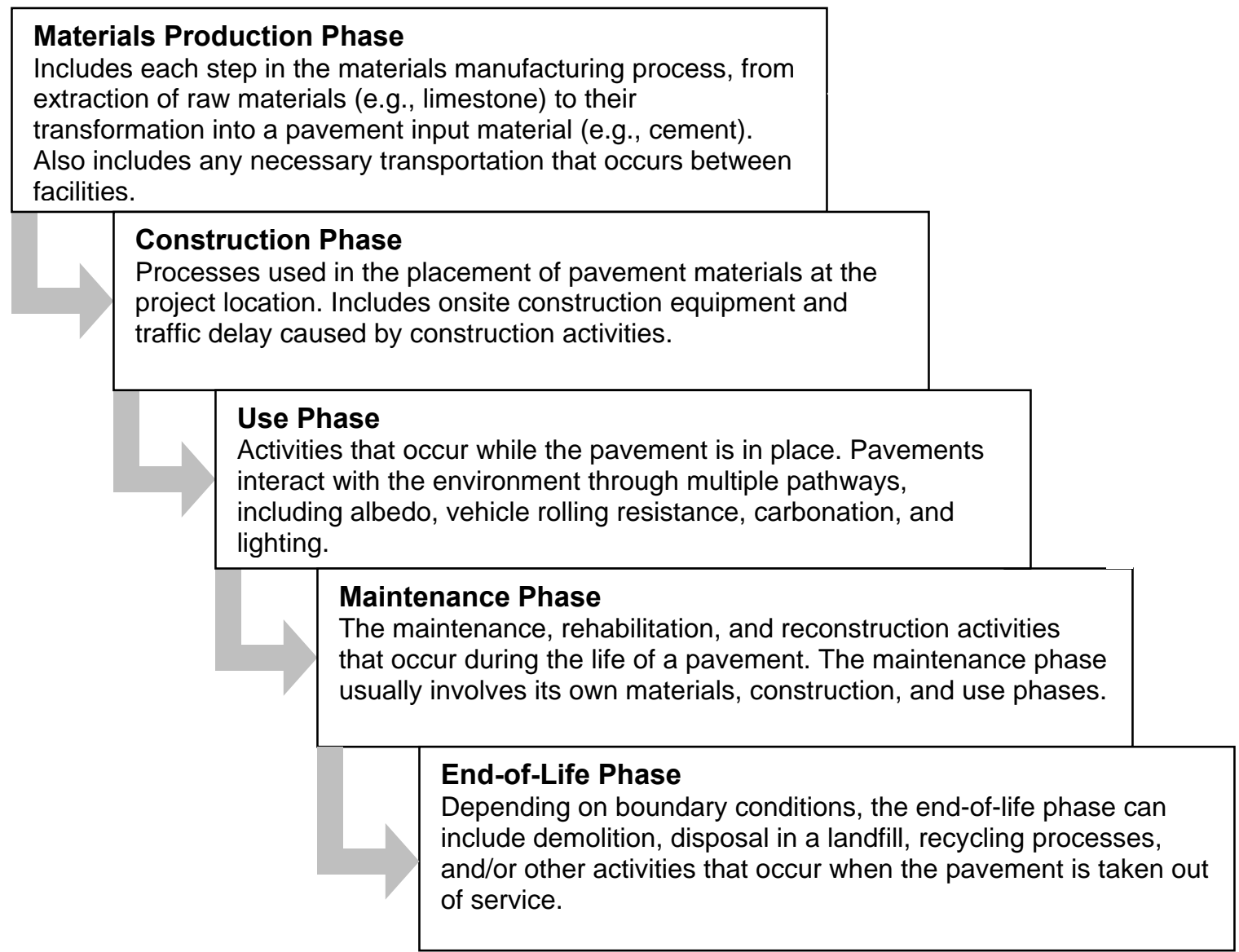

Figure 3. Phases of the pavement life cycle

The categorization of activities into phases is a somewhat arbitrary process, with no firm agreement in the pavement LCA community regarding standard categories. For instance, one reviewed pavement LCA breaks the life cycle into ten LCA phases [11], while others only use four phases, usually by including the maintenance phase with the use phase. This review chooses to isolate the maintenance phase from the use phase in order to better understand how effectively pavement maintenance schedules are incorporated into the LCA framework, as well as the 
impacts attributable to this phase of the life cycle. For consistency, the five-category system proposed in Figure 3 is used throughout this review.

\subsection{Pavement LCA Literature}

The following sections review the relevant pavement LCA literature, and then provide a critical analysis of the literature as a whole. The purpose of the review is to identify the depth and effectiveness of research in each phase of the life cycle. This will help to establish a baseline for the current state of research, identify knowledge gaps, and ultimately assist in outlining a roadmap for future work.

\subsubsection{Relevant pavement LCA studies}

The pavement LCA literature consists of roughly a dozen reports and articles, the first of which appeared in the late 1990s. These studies have been published through a variety of sources, including industry organizations, peer-reviewed journals, and government reports.

The exact number of documents in the literature is somewhat elusive, because defining what constitutes a pavement LCA is a not as straightforward as it may seem. Ideally, an LCA will examine each phase of the product life cycle, across all relevant environmental impact categories, in exhaustive detail. However, given time, data, and knowledge constraints, this process is very difficult for most products, including pavements. All LCAs are thus forced to simplify their scope and examine only those phases and processes that can be reasonably characterized under the study's constraints. The result is a pavement LCA literature bank that is comprised of studies with varying comprehensiveness, none of which achieve the lofty goal of a true and complete LCA. However, many studies follow the guidelines, theory, and intent of LCA sufficiently enough to be considered at least partial pavement LCAs. These are the documents, although somewhat arbitrarily defined, that comprise the current body of work in pavement LCA research.

To complicate things further, despite being put forth as pavement LCAs many studies contain only life-cycle inventories (LCIs) and do not provide life-cycle impact assessments (LCIAs). However, LCIs are considered standalone projects that are supported through the same ISO 14040 series guidelines that govern full LCA studies [4]. For the purposes of this literature review, LCI studies are reviewed along with their LCA counterparts and are generally not differentiated from one another. LCIA and how it is used in environmental assessments of pavements is discussed more in Section 2.3.4.

The twelve studies below represent the published LCA and LCI works related to pavements as of early 2009. Additional works focusing on recycled materials are discussed in Section 2.1.2. The focus of this review is on research reports and papers rather than industry briefings, magazine articles, and other similar media. These other media are generally less research oriented and, as a result, less well documented from a methodological perspective. Following each review is a table summarizing some of the key characteristics of the reviewed work. Included are the country, LCA approach, analysis period, traffic level, pavement structures, and phases of the life cycle that were considered (phases that were not considered are indicated with strikethrough font). When aggregated, these summary tables provide a useful method to compare and contrast the scopes of the reviewed studies. 
While there are strengths and limitations associated with each study, this review does not systematically isolate such strengths and limitations on a study-by-study basis. Rather, this review provides a comprehensive assessment of the strengths and weaknesses of the pavement LCA literature as a whole in Section 2.3. In doing so, the intent is to provide a more useful and constructive assessment of pavement LCA as a field of scientific inquiry, and to highlight broad research directions that should be considered by all pavement LCA researchers to advance the state of the art. The following summaries are in chronological order.

\subsubsection{Häkkinen and Mäkelä (1996)}

Häkkinen and Mäkelä (1996) [12] is a Finnish study that compares a stone-mastic asphalt (SMA) with a doweled jointed plain concrete pavement (JPCP). Although it is among the earliest pavement LCAs, this process-based LCA study is also one of the most comprehensive to date. Its scope includes each phase of the life cycle except the end-of-life phase. The two pavement structures are evaluated by 18 different environmental criteria, including $\mathrm{CO}_{2}$ emissions, energy consumption, air pollutants, and heavy metal releases. The pavement structure is based on a one kilometer stretch of pavement called the Tampere motorway in Finland. Traffic on this section of pavement is assumed to be 20,000 vehicles per day. The percentage of heavy vehicles is not given.

As a process LCA, environmental burdens for the materials phase are quantified by tracing and quantifying the upstream supply chain for each constituent in both of the structures. The data come from a variety of Nordic sources, making this LCA relatively specific to the explored case study. The designs also reflect the uniqueness of the region as issues such as studded tires and road salting play an important role in the structure designs, as well as impact the maintenance and use phases.

Construction phase impacts are limited to the fuel consumption (and resulting emissions) of unspecified onsite paving equipment. The case study assumes completely new pavement construction, therefore rightly omitting any traffic delays caused by the initial construction. However, for the maintenance and rehabilitation phase, traffic disturbances are included in the analysis. Maintenance and rehabilitation plans are carried out per Finnish recommendations over a 50 year analysis period. These plans include one or two grindings for the concrete pavement and a mix of milling and overlays using recycled and virgin materials for the asphalt pavement.

The inclusion of the use phase sets this study apart from others in the field. The scope includes the influence of the pavement on fuel consumption, noise, lighting, dust, and concrete carbonation. An important note is that the authors concluded that differences in fuel consumption between the pavements could not be quantified within reasonable error levels. Such differences are typically attributed to a pavement type in LCA so that net increases or decreases in fuel consumption due to pavement characteristics are included in the assessment. Instead, the authors assess absolute traffic levels, which are useful for putting into context the total environmental impacts of vehicle traffic compared to the total environmental impacts of the pavement life cycle. At 20,000 annual average daily traffic (AADT), absolute traffic emissions over the 50year design life were found to be roughly two orders of magnitude larger than the sum of emissions from all stages in the pavement life cycle. The study does, however, perform a limited "what if" analysis and finds that a 0.1 to $0.5 \%$ decrease in fuel consumption due to beneficial pavement characteristics would produce vehicle emissions "savings" comparable to the 
emissions of the entire pavement life cycle. Concrete carbonation is estimated to sequester $10 \%$ of the initial $\mathrm{CO}_{2}$ released via calcination during the cement manufacturing process.

The results of the study are mixed. In terms of $\mathrm{CO}_{2}$ emissions, the authors estimate that the concrete pavement produces 40 to $60 \%$ more emissions than the asphalt pavement, with the exact difference depending upon the assumed maintenance schedule. Conversely, they estimate that the asphalt pavement consumes roughly twice the amount of non-renewable energy as does its concrete counterpart when feedstock energy of bitumen is included. The exclusion of feedstock energy would bring the energy consumption results much closer, although it would still fall mildly in favor of the concrete pavement. Other environmental metrics are split between the two alternatives. A brief summary of the study is shown in Table 2.

Table 2. Summary of Häkkinen and Mäkelä (1996)

\begin{tabular}{ll}
\hline Author & Häkkinen and Mäkelä (1996) \\
\hline Title & Environmental Adaption of Concrete: Environmental Impact of Concrete and \\
Country & Asphalt Pavements \\
LCA approach & Finland \\
Analysis period & Process \\
Traffic & 20,000 AADT \\
Structures & 1. SMA (50 mm) | AC (190 mm) \\
Phases & 2. JPCP, doweled (220 mm) | AC (120 mm) \\
Studied & Materials | Construction | Use | M\&R | End-of-Life \\
Outputs & energy, air emissions, raw materials, noise \\
\hline
\end{tabular}

\subsubsection{Horvath and Hendrickson (1998)}

Horvath and Hendrickson (1998) [13] is the first study on the life-cycle impacts of pavements to appear in a peer-reviewed journal. The authors use Carnegie Mellon University's EIO-LCA (Economic Input-Output Life-Cycle Assessment) model to assess a hot-mix asphalt (HMA) pavement and a continuously reinforced concrete pavement (CRCP) in the United States. The EIO-LCA model, and hence the study, is an application of the input-output LCA approach. The uses the US 1992 Industry Benchmark EIO-LCA model [14], whose environmental outputs include consumption of various fuel types, electricity demand, ore and fertilizer use, and air, water, and land releases and emissions. A notable metric missing from the analysis is a quantification of greenhouse gas $(\mathrm{GHG})$ emissions (including $\mathrm{CO}_{2}$ ). The pavements studied are designed according to American Association of State Highway and Transportation Officials (AASHTO) standards to withstand ten million equivalent single axle loads (ESALs), which the authors equate to roughly ten years of interstate highway traffic.

The paper focuses on the extraction and production of the different surface materials and only qualitatively explores the construction and end-of-life phases. It focuses the construction phase discussion on the toxic fumes emitted from hot bituminous materials. The end-of-life phase is explored through the recyclability of the two materials. The authors also note that some recycling is quantitatively accounted for implicitly in the EIO-LCA model results. The use phase is not addressed. The maintenance phase is also excluded, citing a lack of reliable data for a generalized analysis such as the one performed in this study. 
The study concludes that for the materials phase of the pavement life cycle, the asphalt pavement consumes $40 \%$ more energy than does the concrete pavement. This study does not include the feedstock energy of the bitumen or other materials. Although energy consumption is decidedly higher for asphalt, most of the other environmental metrics are higher for the concrete pavement. The authors state that the data suggest that asphalt pavements are an "environmentally better choice when recycled effectively" (p. 112). This conclusion is qualified by acknowledging the large uncertainty in the data, including the difficulty in accurately forecasting pavement life and future maintenance activities. Another point of note is that the steel used in CRCP accounted for a considerable portion of its environmental burden. A brief summary of the study is shown in Table 3.

Table 3. Summary of Horvath and Hendrickson (1998)

\begin{tabular}{ll}
\hline Author & Horvath and Hendrickson (1998) \\
\hline Title & Comparison of Environmental Implications of Asphalt and Steel-Reinforced \\
Country & Concrete Pavements \\
LCA Approach & Inited States \\
Analysis Period & $\sim 10$ years \\
Traffic & $\sim 10 \times 10^{6} \mathrm{ESAL}$ (total) \\
Structures & 1. HMA (300 mm) \\
Phases & 2. CRCP (220 mm) \\
Outputs & Materials | Construction | Use | A\&R | End-of-Life \\
\hline
\end{tabular}

\subsubsection{Roudebush (1999)}

Roudebush (1999) [11] compares a concrete and asphalt pavement structure using a unit called emergy. Emergy is a summation method for life-cycle energy consumption that accounts for the quality and source of energy. This thermodynamic approach uses previously researched "transformities" to convert different energy types into their solar energy equivalents, called "solar emjoules". In doing so, the energy source (e.g., wind, petroleum, hydroelectric) is weighted based on how much solar energy was used to transform it from solar to its existing energy state. The exact calculation method, including what is and is not included in the determination of the transformities, is not made clear in the report. This report is an updated and condensed version of a report published in 1996, also by Roudebush [15]. Both reports were commissioned and published by the Portland Cement Association and evaluate pavements in the United States. The functional unit is a 24 feet wide and 3281 feet (one kilometer) long pavement section over a 50-year analysis period. There is no information regarding traffic levels.

Ten different LCA phases are identified in the pavement life cycle, ranging from natural resource exploration and extraction to recycling and disposal. Each of the phases identified by Roudebush can be categorized in one of the five phases used in this review. Ultimately, the report ends up examining only six of the ten phases, which can be categorized into the materials, construction, maintenance, and end-of-life phases defined for this review. The use phase is the only phase that is omitted in its entirety, although the study recommends that the lighting and fuel consumption differences between pavement types should be explored in future research. 
The report finds that the asphalt pavement structure requires $90.8 \%$ more emergy than the concrete pavement. The feedstock energy of bitumen is not included as it is not part of the emergy calculations. The materials and maintenance phases (the latter of which is categorized under the "use" phase by Roudebush) are the drivers of the large disparity between the pavement types, likely caused by an emergy transformity for asphalt that is double that of concrete per mass of material. The asphalt also undergoes maintenance (consisting of resurfacing and removal of old layers) more frequently than the concrete pavement, resulting in a larger demand for overall materials. A brief summary of the study is shown in Table 4.

Table 4. Summary of Roudebush (1999)

\begin{tabular}{ll}
\hline Author & Roudebush (1999) \\
\hline Title & Environmental Value Engineering Assessment of Concrete and Asphalt \\
Country & Pavements \\
LCA approach & United States \\
Analysis period & Po years \\
Traffic & unknown \\
Structures & 1. SMA (127 mm) | aggregate base (356 mm) \\
Phases & 2. JPCP, doweled (229 mm) | aggregate base (152 mm) \\
Studied & Materials | Construction | Use | M\&R | End-of-Life \\
Outputs & emergy \\
\hline
\end{tabular}

\subsubsection{Berthiaume and Bouchard (1999)}

Berthiaume and Bouchard (1999) [16] compare an asphalt and concrete pavement structure using "exergy". Exergy is a derivative of energy that describes the distance that a product is from thermodynamic equilibrium. Like the emergy unit used in Roudebush (1996, 1999), exergy is a measurement of the work and accounts for differences in energy quality. The authors claim that the link between exergy and the environment is more direct than the link between energy and the environment.

The functional unit for the analysis is a square meter of pavement in Canada evaluated over a 40 year analysis period. The scope of the paper is narrowly defined to examine only the surface of the pavement (i.e., the concrete and asphalt wearing courses) and only the exergy as it pertains to materials production, thus neglecting the construction, use, and end-of-life phases. Analyses were performed for structures supporting three traffic levels: residential $(20,000$ ESALSs), urban (150,000 ESALs), and highway (2,000,000 ESALs). Two concrete types (based on wet and dry cement manufacturing processes) and two asphalt seasons (summer and fall) are considered. Maintenance over the life of the pavements is dealt with simplistically. For the concrete pavement, half of the surface covering is "changed", with no other specific details given. For the asphalt pavement, overlays of varying thicknesses $(160 \mathrm{~mm}$ or $200 \mathrm{~mm})$ are applied, depending on the supported traffic level.

The exergy analysis finds that concrete has a higher exergy consumption for each scenario compared to the fall asphalt, except for the concrete made with the dry cement process (for which results suggest exergy is marginally in favor of concrete). In general, concrete from the dry cement process requires much less energy than does concrete from the wet process. The 
difference between fall and summer for asphalt is attributable to the high moisture content of the aggregate in the fall, which requires a larger exergy consumption to dry out prior to mixing with bitumen.

An interesting note is that the authors admit the difficulty in equitably distributing exergy amongst the various refinery products, given that bitumen (a by-product), fuels, and other products share many interrelated refinery processes. An admittedly arbitrary value is used that is somewhere between the exergy of coal and gasoline. Also of note is that the feedstock energy in bitumen is systematically not considered due to the nature of exergy. Because the feedstock energy is stored (i.e., not destroyed) in the pavement, there is no consumption of exergy using this accounting system. Because of this, direct comparison of exergy and primary energy (the standard energy metric used in most other studies) is not recommended. A brief summary of the study is shown in Table 5.

Table 5. Summary of Berthiaume and Bouchard (1999)

\begin{tabular}{|c|c|c|}
\hline Author & & Berthiaume and Bouchard (1999) \\
\hline Title & & Exergy Analysis of the Environmental Impact of Paving Material Manufacture \\
\hline Country & & Canada \\
\hline LCA approach & & Process \\
\hline $\begin{array}{l}\text { Analysis } \\
\text { period }\end{array}$ & & 40 years \\
\hline Traffic & $a$ & $\begin{array}{l}\text { a) } 20,000 \text { ESAL | b) } 150,000 \text { ESAL | c) } 2,000,000 \text { ESAL } \\
\text { 1. AC ( } 75 \mathrm{~mm}) \\
\text { 2. JPCP, doweled }(205 \mathrm{~mm})\end{array}$ \\
\hline Structures & C & $\begin{array}{l}\text { 1. AC }(110 \mathrm{~mm}) \\
\text { 2. JPCP, doweled }(220 \mathrm{~mm}) \\
\text { 1. AC }(260 \mathrm{~mm}) \\
\text { 2. JPCP, doweled }(230 \mathrm{~mm})\end{array}$ \\
\hline $\begin{array}{l}\text { Phases } \\
\text { Studied }\end{array}$ & & Materials | Construction | Use | M\&R | End-of-Life \\
\hline Outputs & & exergy \\
\hline
\end{tabular}

\subsubsection{Mroueh et al. (2000)}

Mroueh et al. (2000) [17] break from the conventional comparison of asphalt and concrete to focus on the use of industrial by-products in the pavement structure. The report examines seven structures that incorporate the use of coal ash, crushed concrete waste, and blast furnace slag as substitutes for virgin materials. Environmental impact categories include resource use, water and land releases, air emissions, waste generation, and noise. These impacts are considered for the materials, construction, and maintenance phases, thus excluding use and end-of-life. The functional unit is for one kilometer of a highway in Finland with 7,000 AADT and 14\% heavy vehicles.

The materials production phase is the primary focus of the study. The authors tap the existing literature for their process data, relying largely on Häkkinen and Mäkelä (1996) for many of their values. Although the sources used in the study are specifically and exhaustively identified, there is a lack of transparency between the inputs and the outputs; gross material volumes give way to results with few supporting environmental coefficients or other numerical 
data. This makes it difficult to assess the comprehensiveness and credibility of the results or to critically review the conclusions with respect to the materials production phase.

The construction phase analysis exhibits the same disclosure problems found in the analysis of materials production. The authors provide sources and a general overview of the approach, but do not elaborate on what equipment is involved, their assumed productivity, or the emissions factors. The magnitude or sign differences between each of the structures are also unclear. Although no values are given in the results, a bar graph illustrates that only a fraction of the total energy is consumed during the construction phase.

The maintenance phase is based on the same Finnish strategy employed by Häkkinen and Mäkelä (1996). The authors assume that each alternative undergoes identical maintenance activities, which essentially eliminates the maintenance phase from the comparison platform. This implies that each structure follows the same performance curve, which may not be a reasonable assumption. The results show that the maintenance phase is non-negligible for some of the environmental metrics, including energy consumption; for others, such as $\mathrm{CO}_{2}$, the impact is minimal.

The report aggregates the various environmental metrics based on an expert-rank weighting system. This allows all environmental burdens to be summed together into a single environmental "score." The system heavily weighted materials and energy consumption metrics, while it weighted other metrics such as water consumption and noise generation lightly. It is difficult to assess what effect this weighting system has on the choice of a structure because not all of the structures were evaluated using this process. In general, structures that utilized recycled or waste materials were more environmentally friendly than the control case which used only virgin materials. It should be noted that the ISO standards caution against using aggregated environmental results in comparative assessments, although weighting is supported as an optional element of the impact assessment phase of LCA [4, 18]. A brief summary of the study is shown in Table 6.

Table 6. Summary of Mroueh et al. (2000)

\begin{tabular}{|c|c|}
\hline Author & Mroueh et al. (2000) \\
\hline Title & Life Cycle Assessment of Road Construction \\
\hline Country & Finland \\
\hline LCA Approach & Process \\
\hline Analysis Period & 50 years \\
\hline \multirow[t]{4}{*}{ Traffic } & 7,000 AADT, $14 \%$ trucks \\
\hline & 1. AC $(160 \mathrm{~mm})$ | stone $(250 \mathrm{~mm})$ | gravel $(250 \mathrm{~mm})$ | sand $(250 \mathrm{~mm})$ \\
\hline & 2. AC $(50 \mathrm{~mm}) \mid$ stone $(150 \mathrm{~mm}) \mid$ fly ash + cement $(650 \mathrm{~mm}) \mid$ sand $(200 \mathrm{~mm})$ \\
\hline & $\begin{array}{l}\text { 3. AC }(160 \mathrm{~mm}) \mid \text { stone }(150 \mathrm{~mm}) \text { | fly ash + cement }(350 \mathrm{~mm}) \mid \text { sand }(200 \\
\mathrm{mm})\end{array}$ \\
\hline \multirow[t]{4}{*}{ structures } & 4. AC (160 mm) | stone $(150 \mathrm{~mm}) \mid$ fly ash $(350 \mathrm{~mm}) \mid$ sand $(200 \mathrm{~mm})$ \\
\hline & 5. AC $(160 \mathrm{~mm}) \mid$ crushed concrete $(450 \mathrm{~mm}) \mid$ sand $(550 \mathrm{~mm})$ \\
\hline & 6. AC $(80 \mathrm{~mm}) \mid$ crushed concrete $(400 \mathrm{~mm}) \mid$ sand $(450 \mathrm{~mm})$ \\
\hline & 7. AC $(160 \mathrm{~mm}) \mid$ crushed BFS $(100 \mathrm{~mm}) \mid$ granulated BFS (450mm) \\
\hline Phases & Materials | Construction | Use | M\&R | End-of-Life \\
\hline Outputs & energy, air emissions, raw materials, leaching water use, noise \\
\hline
\end{tabular}




\subsubsection{Stripple (2001)}

Stripple (2001) [19] is a Swedish study that examines a JPCP and two asphalt pavements produced using hot and cold production techniques. The study builds on a previous (2000) study by the same author that focused exclusively on asphalt pavements [20]. Stripple (2001) looks at each life-cycle phase except the end-of-life phase, which is omitted under the assumption that roads that do not have a "final end." Compared to other pavement LCAs, the traffic level is relatively low at 5,000 AADT, consisting of an unspecified number of heavy vehicles. In theory, lower-trafficked pavements will require fewer materials inputs during initial construction and lower maintenance frequency and intensity. The study considers a large group of environmental metrics, including energy consumption, various water and air pollutants, waste generation, and resource consumption. The data come primarily from Nordic sources and are well referenced throughout the document. An important note is that the study is scoped to include the entire roadway rather than just the pavement structure. The analysis includes the effects of road markings, signs, vegetation, and other issues not directly related to the pavement itself.

The materials production phase is accounted for in great detail. The individual processes needed to produce each material are explicitly defined and quantified, leading to a very transparent methodology. Even lightly used materials such as the tack coat are accounted for in the materials production phase. Transportation between production facilities is a significant factor given some of the long distances assumed (e.g., bitumen is produced in Venezuela for use in Sweden).

The hot and cold methods for asphalt use the same basic mix design, but vary in the final production step where the bitumen and aggregate are mixed to create asphalt concrete. The hot method is the traditional technique of heating bitumen and aggregate to allow for proper mixing of the materials. The cold method employs an emulsifier that reduces the viscosity of the asphalt, thus achieving the same benefits as heating does in the hot method. The proposed advantage of the cold method is the lower temperatures (hence lower energy input) needed to manufacture and construct an asphalt pavement. However, any performance issues between hot- and cold-mix asphalts are not discussed in the report.

The construction phase accounts only for the equipment used to construct the pavement, thus omitting the traffic delay aspect of construction. Stripple thoroughly tabulates the use of a variety of pieces of equipment, including pavers, excavators, loaders, and rollers. The maintenance phase essentially uses the same inputs as the materials and construction phases, only in magnitudes appropriate for the maintenance of the road. While organized and detailed, this study does not precisely define maintenance activities or their schedule. From descriptions in the text, it can be assumed that maintenance is carried out through some combination of grinding, milling, and overlays.

While this study does consider the use phase, there is no differentiation between the pavement types. Lighting and other operations are compiled over a 40 year analysis period and added in equal amounts to the results of each structure. Carbonation of the concrete pavement is briefly discussed but is ultimately omitted citing a long time period necessary to achieve significant carbon sequestration levels. 
The energy consumption results depend on the feedstock energy of the bitumen. The study concludes that without the feedstock energy, the JPCP consumes considerably more energy than do either of the asphalt pavements; the reverse is true when the feedstock energy of bitumen is considered. Interestingly, while the process energy for the two asphalts methods is virtually identical, the feedstock energy of the cold method is notably higher due to the bituminous-based emulsion additive. Regarding $\mathrm{CO}_{2}$ emissions, the JPCP is higher than both of the asphalt pavements. A brief summary of the study is shown in Table 7.

Table 7. Summary of Stripple (2001)

\begin{tabular}{ll}
\hline Author & Stripple (2001) \\
\hline Title & Life Cycle Assessment of Road: A Pilot Study for Inventory Analysis (Second \\
Country & Revised Edition) \\
LCA Approach & Process \\
Analysis Period & 40 years \\
Traffic & 5,000 AADT \\
Assessed & 1. JPCP | stone $(500 \mathrm{~mm}) \mid$ gravel $(1000 \mathrm{~mm})$ \\
structures & 2. AC, hot method (unspecified) | stone $(500 \mathrm{~mm}) \mid$ gravel $(1000 \mathrm{~mm})$ \\
Phases & 3. AC, cold method (unspecified) | stone $(500 \mathrm{~mm}) \mid$ gravel $(1000 \mathrm{~mm})$ \\
Outputs & Materials | Construction | Use | M\&R | End-of-Life \\
\hline
\end{tabular}

\subsubsection{Nisbet et al. (2001)}

Nisbet et al. (2001) [21] is an LCI study that compares an asphalt pavement to a doweled JPCP pavement for both urban collector and highway routes. Much of the supporting data for the asphalt portion of the study come from a report completed in the same year by the same authors [22]. Both studies were commissioned by the Portland Cement Association. The pavements are compared using energy consumption, various air emissions (particulate matter, $\mathrm{CO}_{2}, \mathrm{SO}_{2}, \mathrm{NO}_{\mathrm{x}}$, VOC, $\mathrm{CO}$, and $\mathrm{CH}_{4}$ ), and natural resource use. The data used in the calculations are tabulated in a very transparent fashion, which includes data sources and an estimate of the quality of those sources (many of which are industry reports from the Portland Cement Association).

Each phase of the pavement life cycle is included except for the use phase. The authors do, however, state that some aspects of the use phase (e.g., traffic energy consumption, traffic delay, and lighting) are the topics of other studies. A claim is made that these studies are likely to produce results that are favorable to concrete pavement, although no justification through references or examples is provided. Also, the end-of-life phase is treated using a discussion of the recyclability of the two pavement types, but it is not quantitatively included in the inventory results.

The authors conclude that for both the urban collector and highway scenarios, the concrete pavements require less overall material, have a lower embodied primary energy, and produce lower air emissions (with the exception of $\mathrm{CO}_{2}$ and $\mathrm{NO}_{\mathrm{x}}$, which are both lower for the asphalt pavements). The results include the feedstock energy in bitumen. A unique aspect of this study is the inclusion of a sensitivity analysis that evaluates the relative importance of ten different factors on the results. For instance, the sensitivity analysis found that for asphalt 
pavements, the feedstock energy in bitumen was a dominant factor for the embodied energy calculations, while transportation played only a small role. Other factors evaluated in the sensitivity analysis were: useful life, pavement design, maintenance schedule, PCC mix design, asphalt concrete mix design, use of fly ash, use of reclaimed asphalt pavement (RAP), and construction equipment. The inclusion of a sensitivity analysis is a major advancement and is arguably the most important contribution of this study toward the state of the art. A brief summary of the study is shown in Table 8.

Table 8. Summary of Nisbet et al. (2001)

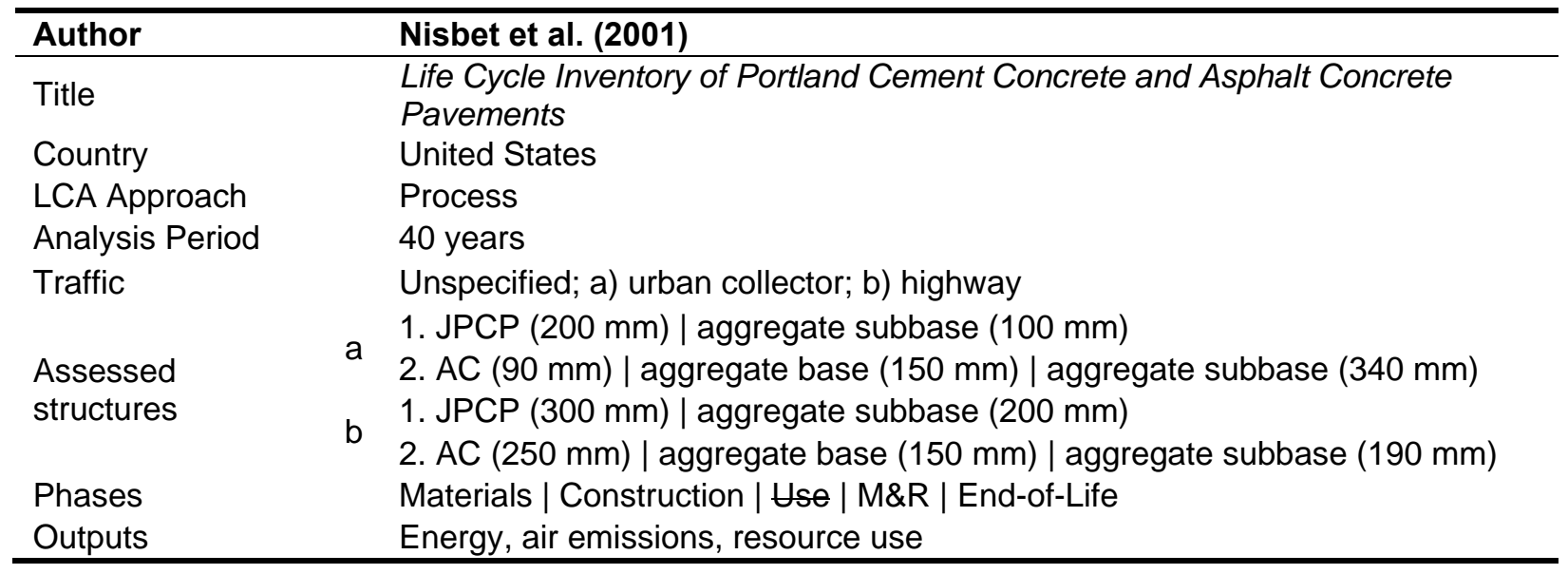

\subsubsection{Park et al. (2003)}

The first published hybrid LCA applied to pavements appears in Park et al. (2003) [23]. This paper combines an IO model of the Korean economy with a national energy balance table to produce estimates for the materials extraction and production phase of the pavement life cycle. The construction and end-of-life phases are analyzed using a process-based approach. Pavement maintenance is handled using both IO and process-based approaches. Energy consumption is the primary environmental stressor discussed, with $\mathrm{NO}_{\mathrm{x}}, \mathrm{SO}_{2}$, and $\mathrm{CO}_{2}$ emission estimates derived as a function of energy consumption.

The study lacks input details necessary for full transparency. Although asphalt and readymixed concrete are analyzed, their thicknesses and underlying structures are not well-defined. Likewise, steel, cement, aggregate, and other materials are included in the study but are not specifically discussed aside from their environmental impact. Likewise, few analytical details of the IO-LCA model are provided (e.g., data sources, model strengths and limitations, sponsoring organization). This lack of supporting documentation makes it difficult to interpret both the study's results and its scientific contribution. A brief summary of the study is shown in Table 9. 
Table 9. Summary of Park et al. (2003)

\begin{tabular}{ll}
\hline Author & Park et al. (2003) \\
\hline Title & Quantitative Assessment of Environmental Impacts on Life Cycle of Highways \\
Country & Korea \\
LCA Approach & Hybrid \\
Analysis Period & 20 years \\
Traffic & Unknown \\
Assessed & 1. surface $(50 \mathrm{~mm}) \mid$ base $(250 \mathrm{~mm}) \mid$ subbase $(300 \mathrm{~mm}) \mid$ selected material \\
structures & $(250 \mathrm{~mm})$ \\
Phases & Materials | Construction | Use | M\&R | End-of-Life \\
Outputs & energy, air emissions \\
\hline
\end{tabular}

\subsubsection{Treloar et al. (2004)}

Treloar et al. (2004) [24] used a hybrid LCA approach to assess eight pavement types, including a CRCP, an undoweled JPCP, a composite pavement, and a variety of asphalt pavements. The setting is a rural highway in Australia that supports 10,000 vehicles per day, $10 \%$ of which are trucks. Each of the life-cycle phases, except the end-of-life phase, are examined. The authors assume that most rural highways remain in place indefinitely, thus negating the need to perform an end-of-life analysis. Each of the structures are compared based on their process energy and do not include the feedstock energy of the bitumen. Most structures considered use a 40-year design life; two structures use a 20-year design, but are structurally inferior to the other designs. The authors note the potential differences in performance between the designs (especially as related to truck traffic), but provide little elaboration on the topic.

The materials production phase is quantified using process LCA, citing a 1998 paper by the authors as the main data source. The pavements are formed using a combination of two types of concrete (wearing and base courses), steel, and asphalt concrete. The construction phase is estimated using an Australian IO model, by removing the embodied energy of the materials from the "road construction" sector. This is based on the premise that initial construction of a road consists only of pavement materials and the construction processes needed to place those materials. Transportation is also included in this assessment, although it is not stated whether it is attributed to the materials production phase or the construction phase. While the authors' approach includes some significant assumptions, their result give at least a rough estimate as to the construction effects without needing to identify the types, productivities, and energy consumption rates for each piece of equipment.

The maintenance phase is modeled as a yearly input of $4 \%$ of the total energy. Inexplicably, this rate is compounded over the analysis period, making the total energy 4.6 times the initial input. (For reference, without compounding, this value is 1.6 times the initial input for a 40 -year analysis period.) The authors admit that the $4 \%$ per annum assumption is a major simplification, but assert that the inclusion of a more sophisticated approach to maintenance will not significantly affect the results. Given the sensitivity to even a $\pm 1 \%$ change in the maintenance assumption (a swing from 3.2 to 6.7 times the initial amount, using compounding), it seems possible that the maintenance phase, as modeled in the paper, is perhaps more relevant than assumed by the authors. 
The use phase is modeled as independent of the pavement type and serves only to benchmark the relative importance of the materials, construction and maintenance phases. The authors account for the fuel consumption of traffic, the embodied energy in vehicle manufacturing, and the cost of owning vehicles, including registration, tires, servicing, insurance, and interest. The IO method was used to determine the energy consumption associated with vehicle manufacturing and ownership. One noteworthy obscurity was a shift from the design traffic distribution of $10 \%$ trucks to a much higher $23.4 \%$ trucks. This undoubtedly led to higher traffic fuel consumption, but the magnitude of the increase is unclear.

Ignoring the two 20 year designs, the undoweled JPCP had the lowest energy input, while the full depth asphalt had the highest energy input. Although not discussed, the assumption of identical maintenance packages rewards those pavements with low initial energy inputs, which is counterintuitive. This is clearly exemplified in the case of the CRCP versus the undoweled JPCP, in which the JPCP has both lower initial energy input and lower maintenance energy. It is important to note that the study's conclusions are not focused on choosing the best pavement type, but on highlighting the relatively small importance of the materials, construction, and maintenance phases of a pavement when compared to the fuel consumption of vehicle traffic. The authors also champion the use of hybrid LCA as a method to improve the accuracy of process LCA while minimizing the truncation errors associated with IO LCA. A brief summary of the study is shown in Table 10.

Table 10. Summary of Treloar et al. (2004)

\begin{tabular}{ll}
\hline Author & Treloar et al. (2004) \\
\hline Title & Hybrid Life-Cycle Inventory for Road Construction and Use \\
Country & Australia \\
LCA Approach & Hybrid \\
Analysis Period & 40 years and 20 years ( $\dagger)$ \\
Traffic & 10,000 AADT, 10\% trucks \\
& 1. CRCP $(102 \mathrm{~mm}) \mid$ low-strength concrete $(107 \mathrm{~mm})$ \\
& 2. JPCP, undoweled (186 mm) | low-strength concrete $(107 \mathrm{~mm})$ \\
& 3. AC $(231 \mathrm{~mm}) \mid$ low-strength concrete $(131 \mathrm{~mm})$ \\
Assessed & 4. AC $(171 \mathrm{~mm}) \mid$ low-strength concrete $(108 \mathrm{~mm})$ \\
structures & 5. AC $(171 \mathrm{~mm}) \mid$ compacted earth \\
& $6^{\dagger}$. compacted earth | compacted earth \\
& 7. AC $(128 \mathrm{~mm}) \mid$ low-strength concrete $(175 \mathrm{~mm})$ \\
& $8^{\dagger}$. AC $(42 \mathrm{~mm}) \mid$ low-strength concrete $(252 \mathrm{~mm})$ \\
Phases & Materials | Construction | Use | M\&R | End-of-Life \\
Outputs & energy \\
\hline
\end{tabular}

\subsubsection{Zapata and Gambatese (2005)}

Zapata and Gambatese (2005) [25] analyze the energy consumption of a CRCP and an asphalt pavement in the United States for the materials production and construction phases of the life cycle. The study is inspired by the contradictory results published in Horvath and Hendrickson (1998) and Stripple (2001), who offer opposing conclusions regarding which pavement type offers the lower energy consumption. Zapata and Gambatese adopt the same pavement structure and traffic assumptions used by Horvath and Hendrickson in order to maintain a fair comparison. 
Zapata and Gambatese attribute the difference in energy consumption results to the different LCA approaches used by the studies (i.e., IO versus process LCA). And more specifically, that at a major factor is the difference in system boundaries between the two approaches. The authors ultimately opt to use the process LCA model due to its widespread global use and transparent methodology.

The study walks through each process associated with materials extraction, manufacturing, and construction, drawing energy data from previous pavements LCAsHäkkinen and Mäkelä (1996), Berthiaume and Bouchard (1999), and Stripple (2001) —and other, more process-specific studies. The authors note that most of the values from previous studies are relatively consistent, with the major exception being the bitumen production process, where values differ by an order of magnitude. The feedstock energy of bitumen is not considered in the study, nor are the maintenance, use, or end-of-life phases of the life cycle.

The results find that the CRCP consumes the most energy over the materials production and construction phases, which aligns with the results from Stripple (2001). It is worth noting that this study's data sources and LCA approach were similar to the Stripple study, so this conclusion is not surprising. The authors conclude that bitumen extraction and production requires less energy than does cement manufacturing. Energy consumption for the asphalt pavement is most affected by the mixing and drying of the aggregates; energy consumption for the CRCP pavement is most affected by cement manufacturing. The authors make note of the difficulty in accurately determining the process energy for bitumen production due to the problem of allocating energy between different refinery products. The conclusions, however, are not sensitive to the different energy values of bitumen extraction and production reported in the literature. A brief summary of the study is shown in Table 11.

Table 11. Summary of Zapata and Gambatese (2005)

\begin{tabular}{ll}
\hline Author & Zapata and Gambatese (2005) \\
\hline Title & Energy Consumption of Asphalt and Reinforced Concrete Pavement Materials \\
Country & United States \\
LCA Approach & Process \\
Analysis Period & $\sim 10$ years \\
Traffic & $\sim 10 \times 10^{6} \mathrm{ESAL}$ (total) \\
Assessed & 1. AC $(300 \mathrm{~mm})$ \\
structures & 2. CRCP $(220 \mathrm{~mm})$ \\
Phases & Materials | Construction | Use | M\&R | End-of-Life \\
Outputs & energy \\
\hline
\end{tabular}

\subsubsection{Athena Institute (2006)}

The Athena Institute (2006) [26] compares the energy and global warming potential of asphalt and JPCP structures in a project commissioned by the Cement Association of Canada. This study is an update to a 1999 report by the same organization [27]. The study uses the process LCA approach for six case studies, with projects ranging from arterial roadways to high volume urban highways. Considerable effort has gone into creating equitable concrete and asphalt designs; a consultant was retained to produce the structures using the Mechanistic Empirical Design Guide 
(MEPDG) model. The environmental data were collected from various Canadian and United States sources. The analysis period is 50 years.

The materials production and maintenance phases are considered in the analysis. Construction is omitted based on the claim that the energy consumption associated with construction equipment is negligibly small compared to the energy consumption of the other lifecycle phases. This claim seems justified based on the relatively small contribution of construction phase to the life-cycle impacts in previous studies (e.g., Zapata and Gamatese (2005)). Moreover, the differences in construction equipment are also minor between the two material types, making the construction phase less important for comparing material types.

The materials production phase includes the extraction and manufacturing of the asphalt, concrete, and base materials needed for the mainline and shoulder structures. Two types of asphalt are assessed: one with virgin materials and one with $20 \%$ RAP. The feedstock energy of bitumen is included and accounts for roughly $75 \%$ of the total energy per unit of asphalt concrete.

The maintenance phase includes typical practices used by Canadian road authorities. Maintenance focuses on procedures where significant amounts of new materials are being installed, such as in overlays and reconstructions. Small and less resource intensive procedures such as crack sealing and diamond grinding are omitted due to their assumed insignificance. The JPCP designs undergo an asphalt overlay in the latter half of the analysis period, with one of the designs also requiring a full reconstruction including new PCC and steel, albeit in the last year of the analysis period (the impact was prorated accordingly in the assessment). The asphalt designs are subjected to more activities and include some combination of asphalt overlays, milling of old asphalt, and complete reconstruction.

The study's results for energy consumption are heavily in favor of concrete designs. With feedstock energy included, the asphalt designs consume two to five times more energy over the materials production and maintenance phases. Excluding feedstock energy, asphalt pavements still consume more energy, although only 0.3 to 0.7 times more than equivalent concrete designs. Estimated differences in global warming potential between material types in each case study are less than $10 \%$, and within the study's confidence intervals, and are thus treated as insignificant. A brief summary of the study is shown in Table 12 . 
Table 12. Summary of Athena Institute (2006)

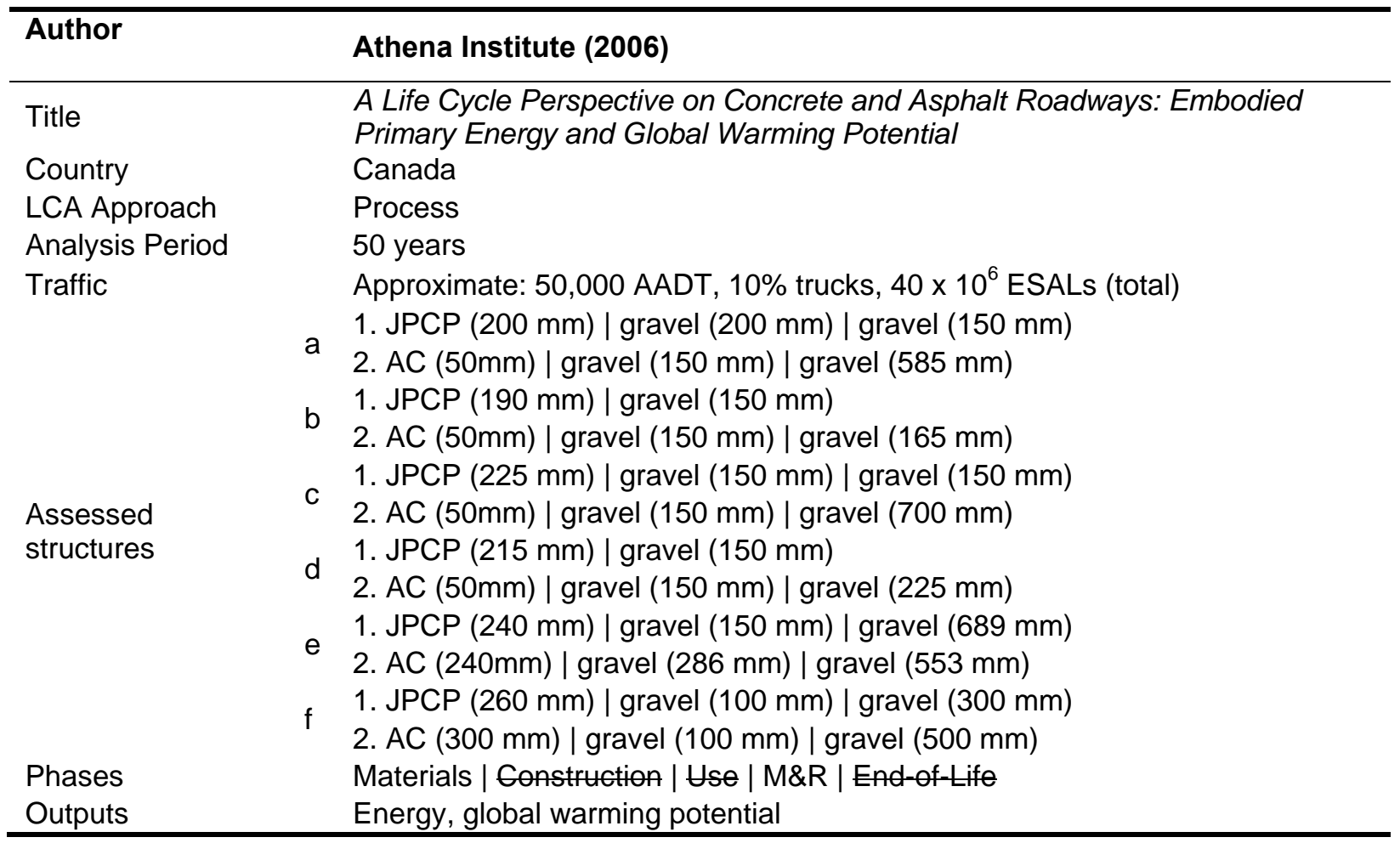

\subsubsection{Chan (2007)}

Thirteen Michigan Department of Transportation (DOT) projects are analyzed by Chan (2007) [28] in his University of Michigan Master of Science thesis. The objective of the thesis was twofold: (1) to identify inaccuracies in the preliminary life-cycle cost analysis (LCCA) of each project and (2) to account for environmental burdens by monetizing the effects of pollution using LCA methodology. Asphalt and concrete alternatives are presented as the comparison platform. The projects are analyzed at different points in their life cycle, depending on their current state at the time of the study. The projects considered spanned newly constructed, reconstructed, or rehabilitated pavements. The thesis accounts for energy consumption, GHG emissions, criteria pollutant emissions (except for ozone), and airborne carcinogens.

The study utilizes environmental data from the Portland Cement Association, the Athena Sustainable Materials Institute, SimaPro 6.0, Stripple (2001), and others to estimate the impact of pavement materials. Only surface materials are considered, and thus the results only represent the differences in those materials. This is a potentially significant boundary choice depending on the type and thickness of the underlying structural layers. Equipment emissions from the construction phase are determined through the United States Environmental Protection Agency's NONROAD2005 model. The maintenance phase is included, although activity schedules and other pertinent details are not provided.

The study provides a significant advancement from previous pavement LCAs by incorporating the traffic delay caused by construction processes into the pavement project's environmental footprint. This is only done for the initial construction phase of the life cycle. A 
tool called $K y U C P$ from the Kentucky Transportation Center estimates the traffic delays, while EPA's MOBILE6 converts the delay into various environmental burdens. The study's results suggest that for high traffic projects, traffic delay during construction is at least comparable, if not dominant, to the materials production phase with respect to energy consumption and $\mathrm{CO}_{2}$ emissions.

The author concludes that the asphalt alternatives generally consume more energy, albeit only with the inclusion of the feedstock energy of bitumen. Without including feedstock energy, the two alternatives are very similar. Concrete is the highest emitter of GHGs due to the generation of $\mathrm{CO}_{2}$ during the calcination process in cement production. Additionally, the study finds that results from the monetization of pollution costs account for only small fraction of the total life-cycle costs. Chan notes the difficulties and assumptions involved an impact assessment of this sort and the inherent inaccuracies that exist. Still, this study marks the first pavement LCA that combines its results with those of a parallel LCCA study. A brief summary of the study is shown in Table 13.

Table 13. Summary of Chan (2007)

\begin{tabular}{ll}
\hline Author & Chan (2007) \\
\hline Title & Economic and Environmental Evaluations of Life Cycle Cost Analysis Practice: \\
Country & A Case Study of Michigan DOT Pavement Projects \\
LCA Approach & United States \\
Analysis Period & Process \\
Traffic & not specified \\
Assessed & variable \\
structures & 26 different structures (13 locations x 2 alternatives (AC vs JPCP)) \\
Phases & Materials | Construction | Use | M\&R | End-of-Life \\
Outputs & Energy, air emissions, raw materials \\
\hline
\end{tabular}

\subsubsection{Secondary Materials in Pavements}

A handful of studies have used LCA or similar techniques to evaluate the environmental impacts of using by-products and recycled materials in pavements. These waste streams include products such as foundry slag, bottom ash, fly ash, RAP, shredded rubber tires, crushed glass, plastics, and crushed concrete. Rather than being landfilled, these products can supplant the use of aggregates, binders, and other virgin materials in pavements. While avoiding landfilling and conserving virgin materials have their own environmental merits, the total environmental benefit (or drawback) for each product needs to account for its life cycle as a pavement material, including its reprocessing into a suitable form, transportation, and effects while in use.

Using a series of case study scenarios, Mroueh et al. (2001) estimated that the use of slag and crushed concrete as a replacements for virgin aggregates decreased the environmental burdens associated with a pavement, with respect to use of natural materials, energy consumption, leaching of heavy metals, and $\mathrm{NO}_{\mathrm{x}}$ and $\mathrm{CO}_{2}$, emissions [29]. The authors do, however, acknowledge that differing transportation and construction practices between projects could affect the results. As a result, the authors caution against drawing general conclusions based on their results. This paper is part of a larger study [30], of which the previously reviewed reference [17] is also a part. 
Roth et al. (2003) qualitatively examine the viability of using crushed concrete, slag, and bottom ash as substitutes for virgin aggregates [31]. The authors suggest that the decision to use these by-products is largely based on value choices, and thus avoid drawing sweeping conclusions about the environmental benefits or drawbacks of secondary materials in pavements. The authors recommend that expanded system boundaries in pavement LCA will help improve the basis for decision-making related to secondary materials use.

Jullien et al. (2006) investigated the effectiveness of varying rates of RAP toward reducing airborne emissions of VOCs, PAHs, and odors [32]. The control case ( $0 \%$ RAP) produced significantly higher odors, but significantly less VOCs and PAHs than the three RAP cases $(10 \%, 20 \%$, and $30 \%)$. PAHs tended to increase with recycling rate, while VOCs and odors showed mixed results.

Birgisdóttir et al. $(2006,2007)$ published two papers [33-34] that use the software tool $R O A D-R E S$ (discussed in Section 2.2.2) as the calculation medium. Similar to the theme of the tool, the papers focused on the use of waste incineration residues as a substitute for virgin pavement materials. One paper found that the use of residues as a substitute for virgin base material had negligible effects on the overall environmental impact of a pavement [33]. The other paper suggested that using residues (in particular, bottom ash) as a sub-base material had a higher environmental impact than landfilling it due to leaching concerns [34].

Carpenter et al. (2007) used the software tools PaLATE (discussed in Section 2.2.1) and HYDRUS2D (a finite element modeling program used to model site-specific impacts, [35]) to evaluate the impact of using bottom ash in lieu of virgin aggregate [36]. The results indicated that the use of bottom ash lowered energy consumption, water consumption, air emissions (CO, $\mathrm{CO}_{2}, \mathrm{NO}_{\mathrm{x}}$ and $\mathrm{SO}_{2}$ ), mercury and lead emissions, and non-cancer human toxicity potential (HTP), but increased cancer HTP due to leaching of bottom ash contaminants. However, the water flow modeling suggested that the leached contaminants may never reach groundwater sources at a significant level, thus minimizing their potential impact.

Huang et al. (2007) performed a review of the use of recycled materials in asphalt pavements [37]. Although not an LCA, the paper provides insightful discussions on the suitability and benefits of using various solid waste streams (glass, slag, tires, and plastics) as substitutes for virgin materials. The paper discusses performance issues, reprocessing costs, and environmental concerns for each material. The authors stop short of making a recommendation regarding the use of secondary materials in pavements, but instead highlight that the benefits of reduced landfilling and virgin materials extraction are countered by financial expenses and potential environmental damages such as contaminant leaching.

Chiu et al. (2008) compared RAP, rubber-modified asphalt, and "Glassphalt" (a proprietary asphalt mix that uses crushed glass in the mix) to traditional hot-mix asphalt [38]. Environmental impacts were weighted using the Eco-indicator 99 approach, which is a European impact assessment method that accounts for human health, ecological quality, and resource consumption. The results suggested that benefits of using recycled materials are mixed: RAP and rubber-modified asphalt were estimated to have a lower impact than traditional asphalt, but Glassphalt was estimated to have a higher impact that traditional asphalt. Impacts were characterized in terms of "eco-burden," which is the metric associated with the Eco-indicator 99 
approach. Furthermore, the study suggests that the most effective way to reduce the eco-burden is to reduce heat requirements during materials manufacturing.

The literature provides interesting perspectives on the environmental implications of using secondary materials in pavements. While there are certainly landfilling and conservation benefits associated with diverting materials from the waste stream, there may also be considerable and uncertain impacts to the environment in the form of water emissions, air emissions, and other environmental hazards. As Roth et al. (2003) pointed out, the use of secondary materials is ultimately dependent upon the value choices made by decision makers. The general inconclusiveness of the existing research as a whole opens the door for further research in this area that more thoroughly quantifies the effect of each secondary material. LCA is an appropriate framework to evaluate such effects.

\subsection{Pavement LCA Models}

There are a number of software tools that are designed for assessing the pavement life cycle. However, the vast majority of such pavement decision-support tools are concerned only with LCCA, which has become a pervasive economic assessment methodology amongst state DOTs. As LCCA has gained popularity, a number of capable software tools have emerged to aid in the evaluation process. According to a recent survey of LCCA practices amongst state DOTs, one of the more widely adopted LCCA tools is the Federal Highway Administration's (FHWA) RealCost [39]. The main advantage of the software is the ability to evaluate user costs alongside conventional agency costs. To calculate user costs, the RealCost algorithm determines the delay to travelers using various traffic characteristics under normal and construction conditions. A value of time is then applied to that delay, thus generating a user cost estimate. This is the most commonly practiced method of user cost evaluation amongst state DOTs [40]. However, by focusing exclusively on traffic delay, externalities such as noise, safety, standard operation fuel consumption, and vehicle wear are neglected, making this an incomplete assessment of the actual user costs.

Compared to its economic counterpart, environmental LCA has thus far gained little traction within transportation agencies' decision-making processes for pavements. Undoubtedly correlated with this is the scarcity of pavement-focused environmental assessment tools. Spreadsheet models such as Caltrans' Cal B/C, FHWA's IMPACTS, and the Sacramento Metropolitan Air Quality Management District's Road Construction Emissions Model explore various environmental aspects of the pavement construction and use phases, but do not look at pavements from a life-cycle perspective. Similarly, the GreenRoads rating system developed by researchers at the University of Washington is designed to "score" the environmental impact of a given pavement, but is not intended to be a comprehensive LCA tool.

There are also a number of LCA tools available for the purpose of assessing the impact of different but related products. An example is the BEES model, which is used to assess the lifecycle impacts of buildings. Pavements are included in $B E E S$ as they are a peripheral part of the building system, most notably in the form of parking lots. However, BEES and similar models do not evaluate pavements in nearly the same depth that a pavement-specific LCA tool would, and are thus not discussed in detail in this report. The same logic excludes the discussion of large commercial LCA tools, such as SimaPro and Gabi, which may contain data on specific 
pavement inputs (e.g., concrete) or processes (e.g., equipment fuel combustion) but are not designed for pavement-specific LCAs.

Tools that take a more comprehensive approach to evaluating the pavement life cycle are rare. This literature review identified two categories of pavement LCA models: (1) projectoriented models that were developed for specific studies; and (2) general pavement LCA models that were designed for more widespread use. Several of the studies reviewed in Section 2.1 cite the use of tools that fall into the former category, although it is unclear whether these tools have subsequently been used by the broader LCA and/or pavement design communities. Studies that fall into the former category include Mroueh et al. (2000) [17], Stripple (2001) [19], and Chan (2007) [28].

This review identified only three LCA tools that fell into the latter category; a brief overview of each tool is provided below.

\subsubsection{PaLATE}

The Pavement Life-Cycle Assessment Tool for Environmental and Economic Effects (PaLATE) is an LCA tool that is designed to estimate the environmental and economic burdens associated with pavement projects in the United States. Originally developed in 2003 at the University of California, Berkeley, PaLATE models the life cycle of a pavement through the materials extraction, production, construction, maintenance, and end-of-life phases. The Excel-based tool combines $E I O-L C A$ data with additional process-based information to create a hybrid LCA framework. Users are responsible for providing material volumes for each pavement layer and maintenance activity. A high-level overview of PaLATE is shown in Figure 4.

PaLATE's environmental outputs include energy and water consumption, global warming potential (GWP), $\mathrm{NO}_{\mathrm{x}}, \mathrm{PM}_{10}, \mathrm{SO}_{2}, \mathrm{CO}, \mathrm{Hg}, \mathrm{Pb}$, hazardous waste generation, and HTP. Aside from its energy, GWP, and HTP estimates, environmental outputs are reported as a raw values rather than as environmental impacts, making PaLATE primarily an LCI (rather than an LCIA) tool. The tool also provides a simple life-cycle costing mechanism, although its analysis is limited to material unit-weights, thereby excluding labor, overhead, user costs, and other economic considerations.

PaLATE has been criticized for using outdated data in its calculations [41], exemplified by the use of the 1992 EIO-LCA model as the source for many of its key environmental assumptions. Other PaLATE data are coarse approximations that were used to fill data gaps at the time of the tool's creation. PaLATE also has a scope that excludes important elements of the life cycle, such as traffic delay and the use phase. Even with its limitations, it remains the only pavement LCA tool (albeit an incomplete one) that is designed for use in the United States. 


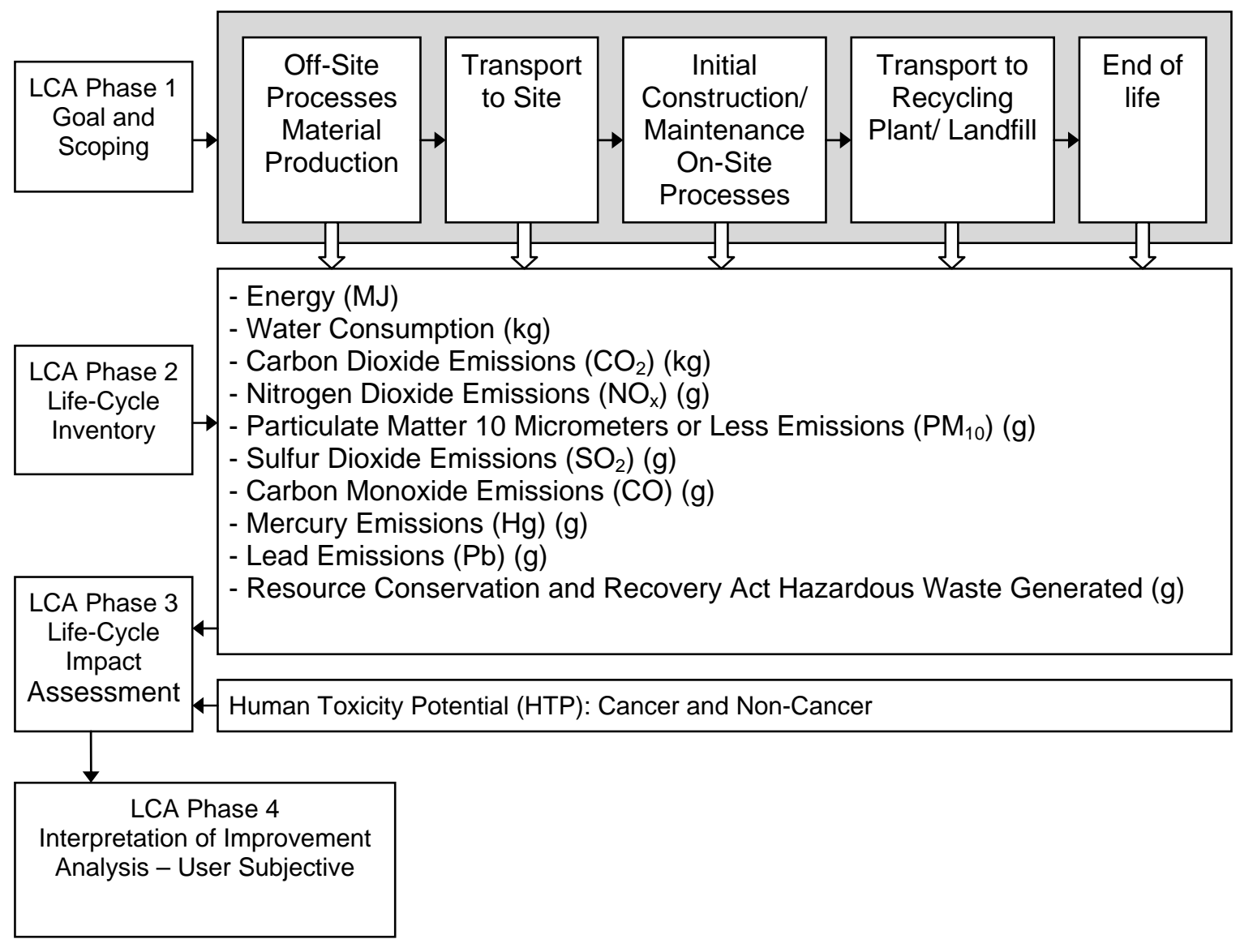

Figure 4. Overview of the PaLATE model [41]

\subsubsection{ROAD-RES}

A Ph.D. dissertation from the Technical University of Denmark discusses a model called ROADRES that assesses the environmental impact of the materials production, construction, maintenance, and end-of-life phases of the pavement life cycle [42]. There is also some leachate information available, thus making it at least partially applicable to the use phase of the pavement life cycle. The model expands beyond just pavements to also incorporate issues with the roadway itself, such as winter service activities (e.g., salting). ROAD-RES is particularly focused on the use of residues from waste incineration and, as such, facilitates comparisons of virgin materials to these waste products. Figure 5 shows an overview of the ROAD-RES model.

ROAD-RES considers eight different impact categories: GWP, photochemical ozone formation, nutrient enrichment, acidification, stratospheric ozone depletion, human toxicity, ecotoxicity, and stored eco-toxicity. These categories cover environmental impacts to air, soil, and water (fresh surface water, marine surface water, and groundwater). The unique focus on residues on and water pollution are important contributions of the model.

ROAD-RES has been used in several subsequent LCA studies, all by the author of the tool (Birgisdóttir). Much like the theme of the tool, these studies focus on the use of waste residues in pavements and assess their impact relative to virgin materials. More on these studies can be found in Section 2.1.2. 


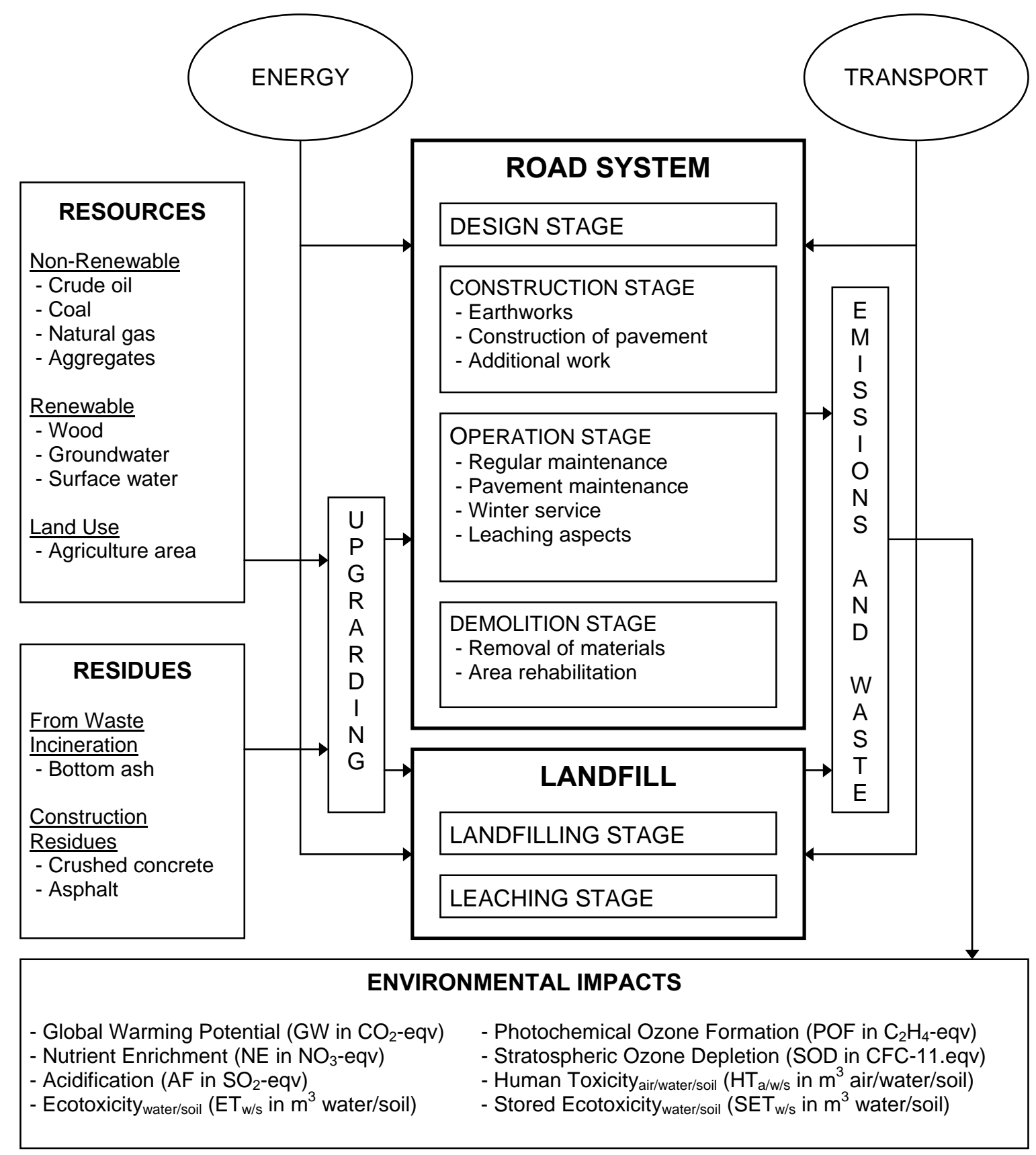

Figure 5. Overview of ROAD-RES model [42]

\subsubsection{UK asphalt pavement LCA model}

A recently published paper by Huang et al. (2009) describes a pavement LCA tool dedicated specifically to the assessment of asphalt pavements [43]. The paper cites five reasons that current pavement LCA tools are inadequate: relevance, adaptability, compliance, scope, and availability. These critiques mirror many of the key limitations of pavements LCA studies reviewed in Section 2.1. The unnamed tool discussed in the paper looks at the materials production, construction (onsite equipment only), and maintenance phases of the pavement life cycle, 
including any necessary transportation. Recycled materials such as glass, bottom ash, and RAP are a part of the materials pool. The tool is designed to analyze pavement in the United Kingdom. An overview of the tool's elements and architecture is provided in Figure 6.

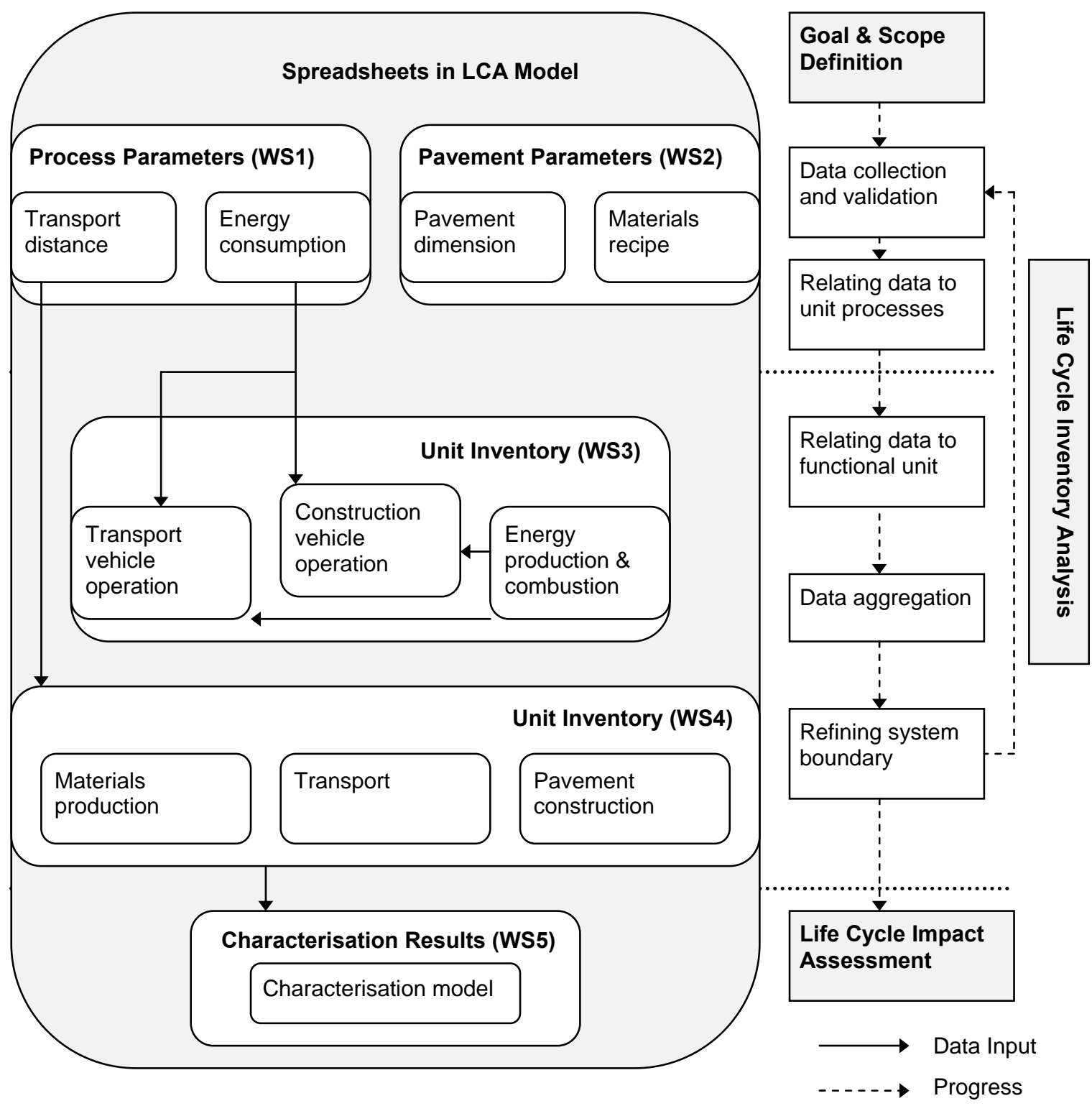

Figure 6. Overview of UK asphalt pavement LCA tool [43]

Eleven impact categories are used to characterize the environmental impact of asphalt pavements: depletion of materials; depletions of fossil fuels, GWP; stratospheric ozone depletion; acidification; photo oxidant formation; human toxicity; eco-toxicity; eutrophication; noise; depletion of landfill space. The paper also recommends grouping and weighting the impact categories using a method called "Eco-points" - an established rating system developed 
by the United Kingdom Built Research Establishment for the construction industry. The authors admit that the ISO 14044 standards do not advocate weighting for comparative assessment since it requires value choices.

The tool is a work in progress and was not publicly available at the time of this review. From its documentation, it appears that the scope is well defined and that the ISO 14040 series of standards are recognized and implemented through the model. The inclusion of LCIA will provide useful information beyond what existing pavement LCIs provide. However, the complexity of the LCIA categories considered, and related data demands, suggest that the tool's LCIA methods should be reviewed when it is publicly available. Notably, the paper does not discuss the inclusion of traffic delay or the use phase, although the authors have addressed traffic delay in subsequent papers [44].

\subsubsection{Discussion of existing LCA models}

Existing pavement LCA models are progressing towards a state of comprehensiveness and quality that should eventually facilitate utilization on a wider scale. However, the scopes of current models are bounded by the more commonly-analyzed phases of the life cycle (materials production, construction, maintenance, and end-of-life), with little attention paid so far to important contributors such as the use phase and traffic delay. Data is also very specific to particular locations, so it is not easy or advisable to use a particular model outside of the region for which its application was intended. Not surprisingly, such drawbacks mirror some of the limitations of the pavement LCAs reviewed in Section 2.1.

It is important to note that the flexibility offered by such models to examine a wide variety of pavements is a crucial advancement over the static, project-specific LCAs reviewed in Section 2.1. Models also have the benefit of reducing the time, money, and expertise needed to perform an LCA, making environmental assessments of pavements a more feasible task. By reducing these barriers to conducting a pavement LCA, existing models may allow transportation agencies, research organizations, and other policymaking enterprises to begin including pavement LCA as an important component of their decision-making framework.

\subsection{Synthesis of Pavement LCA Research}

The existing body of pavement LCA research contains studies and tools with different qualities, depths, and conclusions. All three LCA approaches - IO, process-based, and hybrid - are utilized in this body of work. Data sources also differ greatly, although it is difficult to determine whether data from one study is more reliable than another. Most studies also demonstrate an adequate level of transparency so that the results can be reproduced using the given data and calculation methods. The lack of agreement between results attests to the broad nature of pavement design, the variable LCA frameworks used, and the relative youth of the pavement LCA research field.

The following sections examine five issues that are relevant to the reviewed literature and tools: functional unit, system boundaries, information on bitumen and cement, life-cycle inventory and impact results, and overall utility. The purpose is to highlight areas in the literature that deserve more attention and discussion. 


\subsubsection{Functional unit}

A major drawback of pavement LCAs as a whole is the lack of consensus upon a single functional unit upon which to assess pavements. For example, Stripple (2001) examines a pavement that supports 5,000 vehicles per year with a design life of 40 years that must survive the harsh freeze-thaw conditions that exist in Sweden, whereas Horvath and Hendrickson (1998) use a "typical two-lane highway" in the United States that is built to withstand 10 million ESALs. These are two totally different situations, yet these have been compared and cited in subsequent LCAs.

The problem of the non-standard functional unit is more a testament to the complexity of pavements rather than the disorganization of the pavement LCA community: pavements are not easily defined through one, or even a few functional units. This is due to the fact the pavement structure (i.e., the type and thickness of materials) is heavily influenced by the traffic, environmental conditions, design life, and other project-specific details. The variability of these elements creates a situation where two pavements of equal lengths may have fundamentally different characteristics. Simply packaging a functional unit with the structural dimensions of a pavement is not sufficient information to describe multi-aspect function of pavements. So, whereas freight transportation can be described reasonably accurately through tonne-kilometers, or electricity generation through kilowatt-hours, pavements cannot be neatly bundled into packets of ESAL-kilometers or some equivalent, simple functional unit.

The use of non-standard functional units inhibits the aggregation of the existing literature for comparison and contrasting purposes. In effect, the pavement literature is comprised of a group of seemingly similar studies that, in fact, examine very different scenarios. This makes drawing general conclusions (such as whether asphalt or concrete is more environmentallyfriendly) nearly impossible. If the pavement LCA research was in agreement regarding which pavement was more environmentally friendly, this would arguably trump the problem of differing functional units. However, this is not the case as study results and conclusions routinely differ from one another. In essence, the functional units used in the studies are disparate enough to preclude apples-to-apples comparisons. The conclusions are only applicable to the case that is researched in a given study. A more comparable functional unit would need to include, at minimum, the same traffic level, vehicle characteristics, climate, and period of analysis.

However, resolving the issue by creating a standardized functional unit may not be feasible given the large number of characteristics that define a pavement. Instead, pavement LCA practitioners should be aware that the conclusions drawn from a particular case study may not be relevant for another case study. In order to circumvent this issue and draw broader conclusions, sensitivity analyses (similar to the one performed by Nisbet et al. (2001) [21]) can be performed based on important variables, such as traffic level, location, and design life. Such analyses will help identify the robustness of the conclusions and determine under which scenarios they can be best applied. An alternative approach would be to create a catalog consisting of multiple functional units that recommends best-practices methods based on basic pavement characteristics. This allows for a straightforward assessment of the best environmental approach for a given pavement, but it may be difficult to compile a comprehensive dataset that captures the necessary pavement characteristics. 
The issue of functional units is also of a concern within a given study. Many pavement LCAs focus on comparing the impacts of two or more alternative designs, often asphalt versus concrete. In such comparisons, it is pertinent that the compared designs (together with the modeled maintenance) provide equivalent service over their lives. When this is not the case, designs are compared using biased platforms, seriously jeopardizing the integrity of the results and conclusions.

Creating designs for comparison should be completed by a trained pavement engineer so that equivalency is ensured. This report calls out the method used by the individual authors in the creation of their designs and assumes that equivalency has maintained. However, this assumption may not hold true for some of the reports. The summary tables for each reviewed pavement LCA study in Section 2.1.1 provide the basic design details as presented in the given studies so that readers of this report can evaluate the equivalency of a particular design if necessary.

\subsubsection{System boundaries}

The materials production phase is the primary focus of nearly all the studies. Differing data sources for the processes involved in the extraction and production of the pavement materials account for much of the disparity in results between studies. In particular, the refining of bitumen in oil refineries is especially problematic, as noted by Zapata and Gambatese (2005). The chosen LCA approach (process or input-output) also has significant impact on the results, as demonstrated through the differing conclusions of Horvath and Hendrickson (1998) and Stripple (2001). Differing traffic levels and locations also account for incongruous results for this phase.

Perhaps the largest source of discrepancy in terms of energy consumption is the use of feedstock energy in the calculation of asphalt pavements. When included, feedstock energy accounts for roughly $75 \%$ of the total energy of the materials phase [26, 28]. This tips the energy consumption scale heavily in favor of concrete pavements. The issue of feedstock energy is discussed more in Section 3.3.

While the materials extraction and production phase is considered in each study, the use phase is omitted from nearly all of the pavement LCA literature. The use phase includes potentially influential components such as fuel consumption attributed to pavement roughness and structure, the urban heat island effect, radiative forcing, concrete carbonation, leachate, and tire wear. Häkkinen and Mäkelä (1996), Stripple (2001) and Treloar et al. (2004) are the only studies that attempt to include this phase in the analysis, yet even those analyses are considerably incomplete. The major drawback from these studies is the use of absolute values that reflect the total traffic rather than values that are isolated to the pavement's actual contribution. These values are helpful in understanding the impact of pavements relative to other, related impacts, but cannot be wholly attributed to the pavement life cycle. Differences due to pavement type and roughness are omitted, as is albedo and the urban heat island effect. Concrete carbonation is included in Häkkinen and Mäkelä (1996), mentioned qualitatively in Stripple (2001), but omitted in the rest of the studies. Undoubtedly, the inclusion of the use phase in their study is admittedly stymied by a dearth of data, thus limiting the thoroughness of the assessment. This phase of the life cycle represents the largest research gap in pavement LCA.

The pavement maintenance phase is a far more complicated and involved series of events than what is portrayed in the bulk of current LCAs. Although accurately forecasting future maintenance activities (including rehabilitation) continues to be a challenging task within the 
pavement engineering profession, the level of sophistication extends far beyond the current LCA framework. When included in LCAs, the maintenance phase is generally structured as a series of simple procedures that are repetitively carried out over the service life. In actual practice, maintenance is composed of different activities applied over uneven intervals, each involving a different level of complexity. The maintenance phase has the potential to be a significant contributor to the overall environmental impact, yet there has been little effort to characterize it more comprehensively or even determine the sensitivity of the results to alternative maintenance schedules. The Athena (2006) study provides a good example of the detail that a maintenance schedule can include, but even it admittedly ignores smaller and routine maintenance activities such as diamond grinding and crack sealing. Arguably, these less significant activities are justifiably ignored due to their limited or negligible impact on the results.

The impact of the construction phase is characterized by most studies exclusively through equipment use. This approach neglects the traffic delay arising from construction activities. Chan (2007) is the exception, and his study demonstrated that traffic delay is a potentially important aspect of the life cycle, especially for high traffic pavement sections. Häkkinen and Mäkelä (1996) also consider traffic delay, but only for the limited scope of maintenance activities. The results from Chan show that the energy consumption and $\mathrm{CO}_{2}$ emissions from traffic delay can exceed those of the entire materials production phase. Given the emphasis on materials production in previous LCAs, the inclusion of this single component has the ability to sway entire results and conclusions.

By arbitrarily selecting which phases and components of the life cycle to include in a given analysis, the utility of the results are drastically undermined. Table 14 at the end of this section shows a brief summary of each of the pavement LCAs reviewed in Section 2.1.1. Included in the table is list of the life cycle phases considered in the studies. None of the existing LCAs included all phases of the life cycle, let alone each applicable component within each of those phases. The omitted elements often contribute significantly to the overall life-cycle impact, thus would have potentially changed the conclusions from a given study. Unfortunately, there are often constraints (e.g., data availability) that inhibit including each element of the life cycle in an assessment. In these cases, it is recommended that the omitted elements be fully disclosed to the audience so that the shortcomings are readily apparent.

\subsubsection{Imbalanced information on bitumen and portland cement}

In their simplest form, pavements are combination of aggregates and an adhesive to hold those aggregates together. Portland cement and bitumen are the competing adhering agents, but the depth and sources of existing research on each of these adherents differs greatly. As a result, the quality and credibility of the environmental data are imbalanced between these two products, leading to differences in the accuracy and uncertainty of results derived based on these data.

Bitumen is a residual product in many petroleum refineries [45]. Its primary use is in asphalt pavements, although it is also used in roofing and other waterproofing applications. Environmental analyses for bitumen are generally associated with those of asphalt pavements, which has proven to be a relatively shallow research field to date. Consequently, the understanding of the environmental impact of bitumen production is limited. The few LCAs that investigate bitumen manufacturing are generally focused on impact allocation of products within the oil refining sector as a whole, of which bitumen is only a small part and are thus not tailored 
towards bitumen, but rather more to the refined products. For example, Wang et al. (2004) examines different ways to allocate energy to the various petroleum products, including mass, energy content, and cost-based allocation methods [46]. Although bitumen is included in the assessment, there is little discussion on the actual processes that are specific to bitumen manufacturing. Determining more accurate environmental profiles for bitumen depends largely on improved allocation methods for petroleum products - a research field which is very much still under development. A better understanding of the environmental impacts from each refining process, combined with improved allocation methods for extraction, transportation, and refining, will produce more accurate bitumen environmental profiles.

Whereas bitumen is primarily used in paving applications, cement enjoys a wide array of applications, only one of which is concrete pavements. There are a sizeable number of studies that have documented the environmental impact of cement (e.g., [47-50]). While a large number of studies does not necessarily guarantee accuracy, with more study comes continuous improvement in life-cycle environmental data. The factors used for cement are drawn from more studies, and are almost certainly more refined, than of those for bitumen. Given the importance of using accurate environmental data for materials production in estimating the environmental impacts of pavements, more data and studies in bitumen and asphalt production are needed to improve the robustness of the science. The imbalanced understanding between cement and bitumen is potentially significant source of error within pavement LCAs.

\subsubsection{Life-cycle inventory and impact assessment}

The body of work to date has evaluated pavements using a variety of environmental metrics. The common output between all of the reviewed pavement LCA studies is energy consumption. Six studies added an inventory of conventional air pollutants (e.g., $\left.\mathrm{SO}_{2}, \mathrm{NO}_{\mathrm{X}}, \mathrm{CO}, \mathrm{PM}_{10}\right)[12-13,17$, 19, 21, 23, 28], and another six added GHGs [12, 17, 19, 21, 23, 26, 28]. Four studies reported environmental impacts not associated with energy consumption or air emissions, including nitrogen releases into water [12, 19], hazardous waste generation [13], heavy metal releases [12, 17], and other environmental indicators.

Notably absent from the existing pavement LCA literature are thorough impact assessments. ISO 14040 defines impact assessment as an LCA phase that is "aimed at understanding and evaluating the magnitude and significance of the potential environmental impacts" (p. 2) [18]. This is generally accomplished by grouping pollutants and other environmental indicators into impact categories, which are normalized into a metric that provides an overall measure of the severity of an impact. The U.S. EPA identifies eleven commonly used impact categories: global warming; stratospheric ozone depletion; acidification; eutrophication; photochemical smog; terrestrial toxicity; aquatic toxicity; human health; resource depletion; land use; water use [51].

Many of the studies reviewed are arguably better classified as LCIs because they either partially or wholly exclude the LCIA step. Inventorying the environmental burdens provides valuable information, but may be inadequate for decision-making. Pollutants such as $\mathrm{SO}_{2}, \mathrm{NO}_{\mathrm{x}}$, and $\mathrm{CO}$ are commonly inventoried in the results, but their environmental impact is difficult to judge until they are categorized into more meaningful categories like photochemical smog formation or human toxicity. Some inventory results are close enough to impact categories themselves that a separate impact assessment is unnecessary. Energy consumption and $\mathrm{CO}_{2}$ 
emissions are common outputs from the inventory results, but require very little translation to understand their impact. Energy consumption is closely tied to energy security and fossil fuel consumption, both of which are important social and environmental issues. However, a breakdown into which fuels are being used (e.g., renewable resources, coal, petroleum, etc.) provides a better understanding of these impacts, as security and consumption issues are dependent upon the fuel being used. Moreover, alternative metrics for quantifying life-cycle energy use, such as emergy and exergy discussed in references [11] and [16], respectively, may provide even more insight by measuring the thermodynamic losses incurred across the pavement life cycle. The utility of these metrics is difficult to ascertain given the dearth of relevant research; further research which contrasts energy metrics (e.g., primary energy) with exergy and emergy results would provide useful insights into the potential benefits these alternative metrics as environmental indicators. $\mathrm{CO}_{2}$ emissions are a principal contributor to global warming, making a simple inventory of their emission levels a reasonable impact indicator. The inclusion of other GHGs (e.g., $\mathrm{CH}_{4}, \mathrm{~N}_{2} \mathrm{O}$ ) is recommended for completeness.

Each of the pavement LCAs reviewed in Section 2.1 include energy consumption in one form or another, so each is arguably at least a partial life-cycle assessment. Many also include either $\mathrm{CO}_{2}$ or the impact the category global warming. However, this is where the impact assessment generally ends for most pavement LCAs. Aside from the sporadic inclusion of waste, noise, water consumption, and natural resource depletion, results are generally presented in terms of inventoried pollutants rather than impacts. The step of characterizing these pollutants into impact categories such as human toxicity, eutrophication, and acidification would create more useful information and allow for better understanding of the environmental impact of these pollutants.

Even with the inclusion of a thorough impact assessment, there are outstanding issues that could be included within the environmental impact scope. For bitumen, the risks associated with the extraction of oil and spills during transportation are of concern, as are the potential damages to fragile ecosystems in oil-rich areas. Issues focused on cement production involve the quarrying of hillsides and the consequential disruption to the local ecosystem. These types of macro-environmental issues often fall outside of what is considered in a typical LCA, but potentially should be included depending on the values of the practitioners and their audiences.

\subsubsection{Utility of current pavement LCA literature}

The utility of any LCA hinges on its ability to provide insight into the environmental performance of a product. Most current pavement LCAs have adopted the comparison of two primary materials - asphalt and concrete - as the primary method of offering such insights. Some exceptions are many of the LCAs on secondary materials discussed in Section 2.1.2, and select others pavement LCAs [29, 52]. The utility of knowing the difference between these products is undeniable, but inconsistencies in the functional unit, system boundaries, data quality, and environmental indicators have created a situation where the results of different studies are largely incompatible and therefore cannot be aggregated to draw any broad conclusions from the literature. For instance, energy is considered by all studies in one form or another, but there is no agreement on which material consumes more over the pavement life cycle. The inclusion of feedstock energy sways the energy balance in favor of concrete, but the literature does not routinely consider the feedstock energy of bitumen in energy calculations (the issue of feedstock 
energy accounting is discussed further in Section 3.3). There are also many omitted components (many from the use phase of the pavement life cycle) that are not considered in the energy calculations. And even if energy is decidedly in favor of concrete, there are still unresolved issues such as GHG emissions, conventional air emissions, and water releases that are perhaps more pressing than energy consumption. Using the current pavement LCA literature as ammunition, compelling environmental arguments can be made for both sides of the asphalt versus concrete pavement debate.

The utility of current pavement LCAs is further hampered by the lack of accompanying uncertainty and sensitivity analyses. The environmental information used to evaluate each process come from different data sources and can vary widely based on region of study. For instance, the survey by Zapata and Gambatese (2005) found that the energy consumption for bitumen production varies by over an order of magnitude depending on the data source [25]. Most studies do not acknowledge this type of uncertainty in the results. The sensitivity of the results to data uncertainty or fluctuations in other variables is also typically omitted. Without these analyses, it is difficult to assess the accuracy of the results or the robustness of the conclusions, therefore undermining the utility of the literature.

There are also problems in translating conclusions across regional boundaries. Figure 7 maps the location of the reviewed pavement LCA studies and tools. Differing electricity mixes, production practices, pavement designs, available materials, maintenance practices, and other region-specific elements (e.g., the effect of local climate on pavement design and maintenance) will create different results depending on the location under study. Results from Canada, Finland, the United States, or any of the other locations may not be directly comparable to one another due to these discrepancies. Even state-to-state comparisons are subject to different factors that may significantly change the results. Some studies, such as Athena (2006), do provide regional comparisons and show small but non-negligible differences between different locations. More research is necessary to understand the impact of regional differences on the results and conclusions.

Lastly, the utility of the current body of pavement LCA research may suffer from a perceived shortage of peer-reviewed documents. Less than half of the reviewed studies come from peer-reviewed journals [13, 16, 23-25], with the rest in the form of a report prepared for academic, industry, or governmental organizations. While such reports may indeed be peerreviewed, the rigor or extent of the peer review is not always apparent from the documents themselves. Although the peer-review process is not a guarantee of quality, it does provide chance for other experts in the field to critique the validity and value of a study. Subjecting all published pavements LCAs to the rigors of peer-review will work to expand the overall utility of the field by flushing out inconsistencies in the data and methods used to evaluate pavements. For pavement LCAs published in other media (e.g., technical reports), an explicit designation as peer-reviewed would help communicate that an important quality check has been performed, and would thus improve confidence in the results of such LCAs.

The utility of pavement LCAs is hindered greatly by the aforementioned shortcomings. In order to draw broad, defensible conclusions regarding the environmental performance of pavements, these gaps need to be addressed. By standardizing the functional unit (to the extent feasible), expanding system boundaries, improving data quality, and examining are larger array 
of environmental indicators, equitable assessments and comparisons can be performed with greater reliability and, hence, provide more utility towards the task of improving the environmental performance of pavements.

Many of these topics are discussed in more depth in the following sections. Section 3 looks at some specific issues in greater detail, while Section 4 makes research recommendations based on the knowledge gaps uncovered in Sections 2 and 3. 


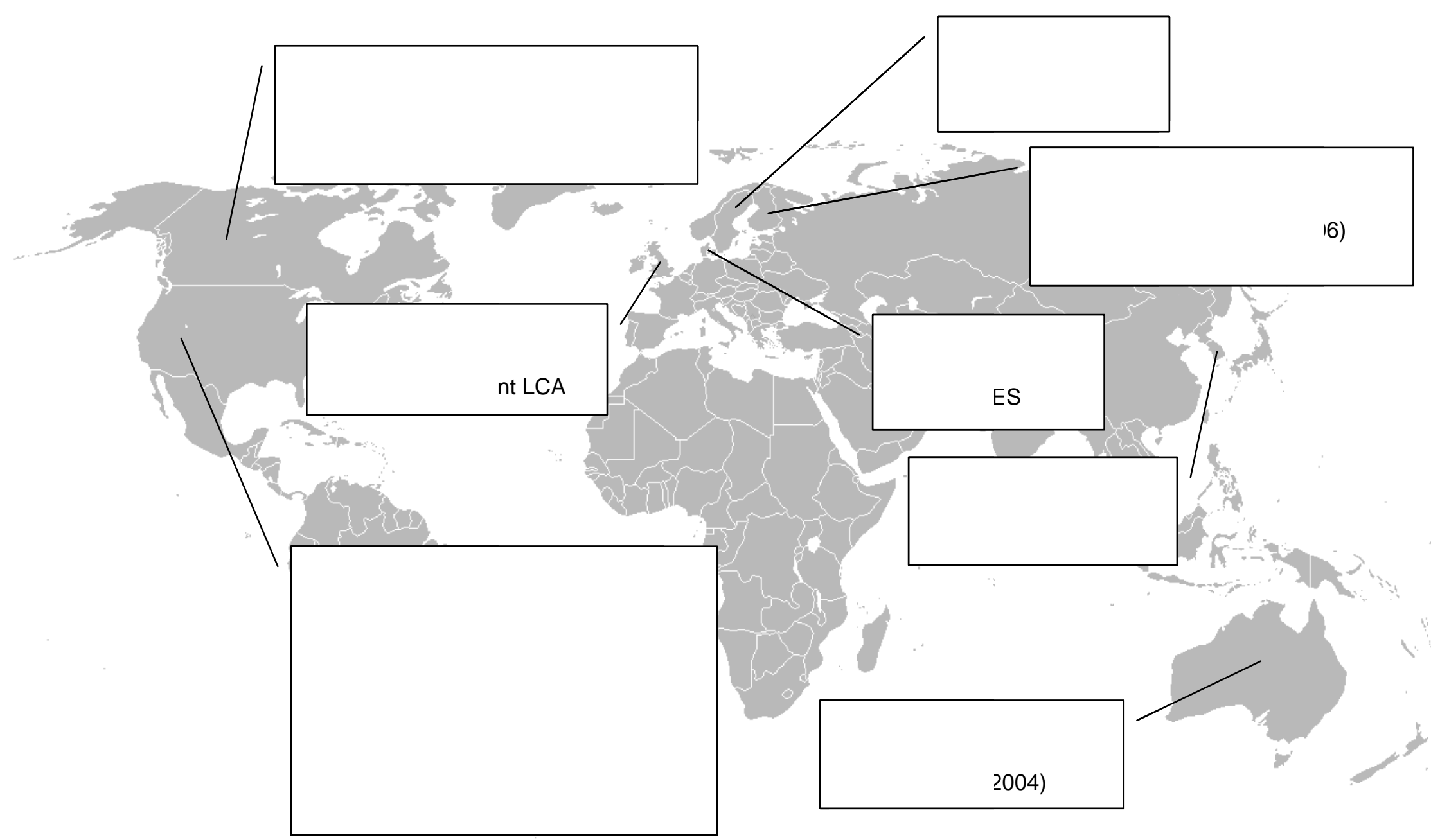

Figure 7. Location of reviewed pavement LCA studies and tools 
Table 14. Summary of existing pavement LCAs

\begin{tabular}{|c|c|c|c|c|c|c|c|}
\hline Author (year) & Ref. & Title & Method & Country & $\begin{array}{l}\text { Analysis } \\
\text { Period }\end{array}$ & Life-Cycle Phases & Outputs \\
\hline $\begin{array}{l}\text { Häkkinen and } \\
\text { Mäkelä (1996) }\end{array}$ & {$[12]$} & $\begin{array}{l}\text { Environmental Adaption of } \\
\text { Concrete: Environmental Impact of } \\
\text { Concrete and Asphalt Pavements }\end{array}$ & Process & Finland & 50 years & $\begin{array}{l}\text { 1. Materials } \\
\text { 2. Construction } \\
\text { 3. Use } \\
\text { 4. M\&R } \\
\text { 5. End-of-Life }\end{array}$ & $\begin{array}{l}\text { energy, air } \\
\text { emissions, raw } \\
\text { materials, noise }\end{array}$ \\
\hline $\begin{array}{l}\text { Horvath and } \\
\text { Hendrickson } \\
(1998)\end{array}$ & [13] & $\begin{array}{l}\text { Comparison of Environmental } \\
\text { Implications of Asphalt and Steel- } \\
\text { Reinforced Concrete Pavements }\end{array}$ & $\begin{array}{l}\text { Input- } \\
\text { Output }\end{array}$ & $\begin{array}{l}\text { United } \\
\text { States }\end{array}$ & -10 years & $\begin{array}{l}\text { 1. Materials } \\
\text { 2. Construction } \\
\text { 3. Use } \\
\text { 4. } \\
\text { 5. End-of-Life }\end{array}$ & $\begin{array}{l}\text { energy, air } \\
\text { emissions, raw } \\
\text { materials, water } \\
\text { releases, } \\
\text { hazardous waste, } \\
\text { water use }\end{array}$ \\
\hline $\begin{array}{l}\text { Roudebush } \\
\text { (1999) }\end{array}$ & {$[11]$} & $\begin{array}{l}\text { Environmental Value Engineering } \\
\text { Assessment of Concrete and } \\
\text { Asphalt Pavements }\end{array}$ & Process & $\begin{array}{l}\text { United } \\
\text { States }\end{array}$ & 50 years & $\begin{array}{l}\text { 1. Materials } \\
\text { 2. Construction } \\
\text { 3. Use } \\
\text { 4. M\&R } \\
\text { 5. End-of-Life }\end{array}$ & emergy \\
\hline $\begin{array}{l}\text { Berthiaume and } \\
\text { Bourchard } \\
(1999)\end{array}$ & {$[16]$} & $\begin{array}{l}\text { Exergy Analysis of the } \\
\text { Environmental Impact of Paving } \\
\text { Material Manufacture }\end{array}$ & Process & Canada & 40 years & $\begin{array}{l}\text { 1. Materials } \\
\text { 2. Eonstruction } \\
\text { 3. Use } \\
\text { 4. M\&R } \\
\text { 5. End-of-Life }\end{array}$ & exergy \\
\hline $\begin{array}{l}\text { Mroueh et al. } \\
(2000)\end{array}$ & {$[17]$} & $\begin{array}{l}\text { Life Cycle Assessment of Road } \\
\text { Construction }\end{array}$ & Process & Finland & 50 years & $\begin{array}{l}\text { 1. Materials } \\
\text { 2. Construction } \\
\text { 3. Use } \\
\text { 4. M\&R } \\
\text { 5. End-of-Life }\end{array}$ & $\begin{array}{l}\text { energy, air } \\
\text { emissions, raw } \\
\text { materials, leaching, } \\
\text { water use, noise }\end{array}$ \\
\hline Stripple (2001) & [19] & $\begin{array}{l}\text { Life Cycle Assessment of Road: A } \\
\text { Pilot Study for Inventory Analysis } \\
\text { (Second Revised Edition) }\end{array}$ & Process & Sweden & 40 years & $\begin{array}{l}\text { 1. Materials } \\
\text { 2. Construction } \\
\text { 3. Use } \\
\text { 4. M\&R } \\
\text { 5. End-of-Life }\end{array}$ & $\begin{array}{l}\text { energy, air } \\
\text { emissions, raw } \\
\text { materials }\end{array}$ \\
\hline $\begin{array}{l}\text { Nisbet et al. } \\
(2001)\end{array}$ & [21] & $\begin{array}{l}\text { Life Cycle Inventory of Portland } \\
\text { Cement Concrete and Asphalt } \\
\text { Concrete Pavements }\end{array}$ & Process & $\begin{array}{l}\text { United } \\
\text { States }\end{array}$ & 40 years & $\begin{array}{l}\text { 1. Materials } \\
\text { 2. Construction } \\
\text { 3. Use } \\
\text { 4. M\&R } \\
\text { 5. End-of-Life }\end{array}$ & $\begin{array}{l}\text { energy, air } \\
\text { emissions, raw } \\
\text { materials }\end{array}$ \\
\hline
\end{tabular}


Table 14. Summary of existing pavement LCAs (continued)

\begin{tabular}{|c|c|c|c|c|c|c|c|}
\hline Author (year) & Ref. & Title & Method & Country & $\begin{array}{l}\text { Analysis } \\
\text { Period }\end{array}$ & Life-Cycle Phases & Outputs \\
\hline $\begin{array}{l}\text { Park et al. } \\
(2003)\end{array}$ & [23] & $\begin{array}{l}\text { Quantitative Assessment of } \\
\text { Environmental Impacts on Life } \\
\text { Cycle of Highways }\end{array}$ & Hybrid & Korea & unspecified & $\begin{array}{l}\text { 1. Materials } \\
\text { 2. Construction } \\
\text { 3. Use } \\
\text { 4. M\&R } \\
\text { 5. End-of-Life }\end{array}$ & $\begin{array}{l}\text { energy, air } \\
\text { emissions }\end{array}$ \\
\hline $\begin{array}{l}\text { Treloar et al. } \\
(2004)\end{array}$ & [24] & $\begin{array}{l}\text { Hybrid Life-Cycle Inventory for Road } \\
\text { Construction and Use }\end{array}$ & Hybrid & Australia & $\begin{array}{l}20 \text { and } 40 \\
\text { years }\end{array}$ & $\begin{array}{l}\text { 1. Materials } \\
\text { 2. Construction } \\
\text { 3. Use } \\
\text { 4. M\&R } \\
\text { 5. End-of-Life }\end{array}$ & energy \\
\hline $\begin{array}{l}\text { Zapata and } \\
\text { Gambatese } \\
(2005)\end{array}$ & {$[25]$} & $\begin{array}{l}\text { Energy Consumption of Asphalt and } \\
\text { Reinforced Concrete Pavement } \\
\text { Materials }\end{array}$ & Process & $\begin{array}{l}\text { United } \\
\text { States }\end{array}$ & -10 years & $\begin{array}{l}\text { 1. Materials } \\
\text { 2. Construction } \\
\text { 3. Use } \\
\text { 4. A\& } \\
\text { 5. End-of-Life }\end{array}$ & energy \\
\hline Athena (2006) & {$[26]$} & $\begin{array}{l}\text { A Life Cycle Perspective on } \\
\text { Concrete and Asphalt Roadways: } \\
\text { Embodied Primary Energy and } \\
\text { Global Warming Potential }\end{array}$ & Process & Canada & 50 years & $\begin{array}{l}\text { 1. Materials } \\
\text { 2. Construction } \\
\text { 3. Use } \\
\text { 4. M\&R } \\
\text { 5. End-of-Life }\end{array}$ & $\begin{array}{l}\text { energy, global } \\
\text { warming potential }\end{array}$ \\
\hline Chan (2007) & [28] & $\begin{array}{l}\text { Economic and Environmental } \\
\text { Evaluations of Life Cycle Cost } \\
\text { Analysis Practice: A Case Study of } \\
\text { Michigan DOT Pavement Projects }\end{array}$ & Process & $\begin{array}{l}\text { United } \\
\text { States }\end{array}$ & unspecified & $\begin{array}{l}\text { 1. Materials } \\
\text { 2. Construction } \\
\text { 3. Use } \\
\text { 4. M\&R } \\
\text { 5. End-of-Life }\end{array}$ & $\begin{array}{l}\text { energy, air } \\
\text { emissions, raw } \\
\text { materials }\end{array}$ \\
\hline
\end{tabular}




\section{FILLING THE RESEARCH GAPS}

This section discusses some key issues omitted from the bulk of the existing pavement LCA literature. Included are investigations of the use phase (including rolling resistance, albedo, carbonation, lighting, leachate, and tire wear), asphalt fumes, the feedstock energy of bitumen, traffic delay, the maintenance phase, and the end-of-life phase. Each of these elements has the potential to be an important contributor to the overall environmental impact of pavements and therefore deserves more specific attention. The following sections outline the current state of knowledge of the individual topics mentioned above. The objective is to convey the quality and depth of research currently available that may be used to better characterize the pavement life cycle in future LCAs. Numbers and quantifications are given when available.

\subsection{Use Phase}

The use phase includes everything that happens while the pavement is in operation that can be directly attributed to a pavement's properties and characteristics. The components that are relevant from an LCA perspective are:

- rolling resistance;

- albedo;

- concrete carbonation;

- lighting demand;

- leachate;

- tire wear.

The use phase has the challenging pretext of being the most impactful yet the most uncertain of the life-cycle phases. Because pavements remain in service for decades and support millions of vehicles over their service life, use phase effects have the potential to be the dominant factor for a pavement LCA. This section reviews available research for each of the use phase components listed above.

\subsubsection{Rolling resistance}

Very small changes in the traffic's fuel consumption will have a very large effect on the overall environmental impact of a pavement. As defined in the scope (Section 1.2), the fuel consumption of a vehicle is allocated to the pavement life cycle only to the extent to which the pavement directly affects it. For instance, if the structure or condition of the pavement increases fuel consumption by one percent, then the marginal energy consumption, GHG emissions, and other environmental impacts associated with that one percent fuel consumption increase are allocated to the pavement. Because of the large numbers of vehicles that travel on a pavement section over its life, even a small change (such as the one percent mentioned above) would result in hundreds of thousands of gallons of marginal fuel consumption over a pavement's service life ${ }^{1}$, depending on the traffic level.

\footnotetext{
${ }^{1}$ Assuming 25 mpg average fuel economy, 40,000 ADT, 40 year pavement life, and 1\% fuel economy decrease: marginal fuel consumption $=\left(\frac{1-\frac{1}{1+0.01}}{25 \mathrm{mpg}}\right) \times 40,000 \frac{\mathrm{veh}}{d} \times 365 \frac{d}{y} \times 40 y=230,000$ gallons
} 
Rolling resistance is the mechanism by which pavements affect the fuel consumption of vehicles. The following variables have been found to be statistically significant in determining a pavement's rolling resistance [53]:

- pavement structure;

- vehicle mass;

- pavement temperature and/or temperature gradients;

- road roughness;

- road grade; and

- vehicle speed.

Note that these variables are relevant to all types of pavement; however, the extent to which each variable affects marginal fuel consumption in practice depends upon the pavement type and traffic characteristics. Of these rolling resistance variables, pavement structure and roughness are the two that are directly related to the pavement life cycle. Judicious pavement engineering, management, and policy making can positively influence these variables. Unfortunately, the literature on this subject is generally inconclusive; because the effect of rolling resistance force is small compared to other resistive forces (e.g., drag), it is difficult to isolate it from other disturbances [54]. What information does exist provides some direction and preliminary quantifications of the pavement's effect on fuel consumption.

The impact of rolling resistance is highly dependent upon traffic levels and vehicle distribution; high volume roads with heavy truck traffic will be affected far more than low volume roads carrying very few trucks. For this reason, the contribution of rolling resistance to the overall environmental impact will vary widely from pavement to pavement based on individual traffic conditions. This relates the problem of non-standard functional units discussed in Section 2.3.1, where knowledge of the location and traffic levels will affect the life-cycle impact of a pavement.

\subsubsection{Pavement structure}

The effect of the pavement structure on fuel consumption revolves around the viscoelastic property of asphalt [55]. The argument is based on the premise that flexible pavements are deflected as vehicles pass overhead, thus absorbing energy that would otherwise be used for accelerating the vehicle [56]. It has been suggested that the rigidity of concrete pavements prevents this from occurring. Figure 2 illustrates the proposed difference between asphalt and concrete pavements.
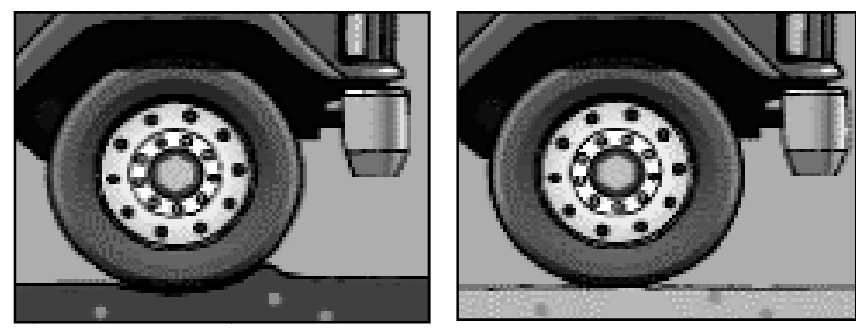

Figure 8. Illustration of asphalt (left) and concrete pavement rolling resistance [57] 
The study by Zaniewski (1989), which was commissioned by the Portland Cement Association, tested both passenger and heavy vehicles on asphalt and concrete pavement structures [56]. The results from the study did not find an appreciable difference between the two pavement types for passenger cars. However, heavy vehicles experienced up to a $20 \%$ drop in fuel efficiency on asphalt when compared to concrete. No statistical analysis was performed in the study, so it is unclear as to the statistical significance of the results. However, the conclusions from this study have been a launching point for subsequent studies on the effect pavement structure on rolling resistance, creating the ad-hoc null hypothesis that (1) concrete pavements are beneficial to fuel economy, and (2) heavy vehicles are the only types affected.

The National Research Council of Canada (NRC) Centre for Surface Transportation Technology and the Canadian Portland Cement Association conducted a multi-phase study to evaluate the effect of pavement surface type on fuel consumption. The second phase of the study found that for a fully-loaded tractor semi-trailer, asphalt pavements have a $6 \%, 8 \%$ and $11 \%$ higher fuel consumption than concrete pavements at speeds of 60, 75, and 100 kilometers per hour, respectively, on one of the test sections [58]. Similar trends for other test sections or load conditions were not confirmed due to unexplained inconsistencies in the data.

A separate analysis on the same dataset was performed in order to create a more robust statistical model [53]. This rework found that asphalt pavements have a $4.1 \%$ to $4.9 \%$ higher fuel consumption at 100 kilometers per hour, and 5.4\% to $6.9 \%$ higher at 60 kilometers per hour. Similarly, composite pavements (a pavement structure consisting of asphalt over concrete) also have higher fuel consumptions, with rates of $2.7 \%$ to $3.2 \%$ higher at 100 kilometers per hours, and $3.6 \%$ to $4.6 \%$ higher at 60 kilometers per hour. The results were found to be statistically significant. The difference between asphalt and composite pavements was not statistically significant at the $95 \%$ confidence interval.

Reviews of the previous studies and results called for a more focused third phase of the study performed by the NRC and Cement Association of Canada [59]. This third phase was viewed as complementary to the previous phases. Concrete, asphalt, and composite pavements were studied while accounting for seasonal and day/night variations. The report found that concrete pavements always had lower fuel consumption than asphalt pavements, although some of the results were not statistically significant. The actual fuel consumption savings of concrete over asphalt ranged from $0.7 \%$ to $3.9 \%$, depending on the state of the truck (empty or full) and the season. The study found similar results for passenger cars, with a range of $0.3 \%$ to $2.9 \%$. Interestingly, the results between composite and concrete pavements were mixed, with each of the structures leading to better economy under different seasonal and day/night conditions. An additional phase of the study determined that fuel consumption differences between pavement types are only statistically significant when the international roughness index (IRI) is lower than $2.2 \mathrm{~m} / \mathrm{km}$ (139 in/mi) [53]. Above this level, fuel economy loss due to roughness begins to dominate, thus obfuscating the contributions of pavement structure on rolling resistance.

In a 2004 European Asphalt Pavement Alliance and Eurobitume summary of fuel consumption literature, the authors cite a theoretical approach to determining fuel consumption losses on flexible pavements [55]. According to model calculations, the fuel economy loss due to the viscoelastic character of asphalt is capped at $0.88 \%$; the average loss would be $0.05 \%$ assuming normal operating conditions. The report also cites a French study that confirms these 
findings. Neither the model results nor the French confirmation could be obtained for assessment in this review.

A notable shortcoming of the existing literature on this subject is the focus on asphalt versus concrete rather than the pavement structure itself. The influence of pavement structure on rolling resistance deals with the entire structure, not just the material type of the surface layer. The thicknesses and properties (e.g., stiffnesses) of each layer comprising the structure (i.e., surface, base, subbase, subgrade, etc.) will affect the deformation of a pavement under a given load [60]. Higher deformation result in higher rolling resistance since the energy that would normally be used to accelerate the vehicle is instead used to deform the pavement. The deformation of a structure can change significantly depending on its specific characteristics, thus changing the accompanying rolling resistance.

Overall, existing information has linked fuel consumption to pavement structure, but the exact relationship is unknown. The few studies that have focused on this effect have found empirical evidence that concrete pavements provide better fuel consumption than asphalt pavements. However, it is important to note that these studies only examined a fraction of the pavement structures that exist. Given the relatively small number of studies completed, combined with the relatively limited scope of those studies, it is still premature to draw sweeping general conclusions about the fuel efficiency benefits of certain pavements in all applications. While the literature indeed suggests that concrete pavements offer fuel economy advantages over asphalt pavements, the magnitude of that advantage, as well as any caveats associated with climate, structural properties, and other variables associated with the pavement, have not been exhaustively examined. Future research should be focused on flushing out the remaining unknowns in the relationship and working towards a comprehensive mechanistic model for the effect that a particular pavement has on fuel consumption.

The lack of definitive numerical relationships between pavement structure and fuel economy has no doubt contributed to the absence of pavement structure considerations in the use-phase analyses of existing pavement LCAs. However, given its potential influence on the results, it future inclusion may significantly alter conclusions. The numerical relationship between pavement structure and fuel consumption needs to be refined before it is included in any analysis, but discussion of its potential impact should be included until such a relationship is available.

\subsubsection{Pavement roughness}

Pavement roughness has been linked to fuel consumption through a handful of studies. Understanding the relationship requires at least a topical knowledge of the science behind pavement roughness characterization. Pavement roughness is a product of the surface texture, which has been categorized into four domains based on their wavelengths (in descending order): unevenness, megatexture, macrotexture, and microtexture. These four domains are illustrated in Figure 9. The larger domains are generally agreed to be the more significant factor in fuel consumption. Conveniently, the smaller domains (microtexture and macrotexture) are responsible for skid resistance [61], thus dispelling a prevailing myth that fuel-friendly and safe pavements are mutually exclusive objectives. 


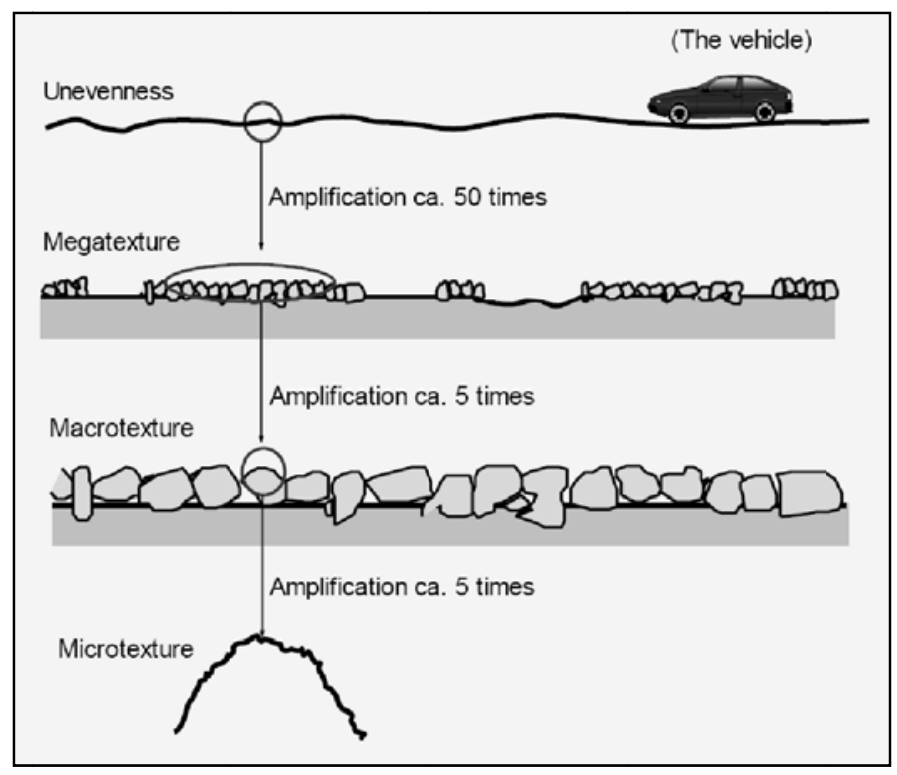

Figure 9. Texture types on pavements [62]

A collection of papers published by the American Society for Testing and Materials (ASTM) in 1990 examines the issue of pavement roughness and fuel consumption. Although many factors have changed over the past two decades (e.g., suspension systems, tire pressures, vehicle technology), these studies still provide a credible foundation regarding the impact of pavement roughness on fuel consumption. Among these studies is one by Descornet (1990), which calculates a $47 \%$ shift in rolling resistance from the "worst" to the "best" pavement surfaces, as measured by rolling resistance coefficients of 0.013 and 0.021 , respectively. No details relating rolling resistance to IRI are provided, although relationships developed by the World Bank [63] could be used to draw such a relationship. The stated shift in rolling resistance translates to a $9 \%$ increase in fuel consumption [64]. Based on the collected data, the study asserts that megatexture is the main factor affecting fuel consumption.

Laganier and Lucas (1990) (another from the ASTM collection) conclude that the macrotexture (measured by a minitexture meter) and unevenness (measured by a longitudinal profile analyzer) of the pavement are the main factors in fuel consumption and are equally important [65]. Over ranges expected to be found on the French highway system, both macrotexture and unevenness accounted for a $6 \%$ increase in fuel consumption for a mediumsized, $800 \mathrm{~kg}$ passenger car. Pavement roughness is conveyed using qualitative rating systems of "poor" to "excellent" for evenness and "fine" to "exceptionally coarse" for macrotexture. Quantitative relationships to IRI are not provided.

Sandberg (1990) (another from the ASTM collection) comes to a similar conclusion as Laganier and Lucas (1990), stating that fuel consumption can increase by as much as $12 \%$ for the tested range [66]. The tested range was composed of 20 sections, each of which was measured for fuel consumption and pavement roughness properties. Unevenness, megatexutre, macrotexture, and microtexture were quantitatively and independently reported, although not in a single aggregated score such as IRI. Sandberg states that macrotexture and unevenness are the primary culprits leading to decreased fuel consumption from pavement roughness, although is 
admitted that the effects of these two elements are difficult to isolate and are correlated with one another. This study also proposes that there is likely a logarithmic relationship between fuel consumption and pavement roughness, though a specific relationship is not put forward.

A study by du Plessis et al. (1990) (the last of the ASTM collection) examines both passenger cars and heavy vehicles [67]. For passenger cars, fuel consumption increases between $2.5 \%$ and $5.1 \%$ after a jump in roughness from 15 QI to 80 QI, where QI is the quarter-car index. The range of the increase depends primarily upon the temperature of tires, with higher temperatures causing higher sensitivity to roughness changes. An important note is that a QI of 80 is equivalent to an IRI of $6.2 \mathrm{~m} / \mathrm{km}$ (390 in $/ \mathrm{mi}$ ) using the relationship developed by the World Bank [63]. This is over twice the target threshold of $2.7 \mathrm{~m} / \mathrm{km}(171 \mathrm{in} / \mathrm{mi})$ specified in the 1998 FHWA National Strategic Plan [68]. The initial QI of 15 is equivalent to an IRI of $1.2 \mathrm{~m} / \mathrm{km}(75$ $\mathrm{in} / \mathrm{mi}$ ), which is more or less considered a smooth pavement. For trucks, a fuel consumption increase of $6.1 \%$ to $6.8 \%$ was found over a shift from roughness of 20 QI (IRI $\approx 1.5 \mathrm{~m} / \mathrm{km}$ (97 in/mi)) to 80 QI. The results were mildly sensitive to the inflation pressure of the tires.

In a more recent and oft-cited study, the FHWA's Westrack project in Nevada measured truck fuel consumption before and after rehabilitation. The decrease in IRI from $2.4+\mathrm{m} / \mathrm{km}$ $(150+\mathrm{in} / \mathrm{mi})$ to $1.2 \mathrm{~m} / \mathrm{km}(75 \mathrm{in} / \mathrm{mi})$ increased fuel economy by $4.5 \%$ [69-70]. The test was run by applying the "coastdown" method with a $160 \mathrm{kN}$ semi-trailer. It has been posited that the fuel consumption savings from rehabilitation would have been greater if the tests were isolated from environmental effects such as wind, speed, and temperature [71]. Although well known, this portion of the Westrack project relied on a limited data collection effort.

The National Center for Asphalt Technology (NCAT) reported similar results on their test track in Alabama. For a change in IRI from $1.08 \mathrm{~m} / \mathrm{km}(68 \mathrm{in} / \mathrm{mi})$ to $1.18 \mathrm{~m} / \mathrm{km}(75 \mathrm{in} / \mathrm{mi})$, fuel consumption increased by $2 \%$ [70]. This change, however, did not account for the vehicle age [72]; if this is isolated from the calculation, fuel economy would likely be less sensitive to changes in roughness than reported values.

A limited study conducted by the University of North Florida measured IRI and fuel consumption rates on five Florida highways. The preliminary report calculated a $1.3 \%$ rise in fuel consumption for a 10\% rise in IRI [72-73]. Of important note are the limitations of the study, including the small sample size and unmitigated externalities (e.g., wind) affecting fuel consumption. Moreover, measurements were taken only once at each location, therefore representing only a single snapshot of the pavement characteristics rather than an average over time. The author notes that the study is still "preliminary" (although a final report does not seem to exist) and that the results are intended to demonstrate only that a correlation exists between roughness and fuel consumption rather than to determine the exact numerical relationship.

In summary, the literature is in agreement that fuel consumption is positively correlated with pavement roughness, but a definitive numerical relationship has not been determined. Uncontrollable, external factors make it difficult to isolate the effect that pavement roughness alone has on fuel consumption. From the basic vehicle force balance relationship, rolling resistance is only one of four major forces resisting a vehicle; the other three are inertial forces, gravitational forces, and air resistance [63]. Moreover, roughness only accounts for a fraction of the rolling resistance, which is also influenced by tire properties (e.g., pressure, tread), pavement structure, and other characteristics that use available energy to deform either the pavement or the 
tire rather than move the vehicle. Because pavement roughness is only a small part of the overall vehicle force balance, isolating it impact and quantifying its effect on fuel consumption is difficult.

In the pavement life cycle, pavement roughness becomes an issue when deciding on a maintenance schedule. An aggressive maintenance schedule may use more materials, but may also provide a smoother and more fuel efficient surface. Differences between surface material types (such as asphalt versus concrete) may also play as factor, although there must be a sufficient reason to believe that a given surface is rougher than another. As with pavement structure, roughness is not incorporated into existing pavement LCAs due to the lack of information on subject. The effect of roughness on the results may be significant and should at least be discussed qualitatively if quantitative estimates are unattainable.

\subsubsection{Albedo}

As shortwave radiation from the sun reaches a pavement, it has the potential to either be absorbed by the pavement or to be reflected as longwave radiation back into the atmosphere (see Figure 10). Albedo (also known as solar reflectance) is a measure of how much radiation is reflected off of a surface, ranging from 0 (complete absorption) to 1 (complete reflectance). From a climate change perspective, pavements with higher albedo help mitigate the greenhouse effect by reducing the amount of solar radiation absorbed by the Earth's surface and by reducing the urban heat island effect (which can drive increased electricity use in affected urban areas).

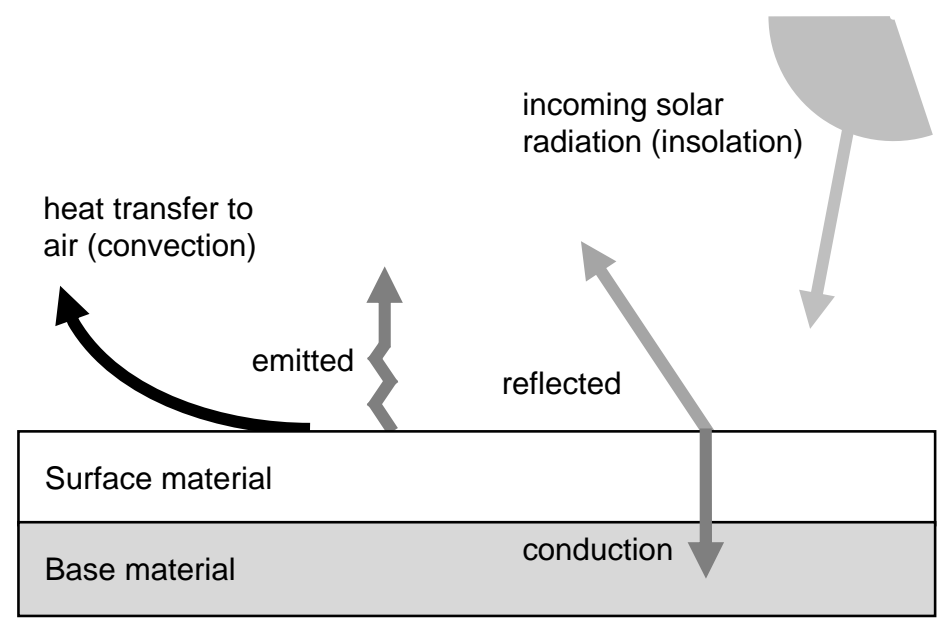

Figure 10. Energy balance at the pavement surface [74]

The literature has shown that both pavement age and type have an influence on the albedo. The expected albedo range for a typical asphalt pavement is 0.05 to 0.20 ; the range for a typical concrete pavement is 0.25 to 0.46 [75-80]. Aged asphalt pavements tend to have higher albedo, while the opposite is true for concrete pavements [75]. High albedo pavements with albedos ranging as high as 0.80 can be achieved with a judicious choice of lighter cement, lighter aggregate, and lighter sand [74]. Choices in additives also affect albedo, as demonstrated by 
higher albedos through the use of slag and lower albedos through the use fly ash in concrete pavements [81].

\subsubsection{Urban heat island}

In dense urban areas, the incoming radiation absorbed by pavements and building rooftops increases the ambient temperature, resulting in the urban heat island effect. The elevated temperature increases the energy demand for urban cooling devices and accelerates the formation of photochemical smog [82]. While these two reactions to albedo in the local environment are commonly agreed upon, quantifying their effect has proven to be a more elusive task. Nonetheless, increasing the albedo in cities by utilizing "cool surfaces" is a worthwhile undertaking; one study estimates that their use on a national scale could reduce the urban heat island cooling energy demand by $20 \%$, or by 40 TWh per year [82].

In large cities, it has been measured that $1^{\circ} \mathrm{C}$ rise in temperature gives way to a $2 \%$ to $4 \%$ rise in electricity demand when temperatures rise above the $15-20^{\circ} \mathrm{C}$ threshold [83]. However, understanding which change in albedo accounts for a $1^{\circ} \mathrm{C}$ swing in urban temperature is the key - and more difficult - question. Some rough estimates have been made on a regional scale, but little information exists pertaining to changes in albedo for individual units of pavement. To gain a perspective on the issue, Rosenfeld et al. (1998) concluded that increasing the albedo of pavements in the Los Angeles basin from 0.05 to 0.30 would result in $0.6^{\circ} \mathrm{C}$ drop in temperature [84]. A similar change was also reported by Pomerantz et al. (2000) [78].

The urban heat island is also affected by the emissivity of a pavement. Emissivity refers to the ability of a material to emit absorbed radiation as heat. Whereas albedo is the most important factor in determining the maximum temperature that a pavement reaches (daytime), the emissivity controls the minimum temperature reached (nighttime) [85]. The emissivity and albedo of a pavement are combined together in the Solar Reflectance Index (SRI), which is commonly used to evaluate the total urban heat island potential of a material. As with albedo, the SRI of new asphalt pavements is considerably worse than new concrete pavements, but the disparity significantly shrinks as both pavements age (i.e., asphalt pavements improve their SRI while concrete pavements degrade their SRI) [86].

The urban heat island effect is not considered in any of the existing pavement LCAs. Although it is unclear as to the importance of this issue, pavements in urban areas with high summer temperatures may benefit significantly increasing albedo. More research needs to be done to estimate marginal impacts from increasing a single pavement's albedo so that any climate change mitigation benefits can be attributed properly to that pavement. 


\subsubsection{Radiative forcing}

Albedo directly contributes to global cooling by adjusting the radiative forcing of the earth's surface. As a surface covering, pavements can reflect a portion of the incoming solar radiation back into space, thus adjusting the global energy balance. Akbari et al. (2008) estimate that for every square meter, $2.55 \mathrm{~kg}$ of emitted $\mathrm{CO}_{2}$ is offset for every 0.01 increase in albedo due to increased radiative forcing [87]. The same paper also cites an alternative method that yields a higher offset of $4.90 \mathrm{~kg}$ of emitted $\mathrm{CO}_{2}$ per square meter. The $\mathrm{CO}_{2}$ emissions offset from radiative forcing offers only a one-time benefit and should be averaged over the entire life of the pavement. Equation 1 gives the means to calculate that benefit.

$$
\begin{aligned}
& \Delta m_{\mathrm{CO}_{2}}=100 \times C \times A \times \Delta \alpha \\
& \text { Where } \quad \begin{aligned}
\Delta m_{C O_{2}} & =\text { mass equivalents of } \mathrm{CO}_{2} \text { mitigated }(\mathrm{kg}) \\
C & =\mathrm{CO}_{2} \text { offset constant }\left(\mathrm{kg} \mathrm{CO}_{2} / \mathrm{m}^{2}\right) \\
A & =\text { area of pavement }(\mathrm{W}) \\
\Delta \alpha & =\text { change in albedo }
\end{aligned}
\end{aligned}
$$

\section{Equation 1}

Work has been done to estimate the global impact of a shift towards products with higher albedo, notably roofs and pavements. Researchers at Lawrence Berkeley National Laboratory (LBNL) estimate that a $\mathrm{CO}_{2}$ equivalent savings of $22 \mathrm{Gt}$ is possible if all urban areas made considerable efforts to increase the albedo of their surfaces. This indicates that widespread use of higher albedo pavement materials, such as concrete or lighter asphalt pavements (e.g., through brighter aggregates), can be a potentially useful tool in mitigating climate change.

As with the urban heat island effect, radiative forcing from pavement albedo is not considered in existing pavement LCAs. However, unlike the urban heat island effect, radiative forcing effects are applicable to all pavements (i.e., not just those in urban areas) and so their omission can be considered a universal deficiency across all pavement LCA studies. Although a numerical relationship exists that could be used to incorporate radiative forcing into pavement LCAs (Equation 1), it should be noted that the research field is still nascent and that there is a potentially high level of uncertainty regarding the stated values.

\subsubsection{Concrete carbonation}

Over time, much of the $\mathrm{CO}_{2}$ that was originally liberated from limestone during cement kiln processes will rebind itself to the cement in the pavement through the carbonation process. The calcium cycle and its basic chemistry are shown in Figure 11. The first process (1) involves the calcination of limestone $\left(\mathrm{CaCO}_{3}\right.$, also referred to as calcite) to produce calcium oxide $(\mathrm{CaO})$, which requires energy and produces $\mathrm{CO}_{2}$. The second step (2) is the hydration of $\mathrm{CaO}$ to produce calcium hydroxide $\left(\mathrm{Ca}(\mathrm{OH})_{2}\right)$ - a binding agent in concrete. Completing the cycle is the eventual sequestering of the released $\mathrm{CO}_{2}$ in the first process to produce the initial product $-\mathrm{CaCO}_{3}$. This final process (3) - called carbonation - is discussed here as it relates to the pavement life cycle. 


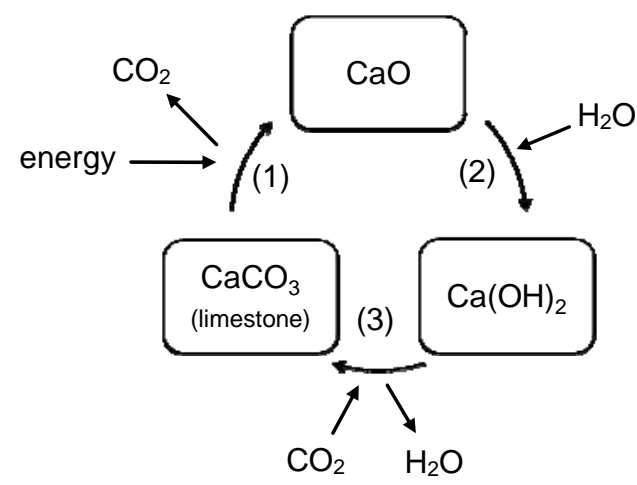

(1) $\mathrm{CaCO}_{3}+$ energy $\rightarrow \mathrm{CaO}+\mathrm{CO}_{2}$

(2) $\mathrm{CaO}+\mathrm{H}_{2} \mathrm{O} \rightarrow \mathrm{Ca}(\mathrm{OH})_{2}$

(3) $\mathrm{Ca}(\mathrm{OH})_{2}+\mathrm{CO}_{2} \rightarrow \mathrm{CaCO}_{3}+\mathrm{H}_{2} \mathrm{O}$

Figure 11. Concrete carbonation cycle

The rate at which $\mathrm{Ca}(\mathrm{OH})_{2}$ sequesters atmospheric $\mathrm{CO}_{2}$ is difficult to determine.

Depending on the chemical composition of the concrete, its structural dimensions, and the ambient environment, the carbonation process can take from years to millennia to complete [88]. Although it is a simplistic assumption, it has been suggested that carbonation of concrete can be modeled using a simplification of Fick's second law of diffusion [89]:

$$
\begin{aligned}
& d_{C}=k \sqrt{t} \\
& \text { Where } \quad \begin{array}{l}
d_{C}=\text { depth of carbonation }(\mathrm{mm}) \\
k=\text { rate factor }\left(\mathrm{mm} / \mathrm{y}^{1 / 2}\right) \\
t=\text { time }(\mathrm{y})
\end{array}
\end{aligned}
$$

\section{Equation 2}

A notable feature of Equation 2 is that because the depth of carbonation is proportional to the square root of time, the carbonation process is considerably swifter during the first few years of exposure.

The rate factor, $k$, is the subject of much of the current carbonation research. The rate factor varies based on the strength of the concrete (which is related to the porosity of the paste), the exposure to the environment, the cement content, the water-to-cement ratio, cement alkali content, and the relative temperature and humidity of the surrounding environment [89-90]. A study by the Portland Cement Association in the United States found carbonation rate factors of $8.5,6.7$, and $4.9 \mathrm{~mm} / \mathrm{y}^{1 / 2}$ for concrete compressive strengths of 21,28 , and $35 \mathrm{MPa}$, respectively [90]. The concrete was not submerged and was exposed directly to the atmosphere (i.e., not buried).

According to Lagerblad (2006), the rate factor ranges from $0.5 \mathrm{~mm} / \mathrm{y}^{1 / 2}$ to $15 \mathrm{~mm} / \mathrm{y}^{1 / 2}$, depending on the strength and exposure type [89]. For concrete with a strength of $35 \mathrm{MPa}$ that is fully exposed the environment, Lagerblad estimates a carbonation rate of $1.0 \mathrm{~mm} / \mathrm{y}^{1 / 2}$. If instead the concrete is buried or not directly exposed to the environment, the carbonation rate drops to $0.75 \mathrm{~mm} / \mathrm{y}^{1 / 2}$. Of note is that the estimate is based on Nordic climates. Regions with higher temperatures and relative humidity between $60 \%$ and $80 \%$ will experience higher carbonation rates [89]. Another source cites an optimal relative humidity of $50 \%$ to $70 \%$ [91]. A study by 
Pade and Guimaraes (2007) builds upon the Lagerblad study by proposing correction factors to the Lagerblad values based on weight percentage additions of limestone, fly ash, silica flume, and ground granulated blast furnace slag to the cement [92]. These additives increase the rate factor by $5 \%$ to $30 \%$ depending on the additive type and its mass percentage. However, when additives are used as substitutes for cement (e.g., crushed limestone, fly ash), the rate at which $\mathrm{CO}_{2}$ is sequestered may not improve even though the carbonation effect has permeated farther into the pavement. For instance, although the presence of slag increases the progression of carbonation through the structure, less cement may actually be carbonated because a portion of the cement has been displaced by slag, which itself does not sequester $\mathrm{CO}_{2}$.

The depth of carbonation, $d_{C}$, refers the depth at which the calcium in the concrete can potentially bind to the atmospheric $\mathrm{CO}_{2}$. However, not all of the calcium in the concrete is expected to bind to $\mathrm{CO}_{2}$ molecules; the binding efficiency is suggested to be roughly $75 \%$ [93]. The mass of $\mathrm{CO}_{2}$ that sequestered is given by Equation 3 .

$$
m_{\mathrm{CO}_{2}}=d_{C} \times A \times \rho_{\text {concrete }} \times m_{\text {cement/concrete }} \times m_{\mathrm{CaO} / \text { cement }} \times \frac{M_{\mathrm{CO}_{2}}}{M_{\mathrm{CaO}}} \times \varepsilon
$$

Equation 3

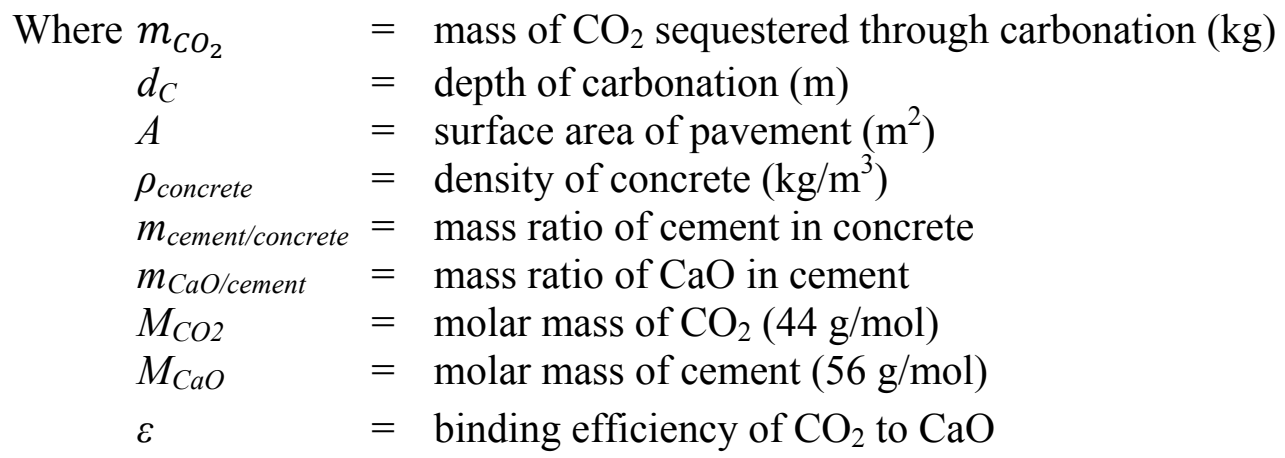

The maximum carbonation is thought to be capped at $75 \%$ of the $\mathrm{CaO}$ in the cement [94]. Crushing and exposing concrete to the open air at the end of its service life dramatically improves the speed of carbonation [92], making carbonation of $75 \%$ at least theoretically achievable. However, there is research that suggests that in cement pastes, carbon is absorbed in more forms than just $\mathrm{CaCO}_{3}$ [95-96]. This could potentially increase the amount of $\mathrm{CO}_{2}$ sequestered over the life of a concrete pavement. Moreover, in theory, concrete could sequester more $\mathrm{CO}_{2}$ than is released during the initial calcination process [95], thereby becoming a potential $\mathrm{CO}_{2}$ sink in terms of cement stoichiometry (there will still be net positive $\mathrm{CO}_{2}$ emissions due to fuel combustion during calcination and other upstream process). This is still a tenuous assertion and considerably more peer-reviewed research is necessary to identify those species and their rate of carbon sequestration.

Carbonation is included quantitatively in Häkkinen and Mäkelä (1996), whose results show a marginal but not insignificant contribution over the life cycle. Stripple (2001) also discusses carbonation, but ultimately decides not to include it in the $\mathrm{CO}_{2}$ calculations on the claim that only a small amount will be sequestered during the 40 -year analysis period. The rest of the existing pavement LCAs do not consider carbonation. Our understanding of carbonation is 
still improving, but the research is such that it can be included quantitatively in a pavement LCA, albeit with an accompanying uncertainty analysis. The impact of carbonation could be significant, especially if the concrete is crushed at the end of its life.

\subsubsection{Pavement lighting}

Electrical lighting is used to illuminate many roadways. This process is relevant in the pavement life cycle only if the pavement itself affects the energy demand needed to adequately illuminate the roadway. The limited published research available on this topic indicates that pavements can indeed influence lighting requirements.

In the same vein as the albedo discussion in Section 3.1.2, the efficiency of light reflectance differs from pavement to pavement. The material type, age, aggregate choice, and other factors influence the reflectivity, and hence, the lighting power needed for proper illumination. Visible reflectance, however, differs from solar reflectance (albedo) in that only the light in the visible spectrum (wavelengths 400 to $700 \mathrm{~nm}$ ) are of importance [97], thus splitting the discussion into two distinct research areas.

Roadways have long been classified by their ability to reflect visible light. A widely adopted classification scheme is based on the specular and diffuse reflectivity of a pavement. Using these criteria, most pavements have been broadly grouped into four classifications: R1, R2, R3, and R4. More recent research has modified this system to reflect changes in pavement materials, but the underlying principals remain the same. A handful of transportation authorities in the United States have adopted guidelines based on the R1-R4 classification scheme that govern the amount needed to illuminate roadways and parking lots. Given the pavement material and the functional classification of the roadway (arterial, freeway, collector, etc.), AASHTO and other authorities have produced recommendations for lighting requirements [98-99]. Table 15 shows a description of the classifications, as well as a sample of the illumination demand for arterial and freeway facilities. Illumination demand refers the amount of lighting necessary to provide adequate lighting for a stretch of roadway. Demand is given in units of lux, which equivalent to lumens per square meter.

Table 15. Pavement class descriptions and illumination demands

\begin{tabular}{|c|c|c|c|}
\hline \multirow{2}{*}{ Class } & \multirow{2}{*}{ Description [99] } & \multicolumn{2}{|c|}{ Illumination Demand (lux) } \\
\hline & & Arterial [98] & Freeway [100] \\
\hline & - Portland Cement concrete road surface & & \\
\hline R1 & $\begin{array}{l}\text { - Asphalt road surface with minimum of } 15 \% \text { of the } \\
\text { aggregate compose of artificial brightener aggregates }\end{array}$ & 12 & 6 \\
\hline R2 & $\begin{array}{l}\text { - Asphalt road surface with an aggregate composed of a } \\
\text { minimum } 60 \% \text { gravel (diameter }>10 \mathrm{~mm} \text { ) } \\
\text { - Asphalt road surface with } 10-60 \% \text { artificial brightener in } \\
\text { aggregate mix }\end{array}$ & 17 & 9 \\
\hline & - Asphalt road surface with dark aggregates & & \\
\hline R3 & $\begin{array}{l}\text { - Asphalt road surface with rough texture after some } \\
\text { month of use }\end{array}$ & 17 & 9 \\
\hline R4 & - Asphalt road surface with very smooth texture & 15 & 8 \\
\hline
\end{tabular}

Typically, concrete pavements are classified as R1 while asphalt pavements are classified as either R2 or R3. Using this assumption, the AASHTO standards recommend that asphalt 
pavements need roughly $33 \%$ to $50 \%$ more light power to achieve sufficient illumination on a given roadway. The Minnesota and Washington, D.C. DOTs have published guidelines that include these values [101-102], so it is probable that the AASHTO recommendations are being implemented in some jurisdictions. More recent research study confirms this general range of differences between asphalt and concrete pavement illumination requirements [103-104].

The lighting component of the life cycle is included in both the Häkkinen and Mäkelä (1996) and Stripple (2001) pavement LCAs. Häkkinen and Mäkelä use the same R1-R4 classification system, but apply it using Finnish norms which state that R2 pavements (asphalt) require 250 Watts per square meter while R1 pavements (concrete) require only 150 Watts per square meter [12]. This results in a $66 \%$ higher lighting demand for asphalt pavements $-\mathrm{a}$ marginally higher increase than the AASHTO recommendations. The difference in lighting electricity demand between the pavements accounted for $2.6 \mathrm{GJ}$ over the 50 year analysis period. This corresponds to $10 \%$ to $23 \%$ of the calculated life-cycle energy of the pavement, depending on the material.

The Stripple study does not differentiate between asphalt and concrete lighting requirements, but still incorporates lighting into the use phase of the pavement. The study calculates that $12 \mathrm{TJ}$ of electrical energy will be required to light the roadway [19], which is roughly $50 \%$ of the total life-cycle energy emissions. The type of lighting is not provided. Although that percentage is notably higher than the Häkkinen and Mäkelä findings, it at least confirms the fact that lighting is indeed an important component of the life cycle. Any differences between asphalt and concrete pavements should be considered as it has the potential to have a non-negligible impact on the results and conclusions.

The impact of the lighting energy demand on the pavement life cycle will likely become smaller as more efficient lighting technologies are adopted. Technologies such as light emitting diodes (LEDs) have the potential to provide the same amount of lighting using only a fraction of the electricity of current lighting technologies. Pavement LCAs should include lighting demand, as it can be a significant contributor to the life-cycle energy consumption of pavements. However, such studies should also account for the fact that lighting technologies are becoming more efficient over time, and thus the relative contribution of lighting to life-cycle energy consumption may shrink over time. It is also recommended that any calculations of lighting energy demand in pavement LCA make explicit the type of lighting technology that was assumed in its calculations such that the results can be interpreted in the proper context.

\subsubsection{Leachate}

Pavements have the potential to adversely affect groundwater and soil through the leaching of pollutants. The pollutants most commonly investigated are heavy metals and polycyclic aromatic hydrocarbons (PAHs) [105]. Metals present in both concrete and asphalt materials could present a variety of health effects if introduced into the bloodstream, either directly through drinking water or indirectly through crops, fish, or other systems that come in contact with the contaminated water. PAHs are found only in asphalt pavements because it is a petroleum-derived product. Concrete is an inorganic material and does not present a risk to leaching of PAHs. The environmental concern of PAHs is the carcinogenic effect of some PAH molecules. 
The current literature is in agreement that leachate from pavement materials does not pose a measurable threat to the environment. Table 16 shows studies by Kriech (1990 [106], 1992 [107]) and Brandt and De Groot (2001) [108] that find PAH levels well under the guidance concentrations set by Townsend and Brantley (1998) [109]. Table 17 shows studies by Kriech (1990 [106], 1992 [107]) and Vashisth et al. (1998) [110] under U.S. EPA drinking water standards [111]. The Vashisth et al. study examined not only dense graded asphalt concrete (DGAC), but also asphalts that used wet and dry-process crumb rubber modifiers (CRM). The tables are adapted from reference [112]. Values with the "less than" $(<)$ symbol preceding them indicate that the constituent was below the detection limit for the study.

Table 16. PAH leachate test results and guidance concentrations (ng/L)

\begin{tabular}{|c|c|c|c|c|c|c|}
\hline \multirow[b]{2}{*}{ PAH } & \multirow{2}{*}{$\begin{array}{l}\text { Kreich } \\
(1990) \\
{[106]} \\
\text { HMA }\end{array}$} & \multicolumn{2}{|c|}{$\begin{array}{l}\text { Kriech } \\
\text { (1992) [107] }\end{array}$} & \multicolumn{2}{|c|}{$\begin{array}{l}\text { Brandt and De Groot } \\
\text { (2001) [108] }\end{array}$} & \multirow{2}{*}{$\begin{array}{l}\text { Townsend and } \\
\text { Brantley (1998) } \\
\text { [109] } \\
\text { Guidance } \\
\text { Concentrations }\end{array}$} \\
\hline & & HMA & PCC & Asphalt & Bitumen & \\
\hline Acenaphthene & $<194$ & $<160$ & $<160$ & $0.8-1$ & $1.3-17$ & 20000 \\
\hline Acenaphthylene & $<150$ & $<250$ & $<250$ & & & 10000 \\
\hline Anthracene & $<15$ & $<21$ & $<21$ & $0.1-0.3$ & $0.1-28$ & 2100000 \\
\hline Benz(a)anthracene & $<48$ & $<13$ & $<13$ & $<0.05-0.2$ & $<0.05-1.4$ & 4000 \\
\hline Benzo(a)pyrene $[\mathrm{B}(\mathrm{a}) \mathrm{P}]$ & $<23$ & $<23$ & $<23$ & $<0.02-0.2$ & $<0.02-0.3$ & 200 \\
\hline Benzo(b)fluoranthene & $<20$ & $<29$ & $<29$ & $<0.01-0.2$ & $<0.01-0.4$ & 4000 \\
\hline Benzo(g,h,i)perylene & $<36$ & $<140$ & $<140$ & $<0.02-0.2$ & $<0.02$ & 10000 \\
\hline Benzo(k)fluoranthene & $<22$ & $<13$ & $<13$ & $<0.02$ & $<0.02-0.2$ & 4000 \\
\hline Chrysene & $<17$ & $<41$ & $<41$ & $0.09-0.2$ & $<0.06-5.3$ & 5000 \\
\hline Dibenzo(a,h)anthracene & $<18$ & $<85$ & $<85$ & $<0.04-0.1$ & $<0.04$ & 7500 \\
\hline Fluoranthene & $<37$ & $<21$ & $<21$ & $<0.05-0.08$ & $0.4-1.7$ & 280000 \\
\hline Fluorine & $<23$ & $<19$ & $<19$ & $<0.02-1.9$ & $2.1-44$ & 280000 \\
\hline Indeno(1,2,3-cd)pyrene & $<21$ & $<28$ & $<28$ & $<0.1$ & $<0.1$ & 7500 \\
\hline Naphthalene & 250 & $<160$ & $<160$ & $33-52$ & $35-371$ & 6800 \\
\hline Phenanthrene & $<33$ & $<160$ & $<160$ & $1.2-2.5$ & $4.1-180$ & 10000 \\
\hline Pyrene & $<40$ & $<75$ & $<75$ & $0.1-0.03$ & $0.4-4$ & 210000 \\
\hline
\end{tabular}


Table 17. Metal leachate test results and drinking water allowable limits ( $\mu \mathrm{g} / \mathrm{L})$

\begin{tabular}{llllllll}
\hline & $\begin{array}{l}\text { Kriech (1990) } \\
\text { [106] }\end{array}$ & $\begin{array}{l}\text { Kriech (1992) } \\
{[\mathbf{1 0 7 ]}}\end{array}$ & \multicolumn{2}{l}{ Vashisth et al (1998) [110] } & $\begin{array}{l}\text { EPA (2004) } \\
\text { [111] } \\
\text { Allowable } \\
\text { Limit }\end{array}$ \\
\hline Metal & HMA & HMA & PCC & DGAC & CRM (dry) & CRM (wet) \\
\hline Arsenic & $<5$ & $<5$ & $<5$ & & & & 10 \\
Barium & $<2000$ & 2900 & $<2000$ & & & & 2000 \\
Cadmium & $<20$ & $<20$ & $<20$ & 0.5 & 0.2 & 0.4 & 5 \\
Chromium & 100 & $<10$ & 72 & 0.5 & 1.1 & 0.5 & 100 \\
Copper & & & & 0.4 & 0.4 & 0.5 & 1000 \\
Lead & $<200$ & $<200$ & $<200$ & BDL & BDL & 2.1 & 15 \\
Mercury & $<5$ & $<5$ & $<5$ & & & & 2 \\
Nickel & & & & 0.8 & 0.8 & 0.7 & 100 \\
Selenium & $<5$ & $<5$ & $<5$ & & & & 50 \\
Silver & $<40$ & $<40$ & $<40$ & & & & 100 \\
Zinc & & & & 5 & 2.5 & 11.5 & 5000 \\
\hline
\end{tabular}

$\mathrm{BDL}=$ below detection limit

The remaining literature studies not presented in Tables 16 and 17 come to the same general conclusion that pavement materials are not a significant source of leachable pollutants. Azizian et al. (2005) tested calcium and aluminum deposits from concrete paving materials and conclude that "the use of PCC and PCC with plasticizers should not be of concern regarding aquatic toxicity" (p. 59) [113]. Marion et al. (2005) looked at heavy metals in paving concretes and conclude that "in view of the very small amounts leached, the risk of contamination of the soil and the water that seeps through it seems non-significant" (p. 956) [114]. Birgisdóttir et al. (2007) studied PAH levels on soil near hot-mix asphalt pavement and concluded that when PAH concentrations are above quality standards, it is "very unlikely to be caused by leaching of PAHs from the asphalt" (p. 1420) [115].

Leachate from secondary materials may pose a more serious health risk than do virgin materials, as discussed in Section 2.1.2. RAP is of particular concern due to exposure to vehicle exhaust, lubricating oils, gasoline, diesel fuel, and tire particles during its initial operating life [116]. The literature, however, is unclear as to the severity of the potential health risk by using and storing RAP. Brantley and Townsend (1999) state that "few if any priority pollutant chemicals leached from the RAP samples collected" (p. 115) [116]. Similarly, Legret et al. (2005) find that "leaching tests generally remained below [effective concentration] limit values for drinking water" (p. 3684), although PAHs concentrations were higher in RAP leachate than in virgin asphalt pavements [105]. Alternatively, Norin and Strömvall (2004) found that stored RAP contained and leached high concentrations of PAHs and concluded that the "release of organic pollutants from asphalt storages could cause environmental problems (p. 337) [117].

Another pavement application that affects leachate is the use of sealcoats on asphalt pavements. A study by Mahler et al. (2005) claimed that runoff from sealcoated parking lots may dominate the PAH loading in urban watersheds [118]. However, a rebuttal to the paper by Demott and Gauthier (2006) questioned the transparency, data, and conclusions of the Mahler et al. (2005) article [119]. Specifically, the Demott and Gauthier (2006) rebuttal took issue with the statement that sealcoats were the dominant source of PAHs in urban watersheds and felt that 
conclusion was unfounded based on the uncertainties of the presented data. Still, the heightened levels of PAHs in sealcoats are an issue. A subsequent study by Van Metre et al. (2009) (the same group as Mahler et al. (2005)) found high levels of PAHs in the dust from coal-tar-based sealcoats [120]. Concentrations of benzo[a]pyrene (a potent PAH) in the pavement and adjacent soils exceeded generic soil screening levels, leading the authors to suggest that sealcoats pose a human health risk.

Inclusion of leachate within existing pavement LCA frameworks is extremely limited. Mroueh et al. (2000) [17] is the only existing pavement LCA to include a comprehensive inventory and impact assessment of pavement leaching. Given the uncertainty of this maturing field of study, it is difficult to quantitatively include leaching within the scope of an LCA study with acceptable levels of uncertainty. Although the existing literature tends to find that pavement leachate is probably not a large health concern, the evidence is not conclusive. Moreover, the use of secondary materials and sealcoats may increase the health risk, but this also needs further research and confirmation. It is recommended that until better quantitative models are developed, leachate be included qualitatively in a pavement LCA. Any quantitative analysis should be accompanied by a robust uncertainty analysis.

\subsubsection{Tire wear and emissions}

The loss of tire tread due to pavement-tire contact creates a multifaceted problem. Firstly, tire wear leads to a demand for more tires, which is a resource and energy intensive product. Secondly, used tires present a serious hazardous materials disposal problem. Lastly, the tire dust generated as tires wear down is composed of compounds containing heavy metals, the most abundant of which is zinc [121-122]. Moreover, most of this dust comes off in the form of $\mathrm{PM}_{10}$, $\mathrm{PM}_{2.5}$, and even ultrafine particles $(\mathrm{d}<100 \mathrm{~nm})$, which themselves pose potentially dangerous respiratory and cardiovascular health scenarios [123-124].

Pavement type and roughness affect the rate of vehicle tire wear, but the extent to which each of them contributes is unknown. According to one study, PCC pavements wear tires down 1.4 to 2 times faster than do asphalt rubber pavements [125]. However, it is unclear as to how much the differing roughness values contribute to the tire wear rate, thus making it difficult to draw any conclusions. This study is also limited to the small subset of asphalt pavements that use rubber-modified binders. In general, the limited research into this topic presents a roadblock as to how to accurately model a particular pavement's effect on tire wear. Given the shortage of information, a numerical inclusion of the tire wear and emissions in the pavement life cycle is difficult and not recommended until further research is performed.

\subsection{Asphalt Fumes}

The fumes from manufacturing and placement of asphalt pavements are a potential source of adverse environmental impact as a human health hazard. Horvath and Hendrickson (1998) provide a succinct description of the problems associated with bitumen fumes in their pavement LCA study and associate it with the construction phase of the pavement life cycle [13]. The paper cites PAHs and volatile organic compounds (VOCs) as the pollutants of concern associated with bitumen fumes. 
There are acute and chronic health concerns from asphalt fumes. According the National Institute of Occupational Safety and Health (NIOSH), exposure to bitumen fumes causes acute health effects including irritation to the eyes, nose, and throat [126]. There is also evidence of acute lower respiratory tract symptoms, although the relationship is not well understood. The chronic and more serious health effects are associated with the potential carcinogenicity of bitumen fumes. In their 2000 hazard assessment, NIOSH states that the existing data regarding bitumen fumes as a potential carcinogen are inconclusive.

Inconclusiveness on the carcinogenicity of bitumen fumes is a common theme throughout the literature. A 2002 study in the United States measured PAH levels for 45 workers across 11 paving sites [127]. Carcinogens were found in the fumes, but at a level 17 times lower than the value corresponding to the minimal carcinogenic effect.

A two-part study concluded in 2003 measured mortality rates over 47 for workers in Denmark, Finland, France, Germany, Israel, the Netherlands, Norway, and Sweden to determine whether bitumen fumes are associated with increased lung cancer rates [128-129]. The conclusions from the studies indicate that workers exposed to bitumen fumes experienced a small increase in lung cancer, although a direct relationship between bitumen fumes and lung cancer could not be verified due to various sources of noise in the data.

The carcinogenicity of bitumen fumes is currently under review by the International Agency for Research on Cancer, which is part of the World Health Organization. The decision and supporting documentation will help clarify the issue of asphalt fumes as a potential carcinogen.

Fumes are discussed qualitatively in Horvath and Hendrickson (1998) and omitted entirely from the remaining studies. Given the direct exposure of hazardous fumes to asphalt works, the human health impacts could be significant within the pavement life cycle. More research is needed to understand the health impacts of asphalt fumes before they are quantitatively used in pavement LCAs.

\subsection{Feedstock Energy of Bitumen}

The ISO 14044 standard defines feedstock energy as the following:

"heat of combustion of a raw material input that is not used as an energy source to a product system, expressed in terms of higher heating value or lower heating value” (p. 3) [18].

The standard goes on to state that such feedstock energy should be included in a product LCI, alongside process energy use and other energy use categories (see ISO 14044, Section 4.2.3.3.2 [18]). For the case of pavements, the most notable input material that falls under this policy is bitumen.

Bitumen (also referred to as asphalt or liquid asphalt) is a residual product from the crude oil distillation process in many refineries. As a hydrocarbon, bitumen has a significant amount of chemical energy, estimated at $40.2 \mathrm{MJ} / \mathrm{kg}$ by the Intergovernmental Panel on Climate Change (IPCC) [45]. To put this into perspective, this review found a published range of bitumen 
production energy between 0.4 to $6 \mathrm{MJ} / \mathrm{kg}$ [25] in the pavement LCA literature. According ISO 14044, this means that the embodied primary energy of bitumen (defined as the process energy plus the feedstock energy) is as high as $46.2 \mathrm{MJ} / \mathrm{kg}$, or 7.7 times greater than the maximum bitumen production energy value found in reference [25].

The difference between bitumen feedstock energy and bitumen production energy is significant enough to alter the results and conclusions of asphalt pavement LCAs when bitumen feedstock energy is not included. Interestingly, only four of the reviewed pavements LCAs accounted for the feedstock energy of bitumen in their energy inventories [12, 21, 26, 28]. Strictly speaking, the omission of bitumen's feedstock energy is at odds with the ISO 14044 guidelines and common practice in the LCA community for products containing petroleum feedstock (e.g., plastic bottles, paints, and lubricants). The reasons for such omissions are not entirely clear, but may include limitations in the data and/or methods used in a particular study, lack of knowledge of LCA standards, or the misperception that, as a residual product, bitumen is not a viable source of energy.

Whatever the reasons for past omissions, moving forward the inclusion of bitumen feedstock energy in pavement LCAs is important for holistic energy accounting and cross-study results compatibility. Clearly, for LCAs that assume either landfill disposal or perpetual recycling/use of asphalt at the pavement end-of-life phase, the chemical energy potential of bitumen remains "untapped" in the pavement life-cycle system.

While there is guidance and precedence for the accounting of feedstock energy in the LCIs of petroleum feedstock products, this review found little evidence of accounting for feedstock mass composition in such LCIs. Such accounting would improve estimates of potential pollutant emissions should the chemical energy be released (e.g., via end-of-life energy recovery), and lead to a better understanding of the implications of contaminants stored in such feedstocks. Energy recovery is likely not practical for end-of-life asphalt, but as a residual product, bitumen does contain a number of substances of environmental concern. Improved mass composition accounting would allow the LCA community to better explore the pros and cons of petroleum feedstock use with respect to such substances, including relative impacts compared to its alternative use as a fuel (Section 3.3.1 provides a brief overview of such issues for bitumen as a direct fuel).

\subsubsection{Bitumen as a direct energy source}

Bitumen, like any other hydrocarbon, can technically be combusted in order to release its feedstock energy given the right conditions. The burning of bitumen and other crude residuals is complicated by their high carbon residue content, asphaltine content, and viscosity, all of which are generally considered impediments to efficient and clean combustion [130]. Special procedures are needed to overcome these hurdles, such emulsification of the bitumen, utilization of a catalyst, and gasification of the bitumen, amongst others [131]. In practice, boilers have been developed that have the ability to fire bitumen and similar heavy residual fuels to produce steam [130], demonstrating that bitumen can in fact be used directly as a fuel. Circulating fluidized beds have also be successfully used to combust bitumen and related fuels [132]. However, combustion itself produces a slew of potential environmental problems due to the chemical makeup of bitumen. Bitumen naturally contains high levels of fuel-bound nitrogen, and sulfur, resulting in the formation of the criteria pollutants $\mathrm{NO}_{\mathrm{X}}$ and $\mathrm{SO}_{\mathrm{X}}$ during the 
combustion process [131]. Moreover, the high content of vanadium, nickel, and other elements yields a highly corrosive ash product that erodes metal walls and piping [131] and should be treated as a hazardous waste. Bitumen and residuals also produce high levels of $\mathrm{CO}_{2}$ emissions per unit of feedstock energy [133], making them higher contributors to global warming than most other fuels. Another critical aspect is the efficiency of bitumen-firing technologies in converting feedstock energy to work, but the literature does not provide much insight into this issue.

\subsubsection{Recommendations}

Given the ISO 14044 guidance and precedence for the accounting of feedstock energy in the LCIs of petroleum feedstock products, it is recommended that the chemical energy embedded in bitumen be included when evaluating the energy associated with the asphalt pavement life cycle. Bitumen can be combusted as a direct fuel in controlled and specialized applications, and this chemical energy remains "untapped" when bitumen is used a binder in pavement.

Further research is also recommended for improved accounting of the mass composition of petroleum feedstocks that are (temporarily or permanently) sequestered in products. This would improve the ability of the LCI analyst to understand the environmental implications of petroleum feedstock use, which could include leachate considerations, pollution generated during energy recovery, or tradeoffs in various environmental impacts associated with using petroleum as a feedstock material as opposed to its use as a direct fuel.

\subsection{Traffic Delay}

Traffic delay arises due to the lane and road closures necessary to construct and maintain a pavement. The environmental impacts associated with traffic delay are contingent upon the project and site characteristics. For small, quick projects on low traffic rural roads, the impacts are likely to be negligibly small; conversely, on large highways supporting hundreds of thousands of vehicles per day, the extra fuel consumption and consequential air emissions from idling cars can easily become a prominent, or even dominant, component of the pavement life cycle.

The impact of the traffic delay can be viewed as an undefined function involving the following parameters:

- Traffic volume

o Passenger cars

o Heavy trucks

- Hourly traffic distribution

- Project duration

- Work zone length

- Closure schedule

o Time of day

o Days of the week

- Closure configuration (i.e., number of lanes closed) 
Numerous software programs exist that estimate traffic delay based on these parameters. RealCost (Federal Highway Administration) [136], QueWZ (Texas Transportation Institute) [137], WorkZone RUC (Colorado DOT) [138], and $C O^{3}$ (University of Michigan) [139] are among the tools available in the United States. Each tool has developed algorithms that estimate the delay, which involves both slowdowns and queues. Tools, such as Ca4PRS (California DOT, or Caltrans), can aid in the determination of delay by estimating construction times based on project details (e.g., project length, equipment productivity) [140]. Using a value of time constant, this delay is quantified into user costs - an increasingly important and implemented component of LCCA.

The literature supports this method of determining construction-related traffic delay emissions. For an LCA of a new concrete bridge deck technology, Keoleian et al. (2005) used the Kentucky Transportation Center's KyUCP model along with MOBILE6.2 to incorporate delay into the life cycle [141]. Although this study is not a pavement LCA, it is closely related and is good example of both an appropriate calculation method and the potential impact of traffic delay. The study concludes that for both energy consumption and GHG emissions, the impact from traffic delay is easily greater than the sum of all other life-cycle phases considered in the study (construction equipment, materials production, materials distribution, maintenance, and end-of-life). Moreover, the impact from delay is intensified when a nominal traffic growth rate is introduced; a $1 \%$ and $2 \%$ annual growth rate would increase the traffic impacts by 13 and 23 times, respectively.

The inclusion of traffic delay in pavement LCAs has thus far been limited. Chan (2007) used an identical process to incorporate traffic delay as Keoleian et al. (2005) in an LCA comparing concrete and asphalt pavements, but found different results [28]. The study found that materials production (rather than traffic) dominated the environmental impacts in 12 of the 13 case studies. The study asserts that the reason for the relatively small traffic delay impacts is due to the low traffic levels (less than 20,000 AADT) on most of the projects. Similarly, Häkkinen and Mäkelä (1996) looked at traffic delay (called "disturbance" in the study) and reported only small impacts relative to the materials production phase [12]. However, a recent paper by Huang et al. (2009) determined that traffic delay during road "maintenance" projects is a significant part of the pavement life cycle and therefore should be considered within the pavement LCA framework [44].

The limited information on traffic delay and its relevance within the pavement life cycle makes it difficult to generalize regarding its impact. On roadways with considerable traffic and where demand is close to capacity, traffic delay potentially plays a very important role in the overall life cycle impact. Conversely, on low-traffic roadways with excess capacity, traffic delay will likely be of minimal importance relative to other life-cycle components. Because of this disparity, making broad conclusions regarding the traffic delay and the pavement life cycle is not warranted. Instead, traffic delay should be examined for each pavement LCA project independently to determine its relevance given the project details and scope.

\subsection{Maintenance and Rehabilitation Phase}

Maintenance and rehabilitation activities for a pavement over its service life are often important contributors to its overall life-cycle impact. Pavements that remain in place for extended periods 
of time undergo myriad maintenance activities that can account for a significant fraction of the pavement's life-cycle impacts. However, the relative importance of the maintenance and rehabilitation phase in any LCA study is highly dependent upon the study's pavement design life and maintenance schedule assumptions. This dependency is exemplified in the current pavement LCA literature: for energy consumption of flexible pavements, one case estimates the maintenance phase as only $10 \%$ of initial construction [28], another at $40 \%$ [19], and yet another at over $120 \%$ [26]. Although these disparities may be explained based on the selection of design life and analysis period in each case, the range of values demonstrates that the maintenance phase is always likely to be an important part of the life cycle.

The accuracy of the pavement maintenance schedule assumed in an LCA hinges how well the study ultimately predicts the future. Although no future pavement maintenance can be predicted precisely, ideally the maintenance phase of a pavement LCA should be based on a realistic schedule of future activities, drawn (when possible) from past experience with similar pavements. In general, three basic analysis elements need to be known:

1. the life expectancy of the initial construction;

2. the series (strategy and order) of activities that will take place;

3. the life expectancy for each of those activities.

Another important consideration is routine maintenance procedures, such as crack sealing and other small activities. Although these should theoretically be included in a completely comprehensive LCA, it is reasonable to assume that their aggregated contribution is small compared to the rest of the life cycle given the relatively small amount of materials and energy needed to perform these activities. A more urgent need is to use a more realistic representation of larger maintenance and rehabilitation activities, loosely defined as those requiring significant materials demand or heavy processes. These include activities such as overlays, slab replacements, and other similar maintenance strategies. The ultimate decision between which activities should be included or excluded rests with the LCA practitioner.

The advance of the mechanistic-empirical pavement design methodology has redefined the way pavements are designed. This new technique considers the effects of traffic, layer thicknesses, materials properties, construction techniques, regional climate, and other parameters in estimation of a given pavement's service life [142]. Moreover, "service life" can be defined through a number of different metrics, including rutting, cracking, faulting, or roughness. These benefits of mechanistic-empirical design can help define the life expectancies of both the initial construction and the subsequent maintenance activities, thus helping define the maintenance schedule in a pavement LCA.

Predicting the type and order of maintenance activities that will occur over the analysis period is an equally challenging task. Activities can include grinding, patching, overlays, seal coats, in-situ recycling, and dozens of other strategies and derivatives designed to improve the quality and life of the existing pavement structure. Budget issues, existing pavement condition, material type, durability requirements, climate concerns, and local preferences are among the constraints that dictate the selection of one activity over another in actual practice. Needless to say, maintenance schedules are hardly an identical commodity on geographic and temporal scales. However, what pavement LCAs should do (as is current practice for LCCAs) is use a schedule that reflects the complexity and detail of actual practice. 
Viable sources of maintenance and rehabilitation schedules are regional DOTs and other transportation agencies. As they are burdened with the task of carrying out the maintenance schedules, they have derived detailed schedules based on past experiences. While actual practice will inevitably be dictated by the present condition of the pavement and budgetary considerations, these schedules serve as a best estimate of future maintenance. They should not be considered standardized templates so much as useful tools for forecasting purposes, such as those required for LCAs and LCCAs. An example of an advanced set of schedules is published by the California Department of Transportation as part of its Life-Cycle Cost Analysis Procedures Manual. Within the manual, 32 pages in the appendix outline over 200 schedules based on climate, existing material, strategy selection, and desired service life [143]. This series, although probably simplified from actuality, has sufficiently more detail than a standard LCA and would constitute a major upgrade in how the LCA maintenance phase is currently modeled. Moreover, the accuracy of this series can be dramatically improved upon if an external model the Mechanistic-Empirical Design Guide, for instance - is used to sharpen the estimated activity service lives based on individual project characteristics.

\subsection{End-of-Life Phase}

The impacts attributable to a pavement's end-of-life phase depend on the ultimate fates of the pavement and its constituent materials, which are notoriously difficult to determine a priori. At the end of its service life, a pavement could be landfilled, recycled, or simply remain in place and serve as part of the underlying structure for another pavement layer. The rate at which each of these options occurs for various pavement types, locations, and other pavement details is not well documented. It is possible that much of the knowledge is held in the heads of maintenance workers, pavement engineers, and other personnel associated with transportation authorities around the United States and could be transferred to the LCA community through better data reporting efforts. Even empirical data gained through surveys and interviews would provide valuable insight into the most accurate way to model the end-of-life phases for pavements.

For pavements that are removed and entirely rebuilt, the end-of-life environmental impact reflects the removal and disposal processes. If the disposal process is simply landfilling, then the analysis is relatively straightforward and involves the demolition, transportation, and landfilling processes. The environmental impacts of landfilling have been well studied from an LCA perspective (e.g., [144-145]) and can be relatively easily applied to the pavement life cycle.

The end-of-life phase is often simplified in pavement LCAs by assuming landfilling due to the straightforward approach necessary to estimate the environmental impact. The trouble with this approach is that concrete and asphalt pavements are both widely recycled materials and any benefits associated with replacing virgin materials are ignored when landfilling is assumed. The exact recycling rates are elusive: a 2007 paper examining the generation of solid waste in the asphalt and reinforced concrete pavement life cycle noted the difficulty in finding current recycling rates for the these products [146]. The paper cites a 1993 FHWA study that finds that approximately $80 \%$ of asphalt pavement is reused or recycled at the end of its life [147]. The paper also cites a 1994 study by the National Cooperative Highway Research Program that concludes that concrete pavements enjoy a similarly high recycling rate of $75 \%$ [148]. It is not unreasonable to assume that both recycling rates are even higher today. 
When an LCA assumes that the pavement material is recycled or reused, the analysis becomes more complex. One approach is that pavements should receive a full or partial systemlevel "credit" of sorts that is equal to the amount of displaced environmental impact that the recycling or reuse creates between the first and second life-cycles of the recycled/reused pavement materials. For instance, if RAP is to be reused as a fill for another project, then the total system-level "credit" for a given impact is equal to the impact of producing an equivalent amount of virgin fill, plus the impact of landfilling the RAP, minus the impact of the RAP recycling process. In essence, a new LCA must be performed on the virgin fill in order to assess the benefit of recyclability. To make this more convoluted, this method also requires the foresight to know exactly how a material will be used at the end of its life. Given pavement lives measured in decades, this is difficult to predict with a reasonable amount of confidence. The function of the pavement material after it is recycled or reused is an important aspect of the endof-life phase. According to a 1996 FHWA report, 33\% of RAP is reused in the production of hotmix asphalt [149]. The other $67 \%$ is used in other pavement-related applications, such as hot and cold in-place recycling, full-depth reclamation, aggregate for shoulder and road base, shoulder surfacing and widening, and other maintenance uses. Crushed concrete is used as an aggregate substitute, with $6 \%$ being used in new cement concrete construction, $9 \%$ in asphalt concrete, and the remaining $85 \%$ in road base, rip-rap, fill, and similar applications [150]. This method of assigning environmental impact by considering multiple product life cycles and services, known generically as system expansion within LCA circles, is widely considered the best practice and is supported by the ISO 14044 framework [18].

Another option is to model pavements materials as though they remain in the pavement structure indefinitely. This is not as farfetched as it may initially seem, as many pavements remain either partially or wholly in place after their functional service life has ended. In these cases, new or reconstituted materials make up a fresh surface wearing course while using the existing, damaged pavement for its underlying support. If similar activities are repeated indefinitely, the pavement structure never reaches its end-of-life phase, instead becoming a part of a perpetual pavement. Determining the environmental impact is complicated as well and mirrors many aspects of the recycling analysis nuances discussed above. Because the old pavement is still adding some structural support to the new pavement, the end-of-life should credit the old pavement with the displaced environmental impacts in accordance with the system expansion approach.

Only four of the twelve studies reviewed in Section 2.1.1 included the end-of-life in the results $([11,13,22-23])$. Of those four, only two $([11,23])$ include the phase quantitatively in the assessment. Even in these two studies, the end-of-life is grossly simplified: Roudebush (1999) [11] assumes that the materials are completely recycled and does not assign emergy to these processes; Park et al. (2003) [23] only considers the demolition and transportation to a landfill, thus omitting the processes occurring when the materials actually arrive at the landfill. Overall, the LCA literature provides very little insight into the influence of the end-of-life phase on the results, so it is unclear as to whether end of life processes are major contributors to the total lifecycle impacts.

Predicting what actually happens at the end of life will inevitably be an uncertain exercise, but increasing the knowledge will help increase the accuracy of the prediction and thus create more realistic, useful end-of-life analyses in LCA. There is also a need to compare the 
end-of-life options (landfilling, recycling, and remain in place) to one another in order to determine what the best course of action is under a variety of circumstances.

\section{RECOMMENDED FUTURE RESEARCH}

The assessment of current pavement LCA research (Section 2) and the investigation of the research gaps (Section 3) provide an overview of the existing knowledge regarding pavements and the environment. It has been shown that pavement LCA is still maturing as a research field and that many of the interactions between pavements and the environment are not well understood and/or well characterized in current pavement LCAs. Table 18 provides recommendations future research that will help advance the state of pavement LCA science and should lead to more transparent, comprehensive, and credible pavement LCAs for use by pavement engineers, urban planners, and policy makers. Each of the recommendations in Table 18 has been derived from the research gaps and deficiencies discussed in Sections 2 and 3.

The recommendations in Table 18 are organized by phase of the pavement LCA cycle for ease of access. Furthermore, a number of recommendations for improving general pavement LCA practices have been provided.

No attempt has been made to prioritize or rank order the research recommendations in Table 18 for the broader pavement LCA research community. Although this review identified important research gaps that are common to many LCAs, the most important research gaps to address in any specific pavement LCA are highly dependent upon that study's available data, research questions, desired insights, and intended audience. Therefore, it is recommended that the research recommendations in Table 18 be reviewed by LCA practitioners in the context of what is most important for his or her particular study. 
Table 18. Recommended future research areas for pavement LCA

\begin{tabular}{|c|c|c|}
\hline Research Area & Research Topic & Specific Research Needs \\
\hline \multirow{5}{*}{$\begin{array}{l}\text { General pavement } \\
\text { LCA practices }\end{array}$} & Functional unit & $\begin{array}{l}\text { Development of a functional unit that accounts } \\
\text { for the function and location of a pavement }\end{array}$ \\
\hline & System boundary & $\begin{array}{l}\text { - Improved incorporation of all life-cycle phases. } \\
\text { Better understanding the impact of each phase } \\
\text { and component relative to the rest of the life } \\
\text { cycle }\end{array}$ \\
\hline & Data depth & $\begin{array}{l}\text { More balanced data and research for cement } \\
\text { and asphalt environmental data, including } \\
\text { better data for refineries and improved } \\
\text { allocation techniques }\end{array}$ \\
\hline & LCI and LCIA scopes & $\begin{array}{l}\text { - Inclusion of environmental indicators other than } \\
\text { energy, greenhouse gases, and conventional } \\
\text { air pollutants (e.g., water pollution and } \\
\text { consumption) } \\
\text { - Use of LCIA (rather than inventory) to evaluate } \\
\text { the environmental impact }\end{array}$ \\
\hline & Overall utility & $\begin{array}{l}\text { - More diverse application of LCA than just } \\
\text { comparisons of asphalt to concrete (e.g., } \\
\text { comparison of pavement maintenance } \\
\text { techniques within a given pavement type, } \\
\text { optimization of design life) } \\
\text { Optimization of maintenance frequency and } \\
\text { pavement design life for given project } \\
\text { parameters are potential research topics } \\
\text { - Uncertainty bounds on LCA results and } \\
\text { conclusions based on data and modeling errors } \\
\text { Testing of results and conclusions to changes } \\
\text { in variables (i.e., sensitivity analysis) }\end{array}$ \\
\hline \multirow{4}{*}{ Materials phase } & Feedstock energy & $\begin{array}{l}\text { - Widespread and consistent use of feedstock } \\
\text { energy in pavement LCA accounting } \\
\text { - Improved understanding of the environmental } \\
\text { impacts associated with bitumen as a direct- } \\
\text { fired fuel }\end{array}$ \\
\hline & $\begin{array}{l}\text { Environmental data for } \\
\text { bitumen }\end{array}$ & $\begin{array}{l}\text { - Increase the understanding of the } \\
\text { environmental impact of bitumen through } \\
\text { further research. This will help address the data } \\
\text { imbalance between bitumen and cement. }\end{array}$ \\
\hline & Secondary materials & $\begin{array}{l}\text { - In-depth review of the use of secondary } \\
\text { materials in pavements, including an } \\
\text { exhaustive list of potential materials. } \\
\text { Improved understanding (via data collection } \\
\text { and analysis) of the environmental impact of } \\
\text { secondary materials. }\end{array}$ \\
\hline & Regional specificity & $\begin{array}{l}\text { Development of environmental emission and } \\
\text { energy data specific to various regions } \\
\text { Consideration of different electricity mixes, } \\
\text { transportation distances, production variability, } \\
\text { and other process that vary between locations }\end{array}$ \\
\hline
\end{tabular}


Table 18. Recommended future research areas for pavement LCA (continued)

\begin{tabular}{|c|c|c|}
\hline Research Area & Research Topic & Specific Research Needs \\
\hline \multirow[t]{2}{*}{ Construction phase } & Traffic delay & $\begin{array}{l}\text { - Integration of economic traffic delay models } \\
\text { with environmental impact models } \\
\text { - Better understanding of traffic detouring and its } \\
\text { contribution to environmental impact }\end{array}$ \\
\hline & Bitumen fumes & $\begin{array}{l}\text { - Determination of carcinogenic effect of bitumen } \\
\text { fumes during production and construction of } \\
\text { asphalt pavements }\end{array}$ \\
\hline Maintenance phase & $\begin{array}{l}\text { Maintenance activities } \\
\text { and schedule }\end{array}$ & $\begin{array}{l}\text { - Utilization of mechanistic-empirical pavement } \\
\text { design models to better forecast maintenance } \\
\text { timeline } \\
\text { - Integration of more accurate maintenance and } \\
\text { rehabilitation schedule of activities } \\
\text { - Proper incorporation of the environmental } \\
\text { effects from the material and construction } \\
\text { phases }\end{array}$ \\
\hline \multirow{7}{*}{ Use phase } & Concrete carbonation & $\begin{array}{l}\text { - Continue to develop data on the rate that } \\
\text { carbonation occurs in concrete pavements in } \\
\text { different scenarios } \\
\text { - Specify the impact of concrete pavement } \\
\text { properties on the carbonation rate }\end{array}$ \\
\hline & Roadway lighting & $\begin{array}{l}\text { - Comprehensive database of lighting } \\
\text { requirements for different pavement types } \\
\text { Better treatment of lighting efficiency } \\
\text { improvements over time }\end{array}$ \\
\hline & $\begin{array}{l}\text { Albedo: } \\
\text { urban heat island }\end{array}$ & $\begin{array}{l}\text { Calculation of marginal impact of pavement } \\
\text { albedo changes on electricity demand due to } \\
\text { increased air conditioning demand }\end{array}$ \\
\hline & $\begin{array}{l}\text { Albedo: } \\
\text { radiative forcing }\end{array}$ & $\begin{array}{l}\text { - Confirmation and refinement of } \mathrm{CO}_{2} \text { offset } \\
\text { calculations for marginal changes in pavement } \\
\text { albedo }\end{array}$ \\
\hline & $\begin{array}{l}\text { Rolling resistance: } \\
\text { pavement structure }\end{array}$ & $\begin{array}{l}\text { - More empirical studies needed to refine and } \\
\text { confirm fuel economy differences between } \\
\text { pavement types } \\
\text { Development of a mechanistic-based } \\
\text { relationship between rolling resistance, fuel } \\
\text { economy, and pavement structure }\end{array}$ \\
\hline & $\begin{array}{l}\text { Rolling resistance: } \\
\text { pavement roughness }\end{array}$ & $\begin{array}{l}\text { - More empirical studies needed to refine the } \\
\text { effect of pavement roughness on fuel } \\
\text { consumption } \\
\text { Development of a mechanistic-based } \\
\text { relationship between rolling resistance, fuel } \\
\text { economy, and pavement roughness }\end{array}$ \\
\hline & Leachate & $\begin{array}{l}\text { - More conclusive tests and data on potential } \\
\text { environmental hazards of leachate from } \\
\text { pavements }\end{array}$ \\
\hline
\end{tabular}


Table 18. Recommended future research areas for pavement LCA (continued)

\begin{tabular}{|c|c|c|}
\hline Research Area & Research Topic & Specific Research Needs \\
\hline Use phase & Tire wear & $\begin{array}{l}\text { - Exploration of how pavement structure and } \\
\text { roughness contributes to tire wear } \\
\text { - Identification of environmental impact of tire } \\
\text { production } \\
\text { - Identification of environmental impact of tire wear }\end{array}$ \\
\hline End-of-life phase & $\begin{array}{l}\text { Landfilling, recycling, and } \\
\text { remain in place scenarios }\end{array}$ & $\begin{array}{l}\text { - Improved data regarding pavement end-of-life } \\
\text { fate (i.e., rates of landfilling, recycling, or } \\
\text { remaining in place) } \\
\text { - Use of system expansion to more accurately } \\
\text { quantify recycling and remain in place } \\
\text { scenarios } \\
\text { - Improved understanding of recycling rates for } \\
\text { pavement materials, including material flows } \\
\text { and products using recycled pavement } \\
\text { materials } \\
\text { - Improved understanding of pavement recycling } \\
\text { processes and their environmental impacts }\end{array}$ \\
\hline
\end{tabular}




\section{CONCLUSIONS}

The field of a pavement LCA is a rapidly growing research area. However, the information and tools currently at our disposable to conduct pavement LCAs only provide a narrow snapshot of the problems and potential solutions. As discussed in Section 2, existing pavement LCAs are relatively few in number and generally have deficiencies in their approaches, which serve as barriers to utilization by pavement engineers and policy makers. This study identified five general weaknesses of the current pavement LCA research: inconsistent functional unit, improper system boundaries, imbalanced data for bitumen and cement, limited inventory and impact assessment categories, and poor overall utility. The few software tools available to assist in the LCA process mirrored the same problems.

In order to improve the quality of pavement LCAs, gaps that exist in the research need to be filled with the best information available. Section 3 identified six distinct areas that would benefit from further research: the use phase (rolling resistance, albedo, carbonation, lighting, leachate, and tire wear and emissions), asphalt fumes, feedstock energy of bitumen, traffic delay, maintenance phase, and end-of-life phase. This study examined each of these topics in more detail to better understand the current state of the research and determine how they could be better assimilated into the pavement LCA methodology. Many of these topics, such as albedo and rolling resistance in the use phase, are still maturing research areas whose data and conclusions would benefit from further refinement. Others, such as traffic delay and the maintenance phase, are more established research areas that offer the opportunity for immediate improvements in pavement LCAs.

Recommendations are laid out in Section 4 for particularly fruitful areas of future research. These recommendations shed light on where improvements in knowledge can be made that will benefit the accuracy and comprehensiveness of pavement LCAs. Each phase of the life cycle, as well as the general pavement LCA methodology, contains areas that can be improved through focused research. Addressing these areas will help create a more comprehensive understanding of the pavement life cycle and, in turn, develop better decision-making frameworks for constructing more sustainable pavements. 


\section{ACKNOWLEDGMENTS}

The research reported in this paper (PCA R\&D SN 3119a) was conducted by Lawrence Berkeley National Laboratory with the sponsorship of the Portland Cement Association (PCA Project Index No. 08-08), California Nevada Cement Association, and American Concrete Pavement Association--Southwest. The contents of this report reflect the views of the authors, who are responsible for the facts and accuracy of the data presented. The contents do not necessarily reflect the views of the Portland Cement Association, California Nevada Cement Association, or American Concrete Pavement Association--Southwest.

The authors gratefully acknowledge the helpful comments and insights provided by the peer reviewers of this report. 


\section{REFERENCES}

[1] Holtz, K. and Eighmy, T.T., Scanning European Advances in the Use of Recycled Materials in Highway Construction. Public Roads (FHWA). Vol. 64, No. 1, pp. 34-40. 2000.

[2] Federal Highway Administration, 2006 Status of the Nation's Highways, Bridges, and Transit: Conditions and Performance. U.S. Department of Transportation. 2006.

[3] Federal Highway Administration. Highway Statistics 2006. 2007 [cited July 18, 2008]; Available from: http://www.fhwa.dot.gov/policy/ohim/hs06/index.htm.

[4] International Organization for Standardization, Environmental Management - Life Cycle Assessment - Principles and Framework. ISO 14040:2006(E). 2006.

[5] Lenzen, M. and Dey, C., Truncation error in embodied energy analyses of basic iron and steel products. Energy. Vol. 25, No. 6, pp. 577-585. 2000.

[6] Lenzen, M., Errors in Conventional and Input-Output-based Life-Cycle Inventories. Journal of Industrial Ecology. Vol. 4, No. 4, pp. 127-148. 2001.

[7] Leontief, W.W., Quantitative Input and Output Relations in the Economic System of the United States. The Review of Economic Statistics. Vol. 18, No. 3, pp. 105-125. 1936.

[8] Bureau of Economic Analysis. Industry Economic Accounts. United States Department of Commerce. 2008 [cited April 16, 2009]; Available from: http://www.bea.gov/industry/.

[9] Hendrickson, C.T., Lave, L.B., and Matthews, H.S., Environmental Life Cycle Assessment of Goods and Services. Washington, DC: Resources for the Future. 2006.

[10] Trealor, G.J., Love, P.E.D., Faniran, O.O., and Iyer-Raniga, U., A hybrid life cycle assessment method for construction. Construction Management and Economics. Vol. 18, No. 1, pp. 5-9. 2000.

[11] Roudebush, W.H., Environmental Value Engineering Assessment of Concrete and Asphalt Pavement. Portland Cement Association. PCA R\&D Serial No. 2088a. 1999.

[12] Häkkinen, T. and Mäkelä, K., Environmental Impact of Concrete and Asphalt Pavements, in Environmental adaption of concrete. Technical Research Center of Finland. Research Notes 1752. 1996.

[13] Horvath, A. and Hendrickson, C., Comparison of Environmental Implications of Asphalt and Steel-Reinforced Concrete Pavements. Transportation Research Record. Vol. 1626, pp. 105-113. 1998.

[14] Carnegie Mellon Green Design Institute. Economic Input-Output Life Cycle Assessment. US 1992 Industry Benchmark Model. 2002 [cited January 21, 2009]; Available from: www.eiolca.net. 
[15] Roudebush, W., Environmental Value Engineering (EVE) Environmental Life Cycle Assessment of Concrete and Asphalt Highway Pavement Systems. Portland Cement Association. PCA R\&D Serial No. 2088. 1996.

[16] Berthiaume, R. and Bouchard, C., Exergy Analysis of the Environmental Impact of Paving Material Manufacture. Transactions of the Canadian Society for Mechanical Engineering. Vol. 23, No. 1B, pp. 187-196. 1999.

[17] Mroueh, U.M., Eskola, P., Laine-Ylijoki, J., Wellman, K., Mäkelä, E., Juvankoski, M., and Ruotoistenmäki, A., Life cycle assessment of road construction. Finnish National Road Administration. Finnra Reports 17/2000. 2000.

[18] International Organization for Standardization, Environmental Management - Life Cycle Assessment - Requirement and Guidelines. ISO 14044:2006(E). 2006.

[19] Stripple, H., Life Cycle Assessment of Road: A Pilot Study for Inventory Analysis (Second Revised Edition). Swedish National Road Administration. IVL B 1210 E. 2001.

[20] Stripple, H., Life Cycle Inventory of Asphalt Pavements. IVL Swedish Environmental Research Institute Ltd. 2000.

[21] Nisbet, M.A., Marceau, M.L., VanGeem, M.G., and Gajda, J., Environmental Life Cycle Inventory of Portland Cement Concrete and Asphalt Concrete Pavements. Portland Cement Association. PCA R\&D Serial No. 2489. 2001.

[22] Nisbet, M.A. and Marceau, M.L., Environmental Life Cycle Inventory of Asphalt Concrete. Portland Cement Association. PCA R\&D Serial No. 2487. 2001.

[23] Park, K., Hwang, Y., Seo, S., and Seo, H., Quantitative Assessment of Environmental Impacts on Life Cycle of Highways. Journal of Construction Engineering and Management. Vol. 129, No. 1, pp. 25-31. 2003.

[24] Treloar, G.J., Love, P.E.D., and Crawford, R.H., Hybrid Life-Cycle Inventory for Road Construction and Use. Journal of Construction Engineering and Management. Vol. 130, No. 1, pp. 43-49. 2004.

[25] Zapata, P. and Gambatese, J.A., Energy Consumption of Asphalt and Reinforced Concrete Pavement Materials and Construction. Journal of Infrastructure Systems. Vol. 11, No. 1, pp. 9-20. 2005.

[26] Athena Institute, A Life Cycle Perspective on Concrete and Asphalt Roadways: Embodied Primary Energy and Global Warming Potential. Cement Assocation of Canada. Prepared for the Cement Association of Canada. 2006.

[27] Athena Sustainable Materials Institute, Life Cycle Embodied Energy and Global Warming Emissions for Concrete and Asphalt Roadways. Canadian Portland Cement Association. 1999. 
[28] Chan, A.W.-C., Economic and Environmental Evaluations of Life Cycle Cost Analysis Practice: A Case Study of Michigan DOT Pavement Projects, Master of Science Thesis in Natural Resource and Environment, University of Michigan. 2007.

[29] Mroueh, U.M., Eskola, P., and Laine-Ylijoki, J., Life-cycle impacts of the use of industrial by-products in road and earth construction. Waste Management. Vol. 21, pp. $271-277.2001$.

[30] Mroueh, U.M., Mäkelä, E., Wahlström, M., Kauppila, J., Sorvari, J., Heikkinen, P., Salminen, R., Juvankoski, M., and Tammirinne, M., By-products in earth construction: Assesment of acceptability. National Technology Agency. Technology Review 96/2000. 2000.

[31] Roth, L. and Eklund, M., Environmental evaluation of reuse of by-products as road construction materials in Sweden. Waste Management. Vol. 23, No. 2, pp. 107-116. 2003.

[32] Jullien, A., Monéron, P., Quaranta, G., and Gaillard, D., Air emissions from pavement layers composed of varying rates of reclaimed asphalt. Resources, Conservation and Recycling. Vol. 47, No. 4, pp. 356-374. 2006.

[33] Birgisdóttir, H., Pihl, K.A., Bhander, G., Hauschild, M.Z., and Christensen, T.H., Environmental assessment of roads constructed with and without bottom ash from municipal solid waste incineration. Transportation Research Part D. Vol. 11, No. 5, pp. 358-368. 2006.

[34] Birgisdóttir, H., Bhander, G., Hauschild, M.Z., and Christensen, T.H., Life cycle assessment of disposal of residues from municipal solid waste incineration: recycling of bottom ash in road construction or landfilling in Denmark evaluated in the ROAD-RES model. Waste Management. Vol. 27, No. 8, pp. S75-84. 2007.

[35] PC-Progress. Hydrus-2D. 2004 [cited July 7, 2009]; Available from: http://www.pcprogress.com/en/Default.aspx?hydrus-2d\#k1.

[36] Carpenter, A.C., Gardner, K.H., Fopiano, J., Benson, C.H., and Edil, T.B., Life cycle based risk assessment of recycled materials in roadway construction. Waste Management. Vol. 27, No. 10, pp. 1458-1464. 2007.

[37] Huang, Y., Bird, R.N., and Heidrich, O., A review of the use of recycled solid waste materials in asphalt pavements. Resources, Conservation and Recycling. Vol. 52, No. 1, pp. 58-73. 2007.

[38] Chiu, C.-T., Hsu, T.-H., and Yang, W.-F., Life cycle assessment on using recycled materials for rehabilitating asphalt pavements. Resources, Conservation and Recycling. Vol. 52, No. 3, pp. 545-556. 2008.

[39] Rangaraju, P.R., Amirkhanian, S., and Guven, Z., Life Cycle Cost Analysis for Pavement Type Selection. South Carolina Department of Transportation. FHWA-SC-08-01. 2008. 
[40] Ozbay, K., Jawad, D., Parker, N.A., and Hussain, S., Life-Cycle Cost Analysis: State of the Practice Versus State of the Art. Transportation Research Record. Vol. 1864, pp. 6270. 2004.

[41] Nathman, R., McNeil, S., and Van Dam, T.J. Integrating Environmental Perspectives into Pavement Management: Adding PaLATE to the Decision-Making Toolbox. Presented at the Transportation Research Board 88th Annual Meeting. Washington, D.C. 2009.

[42] Birgisdóttir, H., Life cycle assessment model for road construction and use of residues from waste incineration, Ph.D. Dissertation in the Institute of Environment and Resources, Technical University of Denmark. 2005.

[43] Huang, Y., Bird, R., and Heidrich, O., Development of a life cycle assessment tool for construction and maintenance of asphalt pavements. Journal of Cleaner Production. Vol. 17, No. 2, pp. 283-296. 2009.

[44] Huang, Y., Bird, R., and Bell, M., A comparative study of the emissions by road maintenance works and the disrupted traffic using life cycle assessment and microsimulation. Transportation Research Part D. Vol. 14, No. 3, pp. 197-204. 2009.

[45] Garg, A., Kazunari, K., and Pulles, T., 2006 IPCC Guidelines for National Greenhouse Gas Inventories. Intergovernmental Panel on Climate Change. 2006.

[46] Wang, M., Lee, H., and Molburg, J., Allocation of Energy Use in Petroleum Refineries to Petroleum Products: Implications for Life-Cycle Energy Use and Emission Inventory of Petroleum Transportation Fuels. International Journal of Life Cycle Assessment. Vol. 9, No. 1, pp. 34-44. 2004.

[47] Marceau, M.L., Nisbet, M.A., and Vangeem, M.G., Life Cycle Inventory of Portland Cement Manufacture. Portland Cement Association. PCA Report No. 2095b. 2006.

[48] Josa, A., Aguado, A., Cardim, A., and Byars, E., Comparative analysis of the life cycle impact assessment of available cement inventories in the EU. Cement and Concrete Research. Vol. 37, No. 5. 2007.

[49] Huntzinger, D.N. and Eatmon, T.D., A life-cycle assessment of portland cement manufacturing: Comparing the traditional process with alternative technologies. Journal of Cleaner Production. Vol. 17, No. 1, pp. 668-675. 2009.

[50] Boesch, M.E., Koehler, A., and Hellweg, S., Model for Cradle-to-Gate Life Cycle Assessment of Clinker Production. Environmental Science and Technology. Vol. 43, No. 19, pp. 7578-7583. 2009.

[51] Curran, M.A., Life Cycle Assessment: Principles and Practice. United States Environmental Protection Agency. EPA/600/R-06/060. 2006.

[52] Muga, H.E., Mukherjee, A., Mihelcic, J.R., and Kueber, M.J., An Integrated Assessment of Continuously Reinforced and Jointed 
Plane Concrete Pavements. Journal of Engineering, Design and Technology. Vol. 7, No. 1, pp. 81-98. 2009.

[53] G.W. Taylor Consulting, Additional Analysis of the Effect of Pavement Structure on Truck Fuel Consumption. Prepared for Government of Canada Action Plan 2000 on Climate Change: Concrete Roads Advisory Committee. 2002.

[54] Leinonen, A., Tyre Rolling Resistance on Road, Master of Science Thesis in Mechanical Engineering, Helsinki University of Technology. 2005.

[55] Beuving, E., De Jonghe, T., Goos, D., Lindahl, T., and Stawiarski, A., Environmental Impacts and Fuel Efficiency of Road Pavements. Europe Asphalt Pavement Association and Eurobitume. 2004.

[56] Zaniewski, J.P., Effect of Pavement Surface Type on Fuel Consumption. Portland Cement Association. PCA R\&D SR289. 1989.

[57] Trusty, W., Using Life Cycle Assessment to Assess Environmental Performance. 2006, Presentation for the the National Research Council Canada. pp.

[58] Taylor, G., Marsh, P., and Oxelgren, E., Effect of Pavement Surface Type on Fuel Consumption - Phase II: Seasonal Tests. Portland Cement Association. CSTT-HWV-CTR041.2000.

[59] Taylor, G.W. and Patten, J.D., Effects of Pavement Structure on Vehicle Fuel Consumption - Phase III. National Research Council of Canada. Project 54-HV775, Technical Report CSTT-HVC-TR-068. 2006.

[60] Santero, N.J., Pavements and the Environment: A Life-Cycle Assessment Approach, Doctoral Dissertation in Civil and Environmental Engineering, University of California, Berkeley. 2009.

[61] Huschek, S., Influence of Road Surface Roughness on Tire Noise Generation in the Federal Republic of Germany, in Surface Characteristics of Roadways: International Research and Technologies, W.E. Meyer and J. Reichert, Editors. American Society for Testing and Materials: Philadelphia, PA. pp. 430-441. 1990.

[62] Sandberg, U. and Ejsmont, J.A., Tyre/Road Reference Book. Noise Control Engineering Journal. Vol. 51, pp. 348. 2002.

[63] Watanatada, T., Dhareshwar, A.M., and Lima, P.R.S.R., Vehicle Speeds and Operating Costs: Models for Road Planning and Management, in The Highway Design and Maintenance Standards Series. The World Bank. Report No. 10082. 1987.

[64] Descornet, G., Road-Surface Influence and Tire Rolling Resistance, in Surface Characteristics of Roadways: International Research and Technologies, W.E. Meyer and J. Reichert, Editors. American Society for Testing and Materials: Philadelphia, PA. pp. 401-415. 1990. 
[65] Laganier, R. and Lucas, J., The Influence of Pavement Evenness and Macrotexture on Fuel Consumption, in Surface Characteristics of Roadways: International Research and Technologies, W.E. Meyer and J. Reichert, Editors. American Society for Testing and Materials: Philadelphia, PA. pp. 454-459. 1990.

[66] Sandberg, U.S.I., Road Macro- and Megatexture Influence on Fuel Consumption, in Surface Characteristics of Roadways: International Research and Technologies, W.E. Meyer and J. Reichert, Editors. American Society for Testing and Materials: Philadelphia, PA. pp. 460-479. 1990.

[67] du Plessis, H.W., Visser, A.T., and Curtayne, P.C., Fuel Consumption of Vehicles as Affected by Road Surface Characteristics, in Surface Characteristics of Roadways: International Research and Technologies, W.E. Meyer and J. Reichert, Editors. American Society for Testing and Materials: Philadelphia, PA. pp. 480-496. 1990.

[68] Transportation, U.S.D.o., 1998 FHWA National Strategic Plan. Federal Highway Administration. FHWA-PL-98-030. 1998.

[69] Epps, J.A., Leahy, R.B., Mitchell, T., Ashmore, C., Seeds, S., Alavi, S., and Monismith, C.L. Westrack - The Road to Performance-Related Specifications. Proceedings of International Conference on Accelerated Pavement Testing. Reno, NV. 1999.

[70] Hugo, F. and Martin, A.E., Significant Findings from Full-Scale Accelerated Pavement Testing. National Cooperative Highway Research Program and Transportation Resarch Board. NCHRP Synthesis 325. 2004.

[71] Sime, M. and Asmore, S.C., WesTrack Track Roughness, Fuel Consumption, and Maintenance Costs. Turner-Fairbank Highway Research Center. 2000.

[72] Gillespie, J.S. and McGhee, K.K., Get In, Get Out, Come Back! Transportation Research Record. Vol. 1990, pp. 32-39. 2007.

[73] Jackson, N.M., An Evaluation of the Relationship Between Fuel Consumption and Pavement Roughness (Preliminary Report). Universtiy of North Florida. 2004.

[74] Kaloush, K.E., Carlson, J.D., Golden, J.S., and Phelan, P.E., The Thermal and Radiative Characteristics of Concrete Pavements in Mitigating Urban Heat Island Effects. Portland Cement Association. PCA R\&D SN2969. 2008.

[75] Pomerantz, M., Akbari, H., Chen, A., Taha, H., and Rosenfeld, A.H., Paving Materials for Heat Island Mitigation. Lawrence Berkeley National Laboratory. LBNL-38074. 1997.

[76] Pomerantz, M. and Akbari, H. Cooler Paving Materials for the Heat Island Mitigation. Proceedings of The 1998 ACEEE Summer Study on Energy Efficiency. Washington, DC. 1998.

[77] Pomerantz, M., Akbari, H., and Harvey, J.T., The benefits of cooler pavements on durability and visibility. Lawrence Berkeley National Laboratory. LBNL-43443. 2000. 
[78] Pomerantz, H., Pon, B., Akbari, H., and Change, S.-C., The Effect of Pavements' Temperatures on Air Temperatures in Large Cities. Lawrence Berkeley National Laboratory. LBNL-43442. 2000.

[79] Marceau, M.L. and VanGeem, M.G., Solar Reflectance of Concretes for LEED Sustainable Sites Credit: Heat Island Effect. Portland Cement Association. PCA R\&D Serial No. 2982. 2007.

[80] Golden, J.S. and Kaloush, K.E., Mesoscale and Microscale Evaluation of Surface Pavement Impacts on the Urban Heat Island Effects. International Journal of Pavement Engineering. Vol. 7, No. 1, pp. 37-52. 2006.

[81] Boriboonsomsin, K. and Reza, F., Mix Design and Benefit Evaluation of High Solar Reflectance Concrete for Pavements. Transportation Research Record. Vol. 2011, pp. 1120. 2007.

[82] Akbari, H., Pomerantz, M., and Taha, H., Cool Surfaces and Shade Trees to Reduce Energy Use and Improve Air Quality in Urban Areas. Solar Energy. Vol. 70, No. 3, pp. 295-310. 2001.

[83] Akbari, H., Davis, S., Dorsano, S., Huang, J., and Winnett, S., Cooling Our Communities: A Guide to Tree Planting and Light-Colored Surfacing. United States Environmental Protection Agency, Office of Policy Analysis, Climate Change Division. 1992.

[84] Rosenfeld, A.H., Akbari, H., Romm, J.J., and Pomerantz, M., Cool Communities: Strategies for Heat Island Mitigation and Smog Reduction. Energy and Buildings. Vol. 28, No. 1, pp. 51-62. 1998.

[85] Gui, J., Phelan, P.E., Kaloush, K.E., and Golden, J.S., Impact of Pavement Thermophysical Properties on Surface Temperatures. Journal of Materials in Civil Engineering. Vol. 19, No. 8. 2007.

[86] Tran, N., Powell, B., Marks, H., West, R., and Kvasnak, A., Strategies for Design and Construction of High-Reflectance Asphalt Pavements. Transportation Research Record. Vol. 2098, pp. 124-130. 2009.

[87] Akbari, H., Menon, S., and Rosenfeld, A., Global Cooling: Increasing World-Wide Urban Albedos to Offset CO2. Climatic Change. Vol. 95, No. 3-4, pp. 275-286. 2009.

[88] Damtoft, J.S., Lukasik, J., Herfort, D., Sorrentino, D., and Gartner, E.M., Sustainable Development and Climate Change Initiatives. Cement and Concrete Research. Vol. 38, No. 2, pp. 115-127. 2008.

[89] Lagerblad, B., Carbon Dioxide Uptake During Concrete Life Cycle - State of the Art. Swedish Cement and Concrete Research Institute, CBI. Nordic Innovation Centre Project Number 03018. 2006. 
[90] Gajda, J., Absorption of Atmospheric Carbon Dioxide by Portland Cement Concrete (revised in 2006). Portland Cement Association. PCA R\&D Serial No. 2255a. 2001.

[91] Neville, A.M., Properties of Concrete. New York, NY: John Wiley and Sons, Inc. 1996.

[92] Pade, C. and Guimaraes, M., The CO2 uptake of concrete in a 100 year perspective. Cement and Concrete Research. Vol. 37, No. 9, pp. 1348-1356. 2007.

[93] Stolaroff, J.K., Lowry, G.V., and Keith, D.W., Using CaO- and MgO-rich Industrial Waste Streams for Carbon Sequestration. Energy Conversion and Management. Vol. 46, No. 5, pp. 687-699. 2005.

[94] Nielsen, C.V. and Glavind, M., Danish Experience with a Decade of Green Concrete. Journal of Advanced Concrete Technology. Vol. 5, No. 1, pp. 3-12. 2007.

[95] Haselbach, L.M. and Ma, S., Potential for Carbon Adsorption on Concrete: Surface XPS Analyses. Environmental Science and Technology. Vol. 42, No. 14, pp. 5329-5334. 2008.

[96] Haselbach, L., Potential for Carbon Dioxide Absorption in Concrete. Journal of Environmental Engineering. Vol. 135, No. 6, pp. 465-472. 2009.

[97] Levinson, R. and Akbari, H., Effects of Composition and Exposure on the Solar Reflectance of Portland Cement Concrete. Cement and Concrete Research. Vol. 32, No. 11, pp. 1679-1698. 2002.

[98] An Informational Guide for Roadway Lighting. American Association of State Highway and Transportation Officials. GL-5. 1984.

[99] Illuminating Engineering Society of North America, American National Standard Practice for Roadway Lighting. ANSI/IES RP-8.1983. 1983.

[100] Illuminating Engineering Society of North America, Lighting Reference Handbook, 9th Edition. 2000.

[101] Minnesota Department of Transportation, Roadway Lighting Design Manual. 2003.

[102] District of Columbia Department of Transportation, Streetlight Policy and Design Guidelines. 2005.

[103] Löfsjögård, M. and Silfwerbrand, J., Proposal for Improvement of Road Lighting Design for Concrete Roads. Nordic Concrete Federation. 2006.

[104] Adrian, W. and Jobanputra, R., Influence of Pavement Reflectance on Lighting for Parking Lots. Portland Cement Association. PCA R\&D Serial No. 2458. 2005.

[105] Legret, M., Odie, L., Demare, D., and Jullien, A., Leaching of heavy metals and polycyclic aromatic hydrocarbons from reclaimed asphalt pavement. Water Research. Vol. 39, No. 15, pp. 3675-3685. 2005.

[106] Kreich, A.J., Evaluation of Hot Mix Asphalt for Leachability. Asphalt Institute. 1990. 
[107] Kriech, A.J., Leachability of Asphalt and Concrete Pavements. Asphalt Institute. 1992.

[108] Brandt, H.C.A. and De Groot, P.C., Aqueous Leaching of Polycyclic Aromatic Hydrocarbons from Bitumen and Asphalt. Water Reserach. Vol. 35, No. 17, pp. 42004207. 2001.

[109] Townsend, T.G. and Brantley, A., Leaching Characteristics of Asphalt Roadways. Florida Center for Solid and Hazardous Waste Management. Report \#98-2. 1998.

[110] Vashisth, P., Lee, K.W., and Wright, R.M., Assessment of Water Pollutants from Asphalt Pavement Containing Recycled Rubber in Rhode Island. Transportation Research Record. Vol. 1626. 1998.

[111] 2004 Edition of the Drinking Water Standards and Health Advisories United States Environmental Protection Agency. EPA 822-R-04-005. 2004.

[112] Santero, N.J., Signore, J., Kaynanian, M., and Harvey, J.T., Water Quality and Toxicity Evaluation of Discharge Generated from Asphalt Pavement Surface Materials:

Literature Review. University of California Pavement Research Center. CTSW-RT-07168-20.1 and UCPRC-TM-2006-09. 2007.

[113] Azizian, M.F., Nelson, P.O., Thayumanavan, P., and Williamson, K.J., Environmental Impacts of Leachate from Portland Cement Concrete (PCC) with and Without Plasticizer in Highway Construction, in Handbook of Environmental Chemistry, Vol. 5, Part F., Vol. 2. Springer Berlin / Heidelberg. 2005.

[114] Marion, A.-M., Lanève, M.D., and Grauw, A.D., Study of the leaching behaviour of paving concretes: quantification of heavy metal content in leachates issued from tank test using demineralized water. Cement and Concrete Research. Vol. 35, No. 5, pp. 951-957. 2005.

[115] Birgisdóttir, H., Gamst, J., and Christensen, T.H., Leaching of PAHs from Hot Mix Asphalt Pavements. Environmental Engineering Science. Vol. 24, No. 10, pp. 1409-1421. 2007.

[116] Brantley, A.S. and Townsend, T.G., Leaching of Pollutants from Reclaimed Asphalt Pavement. Enviromental Engineering Science. Vol. 16, No. 2, pp. 105-116. 1999.

[117] Norin, M. and Strömvall, A.-M., Leaching of Organic Contaminants from Storage of Reclaimed Asphalt Pavement. Environmental Technology. Vol. 25, No. 3, pp. 323-340. 2004.

[118] Mahler, B.J., Metre, P.C.V., Bashara, T.J., Wilson, J.T., and Johns, D.A., Parking Lot Sealcoat: An Unrecognized Source of Urban Polycyclic Aromatic Hydrocarbons. Environmental Science and Technology. Vol. 39, No. 15, pp. 5560-5566. 2005.

[119] DeMott, R.P. and Gauthier, T.D., Comment on "Parking Lot Sealcoat: An Unrecognized Source of Urban Polycyclic Aromatic Hydrocarbons". Environmental Science and Technology. Vol. 40, No. 11, pp. 3657-3658. 2006. 
[120] Van Metre, P.C., Mahler, B.J., and Wilson, J.T., PAHs Underfoot: Contaminated Dust from Coal-Tar Sealcoated Pavement is Widespread in the United States. Environmental Science and Technology. Vol. 43, No. 1, pp. 20-25. 2009.

[121] Adachia, K. and Tainosho, Y., Characterization of heavy metal particles embedded in tire dust. Environment International. Vol. 30, pp. 1009-1017. 2004.

[122] Councell, T.B., Duckenfield, K., Landa, E.R., and Callender, E., Tire-Wear Particles as a Source of Zinc to the Environment. Environmental Science and Technology. Vol. 38, pp. 4206-4214. 2004.

[123] Dahl, A., Gharibi, A., Swietlicki, E., Gudmundsson, A., Bohgard, M., Ljungman, A., Blomqvist, G., and Gustafsson, M., Traffic-generated emissions of ultrafine particles from pavement-tire interface. Atmospheric Environment. Vol. 40, pp. 1314-1323. 2006.

[124] Luhana, L., Sokhi, R., Warner, L., Mao, H., Boulter, P., McCrae, I., Wright, J., and Osborn, D., Measurement of Non-Exhaust Particulate Matter, in Characterisation of Exhaust Particulate Emissions from Road Vehicles. European Commission. Contract No. 2000-RD.11091. 2004.

[125] Alexandrova, O., Kaloush, K.E., and Allen, J.O., Impact of Asphalt Rubber Friction Course Overlays on Tire Wear Emissions and Air Quality Models for Phoenix, Arizona, Airshed. Transportation Research Record. Vol. 2011, pp. 98-106. 2007.

[126] Butler, M.A., et al., Health Effects of Occupational Exposure to Asphalt. National Institute for Occupational Safety and Health. DHHS (NIOSH) Publication No. 2001-110. 2000 .

[127] Kriech, A.J., Kurek, J.T., Wissel, H.L., Osborn, L.V., and Blackburn, G.R., Evaluation of Worker Exposure to Asphalt Paving Fumes Using Traditional and Nontraditional Techniques. American Industrial Hygiene Association Journal. Vol. 63, No. 5, pp. 628635. 2002.

[128] Boffetta, P., et al., Cancer Mortality Among European Asphalt Workers: An International Epidemiological Study. I. Results of the Analysis Based on Job Titles. American Journal of Industrial Medicine. Vol. 43, No. 1, pp. 18-27. 2003.

[129] Boffetta, P., et al., Cancer Mortality Among European Asphalt Workers: An International Epidemiological Study. II. Exposure to Bitumen Fume and Other Agents. American Journal of Industrial Medicine. Vol. 43, No. 1, pp. 28-39. 2003.

[130] Hunt, P.J., Dorman, D.E., and Schreier, W. Boiler Designs for Asphalt Fuels. Proceedings of Power-Gen '99 International. New Orleans, LA. 1999.

[131] Faber, J., Towards small scale use of asphalt as a fuel: an application of interest to developing countries. University of Groningen. Chemiewinkel Rapport C102. 2002. 
[132] Wu, S., Hiltunen, M., and Sellakumar, K. Combustion of Pitch/Asphalt and Related Fuels in Circulating Fluidized Beds. Proceedings of 7th International Conference on Circulating Fluidized Beds. Niagra Falls, Canada. 2002.

[133] Herold, A., Comparison of CO2 emission factors for fuels used in Greenhouse Gas Inventories and consequences for monitoring and reporting under the EC emissions trading scheme. European Toxic Center on Air and Climate Change. ETC/ACC Technical Paper 2003/10. 2003.

[134] Lewis, C.A., Fuel and Energy Production Emission Factors. ETSU. ETSU Report No. R112. 1997.

[135] Chen, Q.L., Yin, Q.H., Wang, S.P., and Hua, B., Energy-use analysis and improvement for delayed coking units. Energy. Vol. 29, No. 12-15, pp. 2225-2237. 2004.

[136] Fenderal Highway Administration. Life-Cycle Cost Analysis Software. 2009 [cited June 23, 2009]; Available from: http://www.fhwa.dot.gov/infrastructure/asstmgmt/lccasoft.cfm.

[137] Copeland, L., User's Manual for QueWZ-98. Texas Transportation Institute. FHWA/TX98/1745-2. 1998.

[138] Colorado Department of Transportation. CDOT Workzone - User Cost Program. 2004 [cited June 23, 2009]; Available from: http://www.dot.state.co.us/ECSU/Download.asp\#CdotWorkZone.

[139] Carr, R.I., Construction Congestion Cost: CO3 User Manual. University of Michigan. 1997.

[140] California Department of Transportation. Construction Analysis for Pavement Rehabilation Strategies: Caltrans "Rapid Rehab" Software. 2007 [cited July 1, 2009]; Available from: http://www.dot.ca.gov/newtech/roadway/ca4prs/index.htm.

[141] Keoleian, G.A., Kendall, A., Dettling, J.E., Smith, V.M., Chandler, R.F., Lepech, M.D., and Li, V.C., Life Cycle Modeling of Concrete Bridge Design: Comparison of Engineered Cementitious Composite Link Slabs and Conventional Steel Expansion Joints. Journal of Infrastructure Systems. Vol. 11, No. 1, pp. 51-60. 2005.

[142] Guide for Mechanistic-Empirical Design of New and Rehabilitated Pavement Structures. National Cooperative Highway Research Project, Transportation Research Board. NCHRP No. 1-37A. 2004.

[143] University of California Pavement Research Center, Life-Cycle Cost Analysis Procedures Manual. California Department of Transportation. Prepared for the California Department of Transportation Division of Design and the Pavement Standards Team. 2007.

[144] United States Environmental Protection Agency, Solid Waste Management and Greenhouse Gases: A Life-Cycle Assessment of Emissions and Sinks: 3rd Edition. 2006. 
[145] Rieradevall, J., Domènech, X., and Fullana, P., Application of Life Cycle Assessment to Landfilling. International Journal of Life Cycle Assessment. Vol. 2, No. 3, pp. 141-144. 1997.

[146] Rajendran, S. and Gambatese, J.A., Solid Waste Generation in Asphalt and Reinforced Concrete Roadway Life Cycles. Journal of Infrastructure Systems. Vol. 13, No. 2, pp. 8896. 2007.

[147] Federal Highway Administration and the Environmental Protection Agency, A Study of the Use of Recycled Pavement Material - Report to Congress. FHWA-RD-93-417 \& EPA/600/R-93/095. 1993.

[148] Collins, R.J. and Ciesielski, S.K., Recycling and Use of Waste Materials and By-Products in Highway Construction. Transportation Research Board. NCHRP Synthesis of Highway Practice No. 199. 1994.

[149] Sullivan, J., Pavement Recycling Executive Summary and Report. Federal Highway Administration. FHWA-SA-95-060. 1996.

[150] Deal, T.A., What it Costs to Recycle Concrete. C\&D Debris Recycling. Vol. 4, No. 6, pp. 10-13. 1997. 